Enterprise Resource Planning systems: an empirical study of adoption and effects MARK VLUGGEN 



\section{Enterprise Resource Planning systems: an empirical study of adoption and effects}

Proefschrift ter verkrijging van de graad van doctor aan de Universiteit Maastricht, op gezag van de Rector Magnificus, prof. mr. G.P.M.F. Mols, volgens het besluit van het College van Decanen, in het openbaar te verdedigen op woensdag I november 2006 om I6.00 uur

door Mark Paul Maria Vluggen 
- PROMOTORES

prof. dr. F. Moers

prof. dr. E.Vaassen RA

- BEOORDELINGSCOMMISSIE

prof. dr. J.E. Hunton voorzitter

prof. dr. A.C.R. Van Riel Université de Liège

prof. dr. ir. M.J. F. Wouters University of Twente 


\section{Dankwoord}

Tempus fugit. Het proces van het schrijven van een proefschrift is lang en zwaar, maar er is loon naar werken. Velen hebben een bijdrage geleverd aan de afronding van dit proefschrift. Ik ben hen allen veel dank verschuldigd en spreek de hoop uit dat dit dankwoord voldoet aan hun 'dankverwachtingen'. Mocht je niet in dit dankwoord zijn opgenomen en vinden dat je wel een plek verdiend hebt, weet dan dat ik dit dankwoord schreef toen het erg laat was. Je hebt vast en zeker wel een plek in mijn hart, hetgeen nog altijd belangrijker is dan een plek in mijn proefschrift.

Allereerst wil ik mijn promotoren Eddy Vaassen en Frank Moers bedanken. Ik dank Eddy voor zijn enthousiasme voor en toewijding aan dit project en zijn mentale ondersteuning en geduld. De kritische en rigide houding van Frank was niet altijd gemakkelijk, maar heeft wel als een sterke kwaliteitsimpuls voor dit proefschrift gefungeerd. Ik ben hem veel dank verschuldigd voor de vele uren die hij tijdens zijn verblijf in de Verenigde Staten in mijn proefschrift heeft geïnvesteerd. Ik dank ook de leden van de beoordelingscommissie James Hunton, Allard van Riel en Marc Wouters voor hun constructieve commentaar op het finale manuscript.

Initieel werd dit proefschrift begeleid door Willem Buijink en Frank Hartmann. Nadat beiden naar een andere universiteit waren verkast, is mijn promotorenteam ook gewisseld. Willem en Frank hebben nochtans een cruciale rol gespeeld in het bepalen van de richting van dit onderzoeksproject. Ik dank hen beiden voor hun waardevolle ondersteuning in die fase.

Het uitvoeren van een enquête is geen sinecure, zeker niet in een periode waarin Nederland enquêtemoe lijkt. Velen hebben geholpen bij het voorbereidend en uitvoerend werk op dit vlak. Ik bedank in dit verband Henny Claessens, Roel Ronken, Ronny Schwachöfer, de vns G en de onderzoekers en projectmanagers die betrokken waren bij de pilot test van deze enquête en uiteraard de respondenten van de enquête.

De moeilijke momenten in het werken aan dit proefschrift werden draaglijk gemaakt door de plezierige werksfeer op het departement Accounting \& Information Management. Daarvoor dank ik al mijn A I Mcollega's. Ik wil een tweetal (ex-)collega's in het bijzonder dankzeggen. Ik bedank Laury Bollen voor zijn vertrouwen in mijn capaciteiten, zijn constructieve commentaar op eerdere versies van het manuscript, zijn 
emotionele steun, onze borrels op vrijdagmiddag en de altijd plezierige samenwerking op het terrein van onderwijs. En natuurlijk bedank ik hem voor zijn immer goed gevulde digitale dropbox, waarin het goed graaien is. Ik bedank Luc Quadackers, aan wie ik veel emotionele steun heb ontleend. Nog belangrijker is dat hij de enige is die mijn voorliefde voor flauwe woordgrappen en trage Argentijnse films over houthakkers onvoorwaardelijk deelt.

Ik bedank mijn ouders en schoonouders voor hun liefde en vertrouwen.

Ik bedank Janneke, die ervoor gezorgd heeft dat dit proefschrift fantastisch oogt. Dat de nieuwe opdrachtgevers maar in rijen van vijf bij haar mogen aanschuiven. Verder bedank ik mijn familie en vrienden. Tevens bedank ik bij voorbaat mijn paranimfen David en Thomas.

En dan Sylvia: zij blijft de meest significante ontdekking van mijn leven. Zeker in de laatste maanden van de afronding van dit proefschrift, leek haar steun geen grenzen te kennen.

Mark Vluggen, september 2006 



\section{Contents}

\section{Introduction}

I.I Objectives of this dissertation -2

I.2 E R P systems -2

I.3 Research Method - 6

I.4 Contribution - 7

I. 5 Outline of this dissertation -7

\section{The determinants of ERP system} adoption levels

2.I Introduction - I2

2.2 Literature review/hypotheses - I4

2.2.I Determinants of ERP usage:

the external environment -20

2.2.2 Determinants of ERP usage:

the internal environment -22

2.2.3 Determinants of ERP usage: technological characteristics -24

2.2.4 Control variables -26

2.3 Research methodology -27

2.3.I Introduction -27

2.3.2 Pilot -28

2.3.3 Data collection procedure -28

2.3.4 Operationalization of variables - 3I

2.3.5 Instrument validation -34

2.4 Results -37

2.4.I Descriptive statistics independent variables -37

2.4.2 Descriptive statistics dependent variable -38

2.4.3 Multivariate analysis -40

2.5 Discussion, limitations and suggestions for further research -46

2.5. I Discussion -46

2.5.2 Limitations -50

2.5.3 Suggestions for further research -5 I 


\section{The financial impact of ERP systems}

3.I Introduction -56

3.2 Literature review and hypothesis development - 57

3.2.I Pitfalls in information systems

success studies -58

3.2.2 ERP Success -59

3.2.2. I Process measures studies -60

3.2.2.2 Market and event studies - 60

3.2.2.3 Financial statement studies -6 I

3.2.3 Hypotheses development - 68

3.3 Research methodology - 70

3.3.I Matching procedure -72

3.3.2 Analyses -73

3.4 Results -74

3.4.I Analysis I: performance effects of ERP

adoption (adopters only) - 74

3.4.2 Analysis Ir: matched pair analysis - 79

3.4.3 Additional analyses - 83

3.4.3.I Analysis i I: adoption level effects -83

3.4.3.2 Analysis Iv: over- or under-

investment -85

3.5 Discussion, limitations and suggestions

for further research -86

3.5.I Discussion -86

3.5.2 Limitations -88

3.5.3 Suggestions for further research -89

\section{Summary and conclusion}

4.I Introduction - 94

4.2 The determinants of ERP adoption

levels -94

4.3 The financial impact of E RP systems -96

4.4 Limitations -98

4.5 Directions for further research - 99

List of literature used - IO2

Appendices:

- appendix A measurement instruments - I08

- appendix в overview sap modules - II2

- appendix c cost categories in Poston

\& Grabski (200I) study - II3

Summary in dutch - II4

Curriculum vitae - II7 

INTRODUCTION 


\subsection{Objectives of this dissertation}

The purpose of this dissertation is to empirically examine (I) the determinants of Enterprise Resource Planning (ERP) system adoption levels and (2) the effects of ERP adoption on the financial performance of organizations. Although E R P systems were the largest business project of the last years in many organizations, research on E R P still is relatively scarce. In an attempt to enhance our understanding of the way in which ERP systems are being employed in organizations, this dissertation brings together two empirical studies on topics related to ER P systems.

First, I address the determinants of E R P adoption levels. Despite the high adoption rates of these software packages, concerns have been expressed about the universal applicability of ERP systems. In lieu of the important role that ER P systems play in modern organizations, it is imperative to understand which factors promote or inhibit the adoption level of E R P systems in organizations. Based on literature in the areas of diffusion-of-innovations theory (Rogers, I983) and information systems implementation research, I examine the role of contextual variables (e.g. the external environment, internal organizational and technological characteristics) in explaining the adoption level of E R P systems.

Secondly, I analyze ERP systems from an outcome perspective, by studying the impact of ERP systems on the financial performance of organizations. Given the substantial investments associated with ERP adoption, it is worthwhile to explore the impact of ERP systems in this respect. In this dissertation I assess the impact of the ERP adoption level on the relation between ERP adoption and firm performance.

In summary, the purpose of this dissertation is twofold: (I) to identify the determinants of the ERP adoption level and (2) to study the financial performance effects of using ERP systems. Therefore, this dissertation addresses the following research questions:

1 What are the determinants of ERP adoption levels?

2 What is the effect of ERP investments on firm performance?

\subsection{ERP systems}

Over the last decade, firms have heavily invested in single-vendor, enterprise-wide software packages known under the collective name of enterprise resource planning (ERP) systems ${ }^{1}$. ERP systems are module-based information systems that integrate information and information-based processes within and across functional areas in an organization through
1 The ERP name reflects the view that ERP systems have evolved from the logistic Material Requirements Planning (MRP-I) and Manufacturing Resources Planning (MRP II) concepts. This view is challenged by Davenport (2000), arguing that ERP software has transcended the MRP-origin to such an extent that ERP is no longer an appropriate name. He uses the term enterprise systems (ES) instead. In both the practitioners' as well as academic literature, ERP still seems to be the more dominant term. Therefore, I use the term ERP throughout this dissertation. 
the use of a central data repository. This is depicted in figure I.I, which shows the anatomy of an ERP system. As this figure illustrates, ERP software packages support the entire range of business functions, from accounting to logistics, from manufacturing to sales. Through the central database, they also offer integration of the administrative processes supporting these activities. Especially in the I990s, the major software suppliers in this area (e.g. SAP, Oracle, Peoplesoft/JD Edwards) have shown tremendous growth figures. Because of their enterprise-wide nature, implementation of these packages is notoriously complex. For many organizations, the implementation of an E RP system was the major organizational change effort over the last years. Initially, ER P systems were especially adopted by large organizations, but recently midsize organizations have also started to adopt ER P software (van Everdingen et al., 2000).

Figure 1.1 ANATOMY OF AN ERP SYSTEM (Davenport, I998)

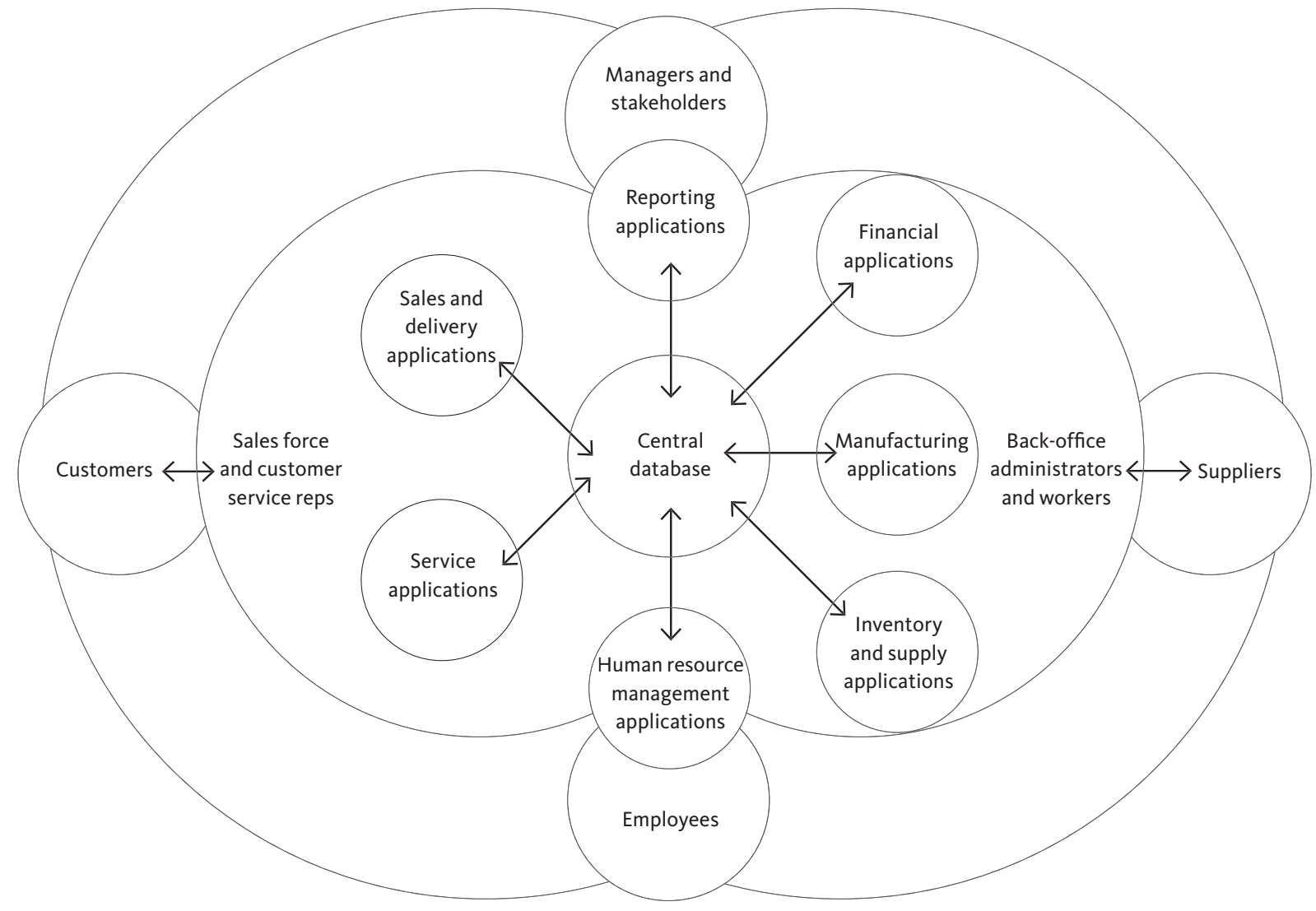


To understand the appeal of ERP systems it is necessary to understand the evolution of the use of information systems in organizations. In the past, companies were prone to use dedicated software packages for each separate business function. These stand-alone applications were custommade for the user organization. Each system had its own application logic and its own data definition. Having multiple systems with unique data definitions led to a wide range of problems in organizations (often referred to as the 'islands of automation' problem, e.g. Palaniswamy \& Frank (2000)). Examples include, but are not limited to, the excessive use of manual re-entries of business data for various types of transactions, problems in the reconciliation of operations data with accounting data (often caused by mistakes made when re-entering data in a different system), manual rollup of data for consolidation purposes, a lengthy review/reconciliation process for closing of monthly reports and large information technology (Іт) staff needed to support multiple systems. In addition, the maintenance of an IT infrastructure with several standalone systems is expensive. By reducing the number of stand-alone systems and their associated costs, the adoption of ERP packages promises to make an end to many of these problems.

A second justification for the investment in ERP systems is the increased availability of operational data (Bendoly, 2002). The central data repository of E RP systems contains a large amount of business information, assembled within one central database. As a result, the availability of business information within the firm considerably increases after ERP adoption. Davenport (2000, p.I) states it as follows: 'For the first time since large businesses were created, managers will be able to monitor the doings of the company in near real time, without having to wait for monthly reports that must be cross-referenced with other monthly reports, all of which may be out of date - or just plain wrong - by the time managers receive them.' Due to the fact that manual re-entries are no longer necessary, information quality can also be enhanced in terms of availability, timeliness and reliability.

Finally, many organizations have embraced ERP packages because they are said to reflect 'best business practices'. The implementation of ERP packages is often accompanied by large scale changes in business processes (business process reengineering). Thus organizations can buy expertise that is 'hard-wired' into the software. Although some organizations have customized the software to make sure it fits their processes, many other organizations have used the adoption of ERP software as a chance to change their basic business processes (O'Leary, 2000). 
2 Given the problem of achieving a match between the ERP software and the organization's business processes, some would argue that reengineering is not so much an advantage of ERP systems, but a sheer necessity; a condition for succesful use of the software.
To summarize, the popularity of ERP systems can be explained by their solution to problems that are associated with stand-alone systems, the contribution of ERP systems to the information processing capabilities of organizations and the business process reengineering opportunities ${ }^{2}$ created by the implementation of these packages.

These theoretical advantages of ER P systems have been challenged by several scholars. Soh et al. (2000) challenge the advantage of 'best business practices' by arguing that there can be 'misfits' between country-, industry- and company-specific business practices and the reference models that are incorporated in E R P systems. In fact, this notion of 'misfit' is a key concern in many E R P and IT publications (Hong \& Kim, 2002; Soh et al., 2000; Swan et al., I999). Whereas individual adopters of ERP software search for ERP software that best fits their particular organization, ERP vendors try to develop software that can be used by as many different firms as possible. In this manner, ERP vendors can 'spread' their development costs over as many installed E RP systems as possible. In general, organizations always have to settle for an imperfect fit when buying off-the-shelf software, instead of using tailor-made software (Lucas jr. et al., I988).

This misfit problem is further aggravated by the fact that the implementation of an ERP system almost forces organizations to conform their business processes to the way these processes are configured in the ERP package. Davenport (I998) emphasizes this disadvantage of ERP systems, arguing that firms that rely on an idiosyncratic way of doing business, put their primary source of competitive advantage at stake when adopting the generic business processes embedded in ERP systems. Arnold et al. (I999) suggest that neither organizations nor workers benefit from E R P implementation, because E R P systems rigidly enforce order across an organization and its business processes, resulting in a highly ordered structure that is inflexible and potentially not responsive to strategic initiatives by competitors. Gattiker \& Goodhue (2004) use a case study to illustrate that differentiation among organizational subunits results in high ER P-related compromise and design costs. These observations all support the notion that although the ER P concept might have universal appeal, the implementation of $\mathrm{ERP}$ software is not a panacea for all firms.

As explained earlier, ERP systems have a modular structure, facilitating an implementation approach where ERP technology is installed in certain areas only. When firms decide to implement an ERP system, they have to decide on the adoption level of their ERP system, i.e. the 
number of ERP modules that they will implement. When firms decide on the scope of their ERP implementation, they face a fundamental trade-off between increased network benefits and increased rigidity of the ERP system. By implementing more modules, the adopting firm facilitates a smooth information exchange between business functions. Thus, with increasing scope of the ERP implementation, the network benefits increase (more business functions share the same data definitions and can therefore exchange business data). At the same time, increasing the number of modules increases the rigidity of the ERP system. Adapting a full-fledged E RP system is much harder than changing an ERP system that is only used in specific business domains, because of the interdependencies between the various modules.

\subsection{Research Method}

The data for this dissertation were gathered in a two-step procedure. First, a survey was administered among Dutch users of the ERP software package sAP. This software vendor was chosen because of its dominance in the Dutch ERP market. More importantly, the use of a single ERP vendor allowed for the comparison of adoption levels of the ERP software, which is one of the main objectives of this dissertation.

A database with member data from the Dutch user organization of SAP was combined with several other sources to generate a list of Dutch SAP users. These organizations were subsequently contacted by e-mail or phone with the request to provide contact details for the internal project manager of their ERP implementation. Among the identified project managers, an internet survey was administered.

In the second step of the data collection procedure, the identities of the surveyed firms were used to combine the survey data with financial statement data. These data were taken from REACH, a database with corporate information of all Dutch firms. Unfortunately, for a large percentage of the respondents of the initial survey, no or limited financial data were available. The possibility to study the financial impact of ERP implementations on the basis of this dataset was further reduced by the problem that some of the firms in this dataset implemented ERP very recently (e.g. 2003), and therefore no financial data for the years after implementation were available. Because of the low number of observations, the firms from the list of SAP users were contacted once more, with the exclusion of firms that had already participated in the earlier survey. These firms were contacted by e-mail with the simple request to 
indicate in which year their ERP system went live. For the firms that responded favourably to this request, I gathered the same financial performance data as for the firms that responded to the initial survey.

\subsection{Contribution}

This dissertation contributes to the existing literature in several ways. First, it develops a metric to measure the adoption level of E R P software. Prior literature has rarely gone beyond dichotomous measures of innovation adoption, although this has been called for in several overviews of the literature (e.g. Fichman, 200I). This dissertation takes advantage of the modular structure of ERP systems to develop a metric that captures the scope of an ERP system implementation, by assessing the proportionate share of relevant ERP modules being used.

Second, this dissertation provides empirical evidence on the role of contextual factors in determining the adoption level of ERP software. Both internal and external organizational contingencies are important in this respect. To be more specific, ER P adoption levels increase along with higher external pressure to adopt ERP, more decentralization and greater information intensity (i.e. dependency on the currency, reliability and timeliness of information).

Third, this dissertation provides empirical evidence on the financial performance effects of ERP systems. In addition, it assesses the impact of the adoption level and potential over- and underinvestment in E R P on the organization's financial performance.

\subsection{Outline of this dissertation}

Besides this introductory chapter, this dissertation consists of two empirical studies (Chapters 2 and 3), and a concluding chapter (Chapter 4). The relation between the chapters in this dissertation is depicted in figure I.2.

Figure 1.2 OVERVIEW OF THE CHAPTERS IN THIS DISSERTATION

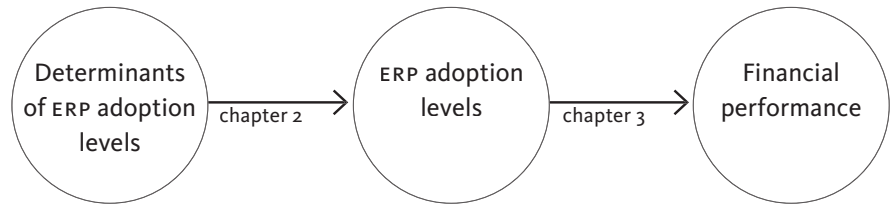


Chapter 2 investigates the determinants of the ERP adoption level. Drawing upon past research on information systems implementation and innovation diffusion, this study examines the determinants of the level of ERP software usage. To be able to study this phenomenon, this chapter develops a metric to measure the adoption level of ERP software, based on the modular structure of ERP systems. By studying the determinants of the ERP adoption level, this chapter intends to contribute to our understanding of the corporate environment (environmental, organizational and technological characteristics) in which high and low adoption levels are observed.

Chapter 3 is the second empirical chapter. This chapter provides empirical evidence on the financial impact of E R P software. Prior literature in this area shows mixed evidence with regard to the financial effects of ERP implementations. Chapter 3 starts with a replication of earlier studies in this area and adds an additional variable to this literature: the adoption level of E RP software as observed in chapter 2.

Finally, chapter 4 concludes by summarizing the dissertation, discussing its limitations and offering suggestions for further research in this area. 




\section{THE}

DETERMINANTS

OF ERP SYSTEM

ADOPTION

LEVELS 


\subsection{Introduction}

This chapter aims to identify the determinants of Enterprise Resource Planning (ERP) system adoption levels (hereafter simply termed ERP adoption levels). In the past years, many companies have embraced the E R P concept. When E R P-products entered the market (the most successful package, SAP R/3 was introduced in 1994), they were typically adopted by large firms. The use of ERP systems is, however, no longer restricted to large firms. Van Everdingen et al. (2000) show that ERP-software is entering small and medium sized businesses rapidly. Bingi et al. (1999) claim that $70 \%$ of the Fortune Ioo० firms have or will soon install an E R P system. Mabert et al. (2000) report an adoption rate of $44 \%$ in u.s. manufacturing firms by the end of I999, whereas another $29 \%$ is either implementing an ERP system or planning an implementation in the upcoming months. On the basis of these figures it is safe to assume that by now the large majority of large and midsized companies use ER P technology.

As the introduction to this dissertation suggests, ERP systems are not a panacea for all firms. When implementing ERP systems firms face a cost-benefit trade-off. Because the ERP concept is based on the notion of interdependence, the type of benefits that ERP brings along increases with the adoption level of the software. Unfortunately, problems that are associated with ERP systems also increase with the adoption level.

The potential benefits of ERP systems are discussed in the introductory chapter of this dissertation. Key benefits are the integration of business data through the use of a single data repository, the enhancement of information processing capabilities and reengineering opportunities.

This list of advantages is by no means complete or intended as an exhaustive coverage of the advantages of ERP technology. Besides the advantages already mentioned, O'Leary (2000) lists the following ways in which ERP creates value: (I) ERP enables organizational standardization (especially relevant in multinational organizations that try to operate in a similar fashion across the globe); (2) ERP eliminates information asymmetries; (3) ERP allows simultaneous access to the same data for planning and control; (4) ERP facilitates intra-organization communication and collaboration and (5) E R P facilitates inter-organization communication and collaboration. Important to note is that all these benefits emerge as a consequence of the interconnectivity of business functions.

As explained in the introductory chapter, the advantages of E R P systems have been challenged by several scholars. Common concerns are the notion of misfits, the generality of the business processes embedded 
in the ERP system and finally the inflexibility (rigidity) of these systems. When firms adopt an E R P system, they have to make a trade-off between the network benefits that come along with these systems, and concerns regarding the rigidity of these standardized systems. Firms can make this trade-off by choosing to implement ERP in only a limited number of business functions. It's the modular structure of ERP systems that allows this. Organizations can deliberately choose to install ERP technology in certain areas while disregarding E R P in other areas.

This dissertation employs a narrow operationalization of the E R P concept, by only referring to single vendor-based systems as E R P systems. Yet, firms can obviously achieve integration in alternative ways, for instance by combining an ERP package from a single vendor with modules from other E R P vendors or with dedicated software packages. Light et al. (200I) refer to this as a best of breed strategy, in which standard software from a variety of vendors is integrated. Achieving a smooth integration of these software packages can however be troublesome and especially the costs of future ownership are bound to be large. Upgrades of the different software components may lead to serious problems in the functionality of the interfaces between the various packages.

In this chapter, I study organizational, environmental and technological factors that promote or inhibit higher ERP adoption levels. ER P adoption can be seen as a series of individual adoption decisions with regard to the individual modules. In many organizations, an incremental approach is used where E RP is implemented on a module-by-module basis. I will use the term adoption level to reflect the proportionate share of the functionality of the ERP system that is being used. By doing so, this study goes beyond the simple dichotomous yes/no adoption decision. Several scholars (Damanpour, I99I; Fichman, 2000; 200I) have called for IT implementation studies that go beyond dichotomous measures. This study contributes to the literature by developing an adoption level metric that captures more than just the simple decision to implement an ER P system.

This study illustrates how companies that use ERP to a large extent (many modules) differ from firms that use ERP only to a minor extent (a limited number of modules). Firms that adopt ERP software often implement the software on a module-by-module basis. Typically backoffice functionality like accounting/human resource management (H RM) is adopted first, followed by modules in the core areas later. The decision to implement modules is not a rash one; the investments associated with the implementation are significant. Lozinsky (1998) states 
figures of several hundred thousand dollars for medium-sized businesses, going up to several million dollars for large corporations. O'Leary (2000) cites a study of the META group, that mentions an average cost of ownership for an ERP implementation of \$I5 million, and an average cost of $\$ 53,320$ per user. Estimates of the cost of ERP implementations vary to a large extent, because typical E R P implementations do not exist. Yet, it is safe to state that the incremental cost associated with the adoption of a single module is very significant. Therefore, firms have to decide on the adoption level of ERP software carefully.

By studying the determinants of the E R P adoption level, this chapter intends to contribute to our understanding of the corporate environment (environmental, organizational and technological characteristics) in which high and low adoption levels of E RP are observed. The underlying notion is that these factors have an influence on the cost-benefit trade-off discussed earlier. In firms that exhibit higher levels of the motivating contextual (organizational, environmental) and innovation (technological)-related variables discussed below (or lower levels of the inhibiting factors), ER P benefits are more likely to outweigh ER P costs, and therefore a higher adoption level is more likely.

The next section provides a literature review and the hypotheses. This section discusses empirical studies that have investigated the determinants of information systems (Is) adoption and diffusion. Section 2.3 illustrates the research methodology that was used in this study. In section 2.4 , the results of the study are given. Section 2.5 provides the conclusion, limitations of the study and suggestions for future research.

\subsection{Literature review/hypotheses}

There is a rich literature concerning the identification of factors that facilitate the spread of a particular administrative or technological innovation (Westphal et al., I997). Fichman (2000, p.I06-I07) argues that these researchers are unified by their concern with three main questions:

1 What determines the rate, pattern, and extent of diffusion of an innovation across a population of potential adopters?

2 What determines the general propensity of an organization to adopt and assimilate innovations over time?

3 What determines the propensity of an organization to adopt and assimilate a particular innovation? 
Diffusion modelling studies primarily deal with the first research question. Typically, data are gathered on the timing of adoptions in some population (e.g. a particular industry) and then fit to a time series of cumulative adoptions (Fichman, 200I). Adopter studies are primarily interested in the second and the third research question. These studies try to understand the differences between adopters and nonadopters, or differences in the intensity of using the innovation.

This study can be classified in the third category. Within this category, many scholars have based their research on the seminal work of Rogers (I983) on Diffusion-Of-Innovations (DOI) theory. Motivated by the parallels between information systems implementation and diffusion of innovations, many IT researchers have based their work on Do I theory. To identify the determinants of E RP adoption levels, I draw upon Do I theory (Rogers, I983) as well as IT implementation research. A review of this literature is provided by Prescott \& Conger (I995). Wolfe (I994) provides an overview of the organizational innovation literature. Chau \& Tam (2000) and Fichman (2000) provide a short summary of the deficiencies of the Dor theory.

In innovation research, innovation is depicted as a multi-phased process. In this literature, a whole array of phase models has been suggested. Basically, the purpose of all the proposed stage models is to capture the organizational learning process that is associated with adopting, and subsequently learning about the capabilities and requirements of an innovation.

Rogers (1983) initial work poses that characteristics of the innovation, the communication channels, and the social system interact with time to affect the diffusion of innovations in organizations. Kwon \& Zmud (I987) have combined the Dor model with application implementation research, thereby suggesting an enlarged model including task and environmental characteristics.

Typically a distinction is made between initiation, adoption and implementation stages. During initiation, change arises because of organizational problems (need-pull forces) and opportunities (technology-push forces) (Kwon \& Zmud, I987; Cooper \& Zmud, I990). In both situations, needs and appropriate technologies come together through the exchange of ideas. The next stage, adoption, involves the decision to invest organizational resources in a specific Iт application (Kwon \& Zmud, I987; Cooper \& Zmud, I990). Finally, implementation is the organizational effort to diffuse a specific technology among organizational members. Kwon \& Zmud (I987) go beyond this prototypical framework 
by combining diffusion of innovations (DOI) theory with insights from IT implementation research. This results in three additional stages being added to include post-implementation phases, as well as adding two different clusters of variables (task characteristics and environmental characteristics) affecting it diffusion. The final model, as proposed in Cooper \& Zmud (I990) is given in table 2.I. A qualitative study by Palaniswamy (2002) applies the six stage model by Kwon and Zmud (I987) and illustrates how firms that are in the process of implementing ERP systems can be positioned in the various stages.

Table 2.1 COOPER AND ZMUD (1990) IMPLEMENTATION MODEL

\begin{tabular}{|c|c|}
\hline INITIATION & $\begin{array}{l}\text { Process Active and/or passive scanning of organizational problems / } \\
\text { opportunities and IT solutions are undertaken } \\
\text { Product A match is found between an IT solution and its application } \\
\text { in the organization }\end{array}$ \\
\hline ADOPTION & $\begin{array}{l}\text { Process Rational and political negotiations ensue to get organiza- } \\
\text { tional backing for implementation of the IT application } \\
\text { Product A decision is reached to invest resources necessary to } \\
\text { accommodate the implementation effort }\end{array}$ \\
\hline ADAPTATION & $\begin{array}{l}\text { Process The IT application is developed, installed and maintained. } \\
\text { Organizational procedures are revised and developed. Organizational } \\
\text { members are trained both in the new procedures and in the IT } \\
\text { application } \\
\text { Product The IT application is available for use in the organization }\end{array}$ \\
\hline ACCEPTANCE & $\begin{array}{l}\text { Process Organizational members induced to commit to IT application } \\
\text { usage } \\
\text { Product The IT application is employed in organizational work }\end{array}$ \\
\hline ROUTINIZATION & $\begin{array}{l}\text { Process Usage of IT application is encouraged as a normal activity } \\
\text { Product The organization's governance systems are adjusted to } \\
\text { account for the IT application; the IT application is no longer } \\
\text { perceived as something out of the ordinary }\end{array}$ \\
\hline INFUSION & $\begin{array}{l}\text { Process Increased organizational effectiveness is obtained by using } \\
\text { the IT application in a more comprehensive and integrated manner to } \\
\text { support higher levels aspects or organizational work } \\
\text { Product The IT application is used within the organization to its fullest } \\
\text { potential }\end{array}$ \\
\hline
\end{tabular}

Most of the literature in this area has used adoption status as the dependent variable, a binary variable that classifies an organization as either an adopter or nonadopter. In this study I choose to focus on the adoption level of ERP software, in an attempt to understand why adopter organizations differ in their level of E RP adoption. Traditionally, many studies have employed dichotomous measures of Iт adoption. Fichman (200I) argues that the nature of IT has been evolving in such a way that 
greater emphasis on aggregated measures of innovation is appropriate. ERP is an example of an umbrella concept that is actually more a cluster of similar technologies than a single technology. Given the modular structure of ERP systems, ERP adoption can be seen as a series of interrelated ERP adoption events. The ERP adoption level is the cumulative result of this series of adoption decisions.

A major part of the research in this area has tried to identify the factors that promote or inhibit initiation, adoption and implementation of new technologies. Nevertheless, the quest for a unitary theory with a given set of determinants that consistently impact firms' innovativeness has been unsuccessful. In response to this, scholars have started to develop taxonomies of innovations, with the underlying notion that the characteristics of the innovation have to be taken into consideration when thinking about determinants of innovation adoption (Downs \& Mohr, I976). Examples include the distinction between product and process innovations (Baptista, I999) and technical and administrative innovations (Kimberly \& Evanisko, I98I). Prescott \& Conger (I995) classify information technology by its locus of impact (Is unit, intra-organizational, inter-organizational). Fichman (2000) explains that although Do I theory is the closest the field has come to producing a single theory of innovation, it does not apply equally well to all kinds of innovations.

One common way to cluster the variables that promote the adoption of a specific technology is introduced by Kwon \& Zmud (I990). Their categorization includes characteristics of: (a) the external environment; (b) the internal environment; (c) the technology; (d) the task and (e) the organizational decision-maker. The first cluster (external environmental factors) includes characteristics of the external organizational environment (e.g. environmental uncertainty, competition, concentration, inter-organizational dependence). The second cluster (internal environment) is also referred to as structural factors. It includes such variables as specialization, centralization and formalization. The third cluster (technology) contains characteristics of the innovation under study (e.g. cost, complexity, compatibility). The fourth cluster (task-related factors) examines the characteristics of tasks (e.g. task uncertainty, autonomy, variety) in promoting the adoption of innovations. Finally, the last cluster (individual decision-maker characteristics) contains individual factors (e.g. job tenure, cosmopolitanism, education) that may drive the adoption of innovations.

The last two clusters are deemed unimportant when studying ERP adoption and diffusion. Although task characteristics may be relevant 
in explaining the adoption and diffusion of dedicated software, (used to support a particular business function), they will not be decisive in determining the adoption level of ERP software, which is used for a whole array of tasks. Individual decision-maker characteristics (e.g. job tenure, education, decision-making style, role involvement) might have an impact on innovation adoption behaviour in small, manager-owned businesses, but are very unlikely to influence adoption decisions with regard to large-scale technologies like E RP in larger firms, where decision-making authority is spread across multiple hierarchical layers. The scale of ERP investments is such that the adoption decision will involve multiple organizational decision-makers.

The adoption of IT is a well-developed body of research in information systems. The question which characteristics promote the adoption (and subsequent use) of information systems is one of the key questions in this literature. When constructing a list of potential determinants of E R P adoption levels, I will discuss those factors that have been found to promote the adoption and diffusion of technologies that exhibit some commonalities with ERP, either on a functional or technological level. The following technologies are deemed relevant:

Material Requirements Planning (M R P-I) and Manufacturing Resources Planning (M R P-II) are deemed important because these logistic technologies are often mentioned as the direct precursor of ERP software. MRP is a tool for performing the material planning function in manufacturing companies. Material Requirements Planning (M R P-I) systems basically aimed at the integration of material requirements, inventory control and purchases. Although quite useful in preparing a production plan on the basis of a sales order, the question whether the company has enough capacity to meet a sales order, was left unanswered. To incorporate this aspect, the functionality of MRP-I was expanded. The new systems came to be known as Manufacturing Resource Planning (M R PII) systems and incorporated capacity planning.

Electronic Data Interchange (EDI) is deemed important because there is a functional parallel with ERP systems. EDI automates interfirm operations. Although ERP is an intrafirm technology, there is a parallel with EDI in the sense that ERP accommodates the automation of interdepartmental operations.

Telecommunications technology is deemed important because it allows the exchange of information of internal parties in a similar fashion as ERP does.

Finally, determinants of decision support systems and executive support 
systems adoption have been included. Although ERP in itself does not offer decision support, the implementation of an E RP system can act as a catalyst for the use of various types of decision support technologies. A necessary requirement and basis for decision-support technologies is the availability of operational data. The introduction of E R P systems has led to an increase in the availability of operational data within firms, alongside a central registration of this data in one database. A traditional bottleneck when building decision support systems has always been the large variety of legacy systems being operated. ERP systems provide a solution to this bottleneck through the use of a univocal data definition.

The following sections will discuss the proposed determinants of ERP usage. The determinants are clustered as external environmentrelated (section 2.2.I), internal environment-related (section 2.2.2) or technology-related (section 2.2.3). The difference in the profile of 'heavy E R P-users' and 'limited E R P users' provides insight into the factors that drive the adoption level of ERP software. The research model is illustrated in figure 2.I.

Figure 2.1 RESEARCH MODEL

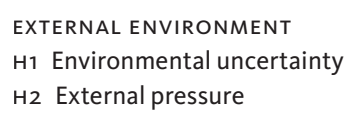


The aim of this study is not to come up with a 'complete explanatory model' of the ER P adoption level. Instead, I build on evidence from the research streams identified earlier and investigate the role of environmental (both internal (organizational) and external) and innovation (technological) characteristics in determining the adoption and diffusion of information technology. Comprehensiveness is not being claimed.

2.2.1 Determinants of ERP usage: the external environment In this study I investigate two external environmental contingencies: environmental uncertainty and external pressure. Environmental uncertainty was conceptualized by Miller \& Friesen (I982) into the components of heterogeneity, dynamism and hostility. Dynamism refers to the turbulence in an organization's external environment; heterogeneity refers to the complexity in the environment and hostility refers to the competitive pressures faced by the organizations. In this study this broad construct of environmental uncertainty is used.

There are two main arguments for a proposed positive impact of environmental uncertainty on E R P adoption levels. First, environmental uncertainty has been shown to facilitate innovation in general (Pierce \& Delbecq, I977). Ettlie \& Bridges (1982) show that perceived environmental uncertainty promotes an aggressive technology policy. This means that firms respond to high levels of environmental uncertainty by aggressively adopting process, product and service innovations (E RP being an example of a process innovation). This policy can be interpreted as a means of coping with an uncertain environment (Ettlie, I983).

The second argument builds on the information processing requirements that are introduced by high levels of environmental uncertainty. When an organization faces a complex and rapidly changing environment, information processing requirements will be more critical, as compared with a stable environment. Organizational participants will look for additional information for planning and control purposes (EwusiMensah, I98I; Gordon \& Naranayan, I984). As Galbraith (I973) explains, one way to respond to increasing environmental uncertainty is through the acquisition of additional information processing capacity. A sophisticated information technology like an ERP system is a prime example of an investment in this area, because of ERP's capability to increase the availability of operational data. This E R P capability will however critically depend on the adoption level chosen; if the system is used in certain isolated business areas only, the information processing capabilities are unlikely to be different from the use of stand-alone technology. But 
with an increasing adoption level, business data can be shared across multiple business functions and the information processing capabilities of the firm are truly enhanced.

Empirically, environmental uncertainty has been shown to have an impact on the adoption of telecommunications technologies (Grover \& Goslar (I993) and executive information systems for collaboration and decision support (Rai \& Bajwa, I997).

This leads to the following hypothesis:

HYPOTHESIS 1 Environmental uncertainty is positively related to the adoption level of ERP software.

A second important characteristic of the external environment is external pressure. In the literature on interorganizational systems, external pressure (most often from a dominant party in the supply chain) has often been documented (e.g. Chwelos et al., 200I; Iacovou et al., I995; Premkumar \& Roberts, I999) to influence adoption and adoption levels. Many IT-applications soon become industry standard. If E RP is perceived as a new industry standard, firms will adopt and diffuse ERP technology in order to keep up with the competition.

External pressure can stem from a variety of sources, including competitors, the government, consultancy firms etc. If a firm's competitors, suppliers or customers are adopting and using ERP software, this results in pressure for nonadopters to also use ERP software. This pressure stems from the perception that adopters will have certain competitive advantages by using E R P systems. To 'level the playing field', nonadopters will soon start using E R P software as well (Bradford \& Florin, 2003). Abrahamson \& Rosenkopf (I993) provide a classification of theories that may explain this phenomenon. Whereas rational-efficiency theories would have it that nonadopters soon become aware of the benefits of ERP and therefore choose to adopt, proponents of fad theories would argue that this can be explained by institutional or competitive bandwagon pressures.

In this study I argue that the organization's perceived threat of being at a competitive disadvantage, creates the pressure to adopt new technologies. This leads to the following hypothesis:

HYPOTHESIS 2 External pressure will be positively related to the adoption level of ERP software. 
2.2.2 Determinants of ERP usage: the internal environment One central assertion in the innovation literature has been that organic organizations are more likely to experience innovation than are mechanistic organizations (Zmud, I982). This distinction between organic and mechanistic organizations is usually operationalized using two organizational variables: centralization and formalization. Centralization indicates the degree of decision-making concentration. Generally, centralization is negatively related to initiation, because the low level of local autonomy does not support initiation. Arguments both in favour of negative and positive relations with adoption have been made (Pierce \& Delbecq, I977; Kimberly \& Evanisko, I981; Zmud, I982). The empirical evidence on the effect of centralization on adoption is ambiguous, which suggests that the effect of centralization on the usage of particular technologies, depends on the type of innovation in question.

In the case of E RP systems, there are several arguments that favour a positive relationship between centralization and E R P adoption. Davenport (1998) argues that European companies were earlier than U.s. based organizations in adopting ERP systems, because of their centralized organizational structure (with the underlying idea that ERP systems better fit a centralized structure). I argue that aside the notion of fit, centralization can be a facilitating condition for adoption of information technology, because it allows a central decision with regard to the acquisition of the ERP software. In a centralized firm, there is usually a politically dominant coalition that has the discretion to decide upon the acquisition of IT-software. Also, centralized firms usually have highly rationalized decision mechanisms for investment purposes (Zmud, I982). Although it is possible that the idea to adopt an E R P system was initiated at the decentralized level (because of the perceived problems of legacy systems for instance), it is highly unlikely that the purchase of ERP software will be a local decision, because of the scope of these systems.

Although there are arguments to posit a positive relation between centralization and the ERP adoption level, it is also possible to develop arguments for a negative relation between centralization and E RP adoption levels. ERP systems can play an important role in decentralized organizations. The adoption and subsequent usage of ERP systems can lead to a situation where ERP facilitates a total democratization of the usage of information. In this situation, E R P systems will allow firms to break down their hierarchical structures and free their people to be more innovative and more flexible (Davenport, I998, p.127). 
This controversy regarding the relation between centralization and the ER P adoption level can be traced back to the different roles that ERP can play. In his study of monitoring technologies, Hubbard (2000) discusses how IT can be used to solve both control and coordination problems. Assuming that ERP can enhance incentives through its monitoring role, it will increase the returns to delegation (decentralization). At the same time, monitoring can also improve coordination (by reducing information asymmetry between organizational layers) and thereby decrease the returns to delegation. This ambiguity in the relation of centralization and the ERP adoption level leads to a null hypothesis:

HYPOTHESIS 3 Centralization will not be related to the adoption level of ERP software.

Formalization is the second variable that is used to operationalize the mechanistic-organic distinction. Formalization reflects the degree to which a firm relies upon rules and procedures. Bureaucratic organizations rely on codified rules, procedures or behaviour prescriptions when handling decisions or work processing (Pierce \& Delbecq, I977). Through formalization, organizations try to increase the predictability of performance. Formalization tends to reduce the initiative of employees, because of this reliance upon rules and procedures.

As explained in section 2.I, one of the main benefits of ERP technology is the fact that certain rules and procedures are hard-wired into the software. When buying ERP software, firms are not so much buying a technology, but a 'way of doing business'. During the implementation process, the rules and procedures of the firm are made explicit in the configuration of the ERP package. This advantage of adopting standardized 'best' business practices is higher for firms that have high levels of formalization than for firms that have low levels of formalization. With increasing formalization levels, the rule-based nature of E R P technology is more likely to be applicable in multiple business functions. In an unformalized setting, the rigidity of ERP packages will have severe drawbacks. Thus I hypothesize:

HYPOTHESIS 4 Formalization will be positively related to the adoption level of ERP software.

The concept of information intensity was introduced by Porter \& Millar (I985). Information intensity reflects the degree to which information 
is present in the product/service of a firm (Porter \& Millar, I985). The production process of information-intensive products/services is complex and brings along more strict information needs in order to manage these complexities. For instance, insurance and mortgage banking firms are more information-intensive, as their primary business function is to process information. For every step in the production process of their information-intensive products/services, accompanying information is needed. ER P systems may provide this type of information, because the ERP-database will contain all information relevant for the product/service that is being made/delivered. In addition, an ERP system will allow firms to capture this information in a central data repository and use this information across multiple business functions. Especially the central database of the ERP system can play a crucial role in this respect, because this repository allows employees in different departments and/ or even locations, to work with the same real-time data. This role of ERP will be even more pronounced if ERP is adopted in multiple business areas (i.e. a higher adoption level). Therefore I hypothesize that information intensity is a driver of the ERP adoption level:

HYPOTHESIS 5 Information intensity will be positively related to the adoption level of ERP software.

2.2.3 Determinants of ERP usage: technological characteristics Besides environmental and organizational characteristics, the adoption level of E R P systems can also be influenced by characteristics of the technology itself. A basic distinction can be made between primary and perceived characteristics of an innovation. Primary characteristics are intrinsic to an innovation and independent of their perception by potential adopters. Prior research (Downs \& Mohr, I976; Moore \& Benbasat, I991) has shown that the perceived characteristics of IT applications are much more important in explaining adoption and diffusion than their primary characteristics. The problem is that very few characteristics of an innovation are truly primary. For the large majority of technological characteristics, it is possible that they are perceived by individuals in multiple ways. What constitutes a useful or easy-to-use technology for one organization, may be useless and difficult-to-use for another organization. Because individuals' behaviour is predicated by how they perceive these primary attributes, scholars have started to focus on the perceived characteristics of innovations.

Tornatzky \& Klein (I982) performed a meta-analysis of frequently 
studied innovation characteristics. The meta-analysis shows that among as many as 25 attributes (e.g. cost, divisibility, social approval), compatibility, complexity and relative advantage have consistently been shown to impact the adoption decision.

Therefore, the following three attributes of the innovation (Rogers, I983) are included in the study:

RELATIVE ADVANTAGE the degree to which an innovation is perceived as being better than its precursor;

COMPATIBILITY the degree to which an innovation is perceived as being consistent with the existing values, needs, and past experiences of potential adopters;

COMPLEXITY the degree to which an innovation is perceived as being difficult to use;

Perceived relative advantage is of key importance in diffusion of innovations. It is the perception of benefits that provides the economic and political legitimacy to the decision to invest in a new technology (Premkumar et al., I997). Perceived ERP advantages should motivate firms to seek a higher adoption level of their ERP system, especially because ERP advantages stem from the benefits of having higher integration levels. Firms that want to reap E RP advantages will therefore do this by seeking higher ER P adoption levels. This discussion leads to the following hypothesis:

HYPOTHESIS 6 The relative advantage of ERP software will be positively related to the adoption level of ERP software.

The more an innovation is perceived as being consistent with existing systems, procedures, and value systems of the organization, the more likely it is that the innovation will be used. Schultz \& Slevin (I975) distinguish between organizational and technical compatibility. Organizational compatibility evaluates the compatibility with existing attitudes, beliefs, and value systems, technical validity evaluates the compatibility with existing systems. Any innovation is accompanied by changes to existing work practices; this is certainly the case for ERP systems. The introduction of these systems is often combined with business process reengineering (В Р R) efforts. A lack of organizational compatibility will lead to higher organizational resistance to ERP technology. In addition, technical compatibility is of importance because ERP systems are typically 
used in conjunction with retained systems. Therefore, both forms of compatibility are deemed relevant in the context of ERP systems. This leads to the following hypothesis:

HYPOTHESIS 7 The compatibility of ERP software will be positively related to the adoption level of ERP software.

Companies that perceive ERP technology as having high complexity, will tend to diffuse the software slowly and in limited capacity (Bradford $\&$ Florin, 2003). Although ER P software is often said to be complex, It is important to note that complexity is also a perceived innovation characteristic. Thus, complexity captures the perceived difficulty of understanding and employing a particular technology. Differences in experience levels with precursor technologies, or differences in the maturity of the IT organization, may lead to differences in the perception of a technology's complexity. Complexity will not only inhibit the initial adoption of ERP technology, but will continue to be of importance when seeking higher ERP adoption levels, because the technology will meet with resistance from various user groups. Therefore I hypothesize:

HYPOTHESIS 8 The complexity of ERP software will be negatively related to the adoption level of ERP software.

2.2.4 Control variables Five variables are used as control variables: business size, elapsed time, top management support and two industry dummies (manufacturing and wholesale/retail).

Large businesses have more resources to facilitate the adoption of information systems (Dewar \& Dutton, I986; Moch \& Morse, I977; Thong, I999). Not only do small firms have severe constraints on financial resources, in-house IT skills may also be limited. Given the high cost and complexity of ER P systems, these two constraints will impose a barrier on small firms when considering adoption and diffusion of ERP technology. Therefore, business size is controlled for.

The stage model of diffusion of innovations shows how an innovation 'spreads' through an organization over an extended time period. Obviously, it will take time to adapt to E R P technology and users have to learn new ways of performing their tasks. Because an ERP implementation may be very disruptive to an organization, many firms decide to implement ERP technology in a phased manner. Once the suitability of E R P technology has been demonstrated in one particular business area, 
the technology is implemented in other business areas. Hence it is possible that the adoption level of the software is also a function of time. To control for this effect, elapsed time since the implementation of the first ERP-module is controlled for. This is in conformity with the recommendation by Fichman (2000). A similar control is applied in studies by Premkumar et al. (1994) in the context of electronic data interchange, and Bradford \& Florin (2003) in the context of ERP systems.

This study also controls for top management support. Top management support has consistently been found to be of importance in the adoption of information systems (Premkumar et al., I994; Rai \& Bajwa, I997). The implementation of ERP systems will impact the way companies communicate with their suppliers and their customers. This may impact the competitive position of the firm and thereby top management support becomes critical. Top management support is necessary to make sure that every business unit understand the importance of E R P technology and carry it through all the organizational units. Therefore, top management support will not only be vital in taking the first adoption hurdle but will continue to be of importance when the package is subsequently introduced in new functional areas.

Finally, two dummy variables are used to control for industry effects. These dummies are necessary to account for the possibility that adoption rates in particular industries are higher, because of higher applicability of the logistic concepts that underlie ERP software. This is most likely to be the case in the manufacturing and the retail/wholesale industries. Therefore, dummy variables are included for these industries.

\subsection{Research methodology}

2.3.1 Introduction The survey method was chosen as the appropriate methodology for this study. There are two dominant reasons for this choice. First, the objective of this study is to identify variables that explain the adoption level of ER P software. The use of a large statistically testable sample allows this. Secondly, much of the work in the is implementation area and the diffusion of innovations field, is based on questionnaires and has used similar variables as the ones that are proposed in this study. This enhances the replicability and cross study comparability of the study and its results.

The survey was administered via the Internet. The advantages of an internet survey as compared to other forms are the following: (I) web surveys allow dynamic interaction with the respondents, for instance 
through the use of skip patterns, pop-up instructions for individual questions, and drop-down boxes with long lists of answer choices; (2) web surveys can have a very refined appearance, as compared to especially surveys by e-mail.

The use of Internet surveys does have a number of potential pitfalls though (Dillman, 2000). The first one is the mere fact that not every organization has an Internet connection or e-mail. Given the size of the organizations that adopt ER P systems, this problem was deemed irrelevant. A second pitfall is the fact that the features of one's computer system may influence the appearance of a Web based questionnaire image. A related problem is that users may use a partial (tiled) screen view and will thereby be unable to see the entire question or answer categories. This was avoided by the internet page design. A third problem is that the transmission capabilities of Internet connections differ widely. Given that this is less the case for businesses than for private households, this was deemed less important.

The survey was tested using different versions of Internet Explorer and Netscape Navigator. Following the principles described by Dillman (2000), the web questionnaire started with a welcome screen that motivated the importance of the study, emphasized the ease of responding, and instructed the respondents to proceed to the next page. All questions were presented in the same, conventional format. The use of colour was restrained. Respondents were informed of their progress with statements like 'You have completed $25 \%$ of the survey'.

2.3.2 Pilot Before the actual data collection took place, a pilot study was undertaken. Pilot tests can play a vital role in assessing whether questions can be correctly understood and answered by the respondents. Four academics and three SAP implementation project managers from practice were chosen for the pilot. Responses from the pilot are not included in the final sample. The pilot participants were interviewed face-to-face or by telephone to determine whether there were any interpretation or other problems with the questionnaire. Their responses led to minor modifications of the questionnaire.

2.3.3 Data collection procedure The sample was restricted to users of the ERP package SAP. SAP was chosen because of the dominance of SAP in the Dutch ERP market. Although at the time when this study was initiated, the number of SAP installations in the Netherlands was probably outnumbered by the number of Baan implementations, Baan was con-
3 The following example may illustrate this problem. Appendix B lists the 13 modules of the SAP R/3 system. In contrast, the Oracle ERP suite is divided into three primary groups: demand, supply, and finance. Demand includes order entry, accounts receivable, and inventory. Supply includes engineering, bill of materials, materials requirements planning, work-in-process, and purchasing. Finance includes general ledger, accounts payable, and cost management (O' Leary, 2000). These differences in the names and functionality of modules make it difficult to construct a usage metric on a module-by-module basis that could be compared across vendors.

4 Organizations that have implemented a certain software package usually register as a member of the user organization. This user organization allows the software vendor and the software users to exchange their experiences. The vNSG has two purposes: (1) to provide and further develop an infrastructure that allows SAP users to share their knowledge, skills and experiences as it relates to SAP software products; (2) to strive for quality improvements of SAP software on behalf of the SAP users. VNSG distinguishes licence members and advice members. Advice members are not using SAP within their firm, but offer support services in the area of ERPsoftware; licence members 
are the actual users of SAP software. For this study, only the latter group is difficult.

5 Some erp implementations are led by an external project manager, usually from an ICT-consultancy firm. Firms that only worked with an external project manager were excluded from this study, because the questionnaire can only be completed reliably by an internal project manager. sidered to be a too risky choice because of the financial difficulties of Baan at the time. Restricting the sample to one ERP vendor does have the limitation that the external validity of the study might be restricted to just the SAP package, although the ER P concept is obviously the same for all ERP packages. The use of just one ERP vendor does bring along the advantage of ease of comparison of adoption levels of E R P-adopters on a module basis. If the survey would have been administered under users of various ERP packages it would have been hard, if not impossible, to compare adoption levels on a module basis, because of differences in both the number of modules as well as the functionality of these modules across the respective ER P vendors'.

A database with member data of the 'Vereniging van Nederlandse SAP Gebruikers' (vNSG) 4: the Dutch user organization of sAP, was used to identify SAP users. This database resulted in the names of around 300 Dutch organizations that are using SAP. This list was complemented by data on Dutch sAP users that were gathered by (a) announcements of SAP implementations in a Dutch professional magazine in the logistics area: (b) public announcement of customer data by sAP Netherlands itself and (c) public announcement of customer data by SAP-consultants in the Netherlands. This led to a total list of 502 SAP-users in the Netherlands. Ultimately, not all the firms on this list turned out to be sap-users. The list included sap-consultancy firms that had only adopted instruction versions of the software and that were not using the SAP system for their own administration. Other listed firms had migrated to different ER P packages by the time that the survey for this study was administered. Some of the firms that were listed in the member database of the user organization were member for other reasons than usage of the sap system (e.g. software developers that needed to make sure that their products could be interfaced with the SAP application). Finally, some firms had not yet started with the sAP implementation, but were planning to do so. At the time when the survey was undertaken, the SAP website mentioned a total of about 400 installations in the Netherlands.

The 502 organizations were contacted by e-mail. E-mail addresses were obtained from the corporate website (if the firm was present on the Internet) or from REACH, a database with corporate information of all Dutch firms. Firms were contacted with the request to provide the contact data (telephone number and/or e-mail address) of the internal project manager of their SAP implementation5. The e-mail explained that the author of this chapter was seeking cooperation from the firm's 
project manager in a study about ERP. If firms did not respond within two weeks a reminder was sent. Ultimately this led to the collection of I4I contact addresses of project managers. Firms that were not willing to provide the contact address of their project manager neglected to do so for several reasons. Reasons often mentioned were: (a) corporate policy not to cooperate in any research project; (b) the ERP implementation was led by an external project manager; (c) the project manager had left the firm after the implementation; (d) the project manager does not have enough time to cooperate (often because implementations were still underway); (e) the project manager was no longer working in the Dutch organization (this was the case in some multinational firms. Multinational corporations often work with global implementation teams that leave the local organization after the sAP package has been 'rolled out'); (f) implementation planned for a later stage; project manager not yet appointed; (g) confidentiality of personnel data.

Project managers were chosen as the key informant in this study. When selecting a project manager, firms will search for employees that are well aware of the type of organizational variables that are studied in this chapter. More importantly, the project managers have been involved in the ERP implementation process and are the best possible informants when it comes to measurement of ERP adoption levels.

Project managers that provided their contact information were contacted (by e-mail and on rare occasions by telephone) with the request to complete the survey. The survey was administered on a webpage of the university. One question asked respondents to indicate the name of their organization. This made it possible to send a reminder (after two weeks) to respondents that had not yet completed the survey. The name of the organization was also necessary for the study that is reported in chapter 3 , in which the data from the survey are combined with corporate financial information. The identities of the firms were only used to combine the survey data with financial statement data.

If the project manager did not complete the survey within 3 weeks a reminder was sent. Ultimately Io8 usable responses were obtained. Over the total installation base of SAP users in the Netherlands this constitutes a $27.0 \%$ response rate, assuming the correctness of the data from the corporate SAP website at the time (400 installations). If the number of project managers that provided their contact information is taken as the basis for the calculation, the response rate is $75.9 \%$.

To check the representativeness of the responses, non-response bias was assessed by comparing the means of each of the variables of interest 
for early and late respondents. The underlying assumption of this test is that late respondents are more likely to be similar to non-respondents than early respondents. If this test results in no significant differences between early and late respondents, this suggests there is no bias from non-response. I split the sample at the median response time and calculate a t-test for differences in means for each of the variables of interest to this study. The results in table 2.2 indicate that there are no significant differences between early and late respondents for any of the variables, which suggests the absence of non-response bias.

Table 2.2 TEST FOR NON-RESPONSE BIAS

\begin{tabular}{lcccc} 
Variable & Early responders & Late responders & t-value & p-value \\
\hline $\begin{array}{l}\text { Dependent variable: } \\
\text { Adoption level }\end{array}$ & & & & \\
Independent variables: & 0.6296 & 0.6116 & -0.507 & 0.613 \\
Environmental uncertainty & 2.9454 & & & \\
External pressure & 3.6293 & 2.8505 & -0.926 & 0.357 \\
Centralization & 3.7000 & 3.3704 & -1.595 & 0.114 \\
Formalization & 2.7269 & 3.8815 & 1.174 & 0.243 \\
Information intensity & 4.0857 & 2.7778 & 0.384 & 0.702 \\
Relative advantage & 3.7557 & 4.0556 & -0.306 & 0.760 \\
Compatibility & 3.2841 & 3.6934 & -0.658 & 0.512 \\
Complexity & 3.3704 & 3.3086 & 0.141 & 0.888 \\
& & 3.5926 & 1.052 & 0.295
\end{tabular}

A final test for non-response bias was done by comparing the difference in firm size between the respondents, and the non-respondents (as identified on the list of sap users). A t-test showed no significant difference in terms of the employee level.

2.3.4 Operationalization of variables Given that the data are obtained through questionnaires, all measures, with the exception of firm size, are perceptual measures. In the questionnaire for this study, existing measurement instruments have been used as much as possible. Environmental uncertainty is measured using a five-point scale for which the extremes are anchored. For all other instruments, five-point fully anchored scales are used. To measure perceived relative advantage, items were chosen that reflect E R P benefits. This construct can only be measured in a meaningful way by making sure that the items address the benefits of the technology being studied. The measurement instruments for external pressure, top management support, compatibility and complexity were rephrased to make sure that the items address these variables 
in the context of ERP systems. To measure the dependent variable (the adoption level of ERP systems), I develop a metric based on the use of the various SAP-modules. This is explained in more detail later in this section. All instruments are given in Appendix A. The use of existing measurement instruments, in combination with pilot testing, should guarantee content validity, which assesses if the measurement is complete and sound. Table 2.3 gives an overview of the measurement of the independent variables.

Table 2.3 OVERVIEW of MEASUREMENT INDEPENDENT VARIABLES

Variables References Number of items

Cluster 1: External Environment

Environmental uncertainty $\quad$ Rai \& Bajwa (1997), Miller and Friesen (1982) 14

External pressure $\quad$ Premkumar \& Ramamurthy $(1995)^{\star} \quad 3$

Cluster 2: Internal Environment

Centralization

Grover \& Goslar (1993); Hage and Aiken $(1967,1969) \quad 5$

Formalization

Grover \& Goslar (1993); Hage and Aiken (1969); 4

Information intensity

Thong (1999)

Firm size (control variable)

n.a.

Top management support

(control variable)

Rai \& Bajwa (1997)*

Cluster 3: Technology

Relative advantage

Developed for this study

Compatibility

Ramamurthy et al. (1999)*

Premkumar et al. (1994)*

Complexity

items address ERP systems.

The dependent variable, ERP adoption level, was measured by having respondents indicate their usage of a set of SAP modules. This list of modules was taken from sap-documentation. The list with sAP modules can be found in appendix в. Respondents were asked to indicate the status of the usage of the respective modules (see Appendix в for details). Semi-structured interviews with two experienced sap-consultants generated a list of relevant modules per industry. This procedure was necessary to adjust for the fact that some modules are not relevant in certain industries. An insurance firm has no use for a production planning module; a retailer has no use for a plant maintenance module. The ERP adoption level was measured by a ratio. The number of modules in use was used as the numerator, and the number of relevant modules as the denominator.

The instrument to measure environmental uncertainty was taken from Rai \& Bajwa (I997). This instrument is derived from Miller \& Friesen 
(I982). It consists of I4 items with respect to the external environment of the responding firm. Six items are used to indicate the dynamism of the external environment, three items are used to capture the heterogeneity of the products/services offered and five items indicate the hostility of the external environment.

The instrument to measure external pressure is taken from Premkumar \& Ramamurthy (I995). This instrument consists of three items that assess the extent of pressure exerted by customers, suppliers and the industry as a whole.

The instruments to measure centralization and formalization are taken from Grover \& Goslar (I993). Both instruments are derived from Hage $\&$ Aiken (1967, 1969). The centralization instrument consists of five items that assess the location of decision-making authority across five different domains. The formalization instrument consists of four items that assess the existence of various types of rules and regulations that define role obligations.

The instrument to measure information intensity is taken from Thong (I999). It consists of three items that measure the dependence of an organization on three attributes of information: currency, reliability and timeliness.

Relative advantage was measured by indicators that assess ERP benefits in the areas of cost reduction, business process reengineering and information quality improvements. In this study, it is the project manager's perception that ERP will improve organizational practices and/or organizational performance. The indicators were chosen to reflect the theoretical ER P benefits that were addressed in chapter I of this dissertation.

The instrument to measure compatibility was taken from Ramamurthy et al. (I999). One item reflects the technical compatibility of ER P with existing hardware and software; two items reflect the organizational compatibility with respect to work procedures and value systems of the ERP users.

Complexity was measured using a single item (Premkumar et al., I994) that reflects the perceived complexity of using E RP in the organization.

Five variables were used as control variables: business size, elapsed time, top management support and two industry dummies (manufacturing and wholesale/retail). The number of employees is used as a measure of business size. Other studies on organizational innovation (e.g. Kimberly \& Evanisko, I98I, Rai \& Bajwa, I997) have also employed this 
metric. To account for large variations in organization size, the natural logarithm of organization size was computed and used for further analysis. Industry effects were captured using a dummy for manufacturing firms ( $\mathrm{I}=$ manufacturing; $\mathrm{O}=$ other) and a dummy for wholesale/retail firms ( $\mathrm{I}=$ wholesale/retail; $\mathrm{O}=$ other). Elapsed time was measured as the number of years since the introduction of the initial E R P-module. Finally, top management support was measured using an instrument from Rai \& Bajwa (I997). It consists of six items that assess top management involvement and support with regard to the organizational ER P efforts.

I anticipated that some of the respondents would not be familiar enough with the English language to administer the survey in the English language. Therefore I decided to use the Dutch language. The original measurement instruments were translated in Dutch. The resulting draft version of the questionnaire was reviewed by one of my supervisors who is fluent in Dutch and English. He translated the questionnaire back to English; this translation was compared with the original, Englishlanguage instrument. Adjustments were unnecessary.

2.3.5 Instrument validation The psychometric properties of the different variables were examined. Construct validity was assessed using convergent and discriminant validity. Convergent validity evaluates whether all the items measuring a construct cluster together to form a single construct, whereas discriminant validity measures the degree to which a concept differs from other concepts.

Convergent validity of the variables was assessed using principal component analysis with varimax rotation ${ }^{6}$ for each separate construct. For the instruments for external pressure, centralization, formalization, information intensity, compatibility and top management support, the items load significantly on their intended construct, with all factor loadings above the cutoff point of 0.50 .

The principal component analysis indicates multi-dimensionality for the environmental uncertainty construct. The first factor corresponds with the dimension of environmental dynamism, whereas the second factor corresponds with the dimension of environmental heterogeneity. The other factors do not correspond with the dimension of environmental hostility and can not be interpreted in a meaningful way. As a result I delete these items from the measurement instrument and continue the analysis with the separate dimensions of dynamism and heterogeneity.

The items measuring perceived relative advantage split into three separate factors measuring benefits in the areas of cost reduction (items
6 Varimax rotation is the most widely employed orthogonal rotation method. Pedhazur \& Pedhazur Schmelkin (1991) give an overview of criticism of orthogonal rotation methods and discuss the alternative of oblique rotations. I follow their recommendation to rotate both orthogonally and obliquely. Comparison of the pattern and the structure matrix indicates that the correlations among the factors are negligible. Therefore, it is tenable to use the more simple orthogonal solution. In addition, Hair et al. (1998) discuss the problem that obliquely rotated factors have an additional way of becoming specific to the sample in settings with small samples or a low cases-to-variable ratio. 7 The identified separate factor consisted of this individual item only. The item did still have a fair factor loading (0.459) on the top management support construct. The regression analyses that are reported later in this chapter were performed both including and excluding this item. Inclusion of the item does not alter any of the results reported later. 
I, 5 and 6), business process improvements (items 2, 3, 4 and 9) and information quality improvements (items 7 and 8). This multidimensionality is not surprising; whereas some organizations will mainly perceive ERP as a vehicle to replace stand-alone systems, others envision a role for ERP in enhancing the information processing capabilities of the firm. Given that I'm interested in the total effect of perceived relative advantage, I treat the three factors as a single variable. This approach has been extensively used in information systems research (e.g. Premkumar et al., I994). For sensitivity analysis purposes, I examine the three identified factors separately.

Discriminant validity was assessed using principal component analysis with varimax rotation for all constructs simultaneously. The results of this analysis are shown in table 2.4. One question for top management support (TMS3) loaded onto a separate construct7. This item was excluded from the analysis. 


\begin{tabular}{|c|c|c|c|c|c|c|c|c|}
\hline Question & 1 & 2 & 3 & 4 & 5 & 6 & 7 & 8 \\
\hline EU - DYN1 & 0.02978 & -0.0876 & 0.76388 & 0.1441 & 0.1528 & -0.0709 & 0.06143 & -0.0039 \\
\hline EU - DYN2 & 0.09258 & -0.1981 & 0.56383 & 0.35711 & -0.0151 & -0.1251 & -0.2315 & 0.03581 \\
\hline EU - DYN3 & -0.0745 & 0.11142 & 0.67669 & 0.19578 & 0.14847 & 0.03014 & -0.1389 & -0.127 \\
\hline EU - DYN4 & -0.0243 & -0.2101 & 0.55431 & 0.10522 & -0.0047 & -0.075 & -0.3129 & 0.04878 \\
\hline EU - DYN5 & -0.0596 & -0.0314 & 0.48718 & 0.17656 & -0.1547 & 0.04988 & -0.0991 & 0.16149 \\
\hline EU - DYN6 & -0.0077 & 0.18875 & 0.71095 & -0.009 & -0.0676 & 0.03667 & 0.19676 & 0.06619 \\
\hline EU - HET1 & 0.01187 & -0.0262 & 0.08092 & 0.80254 & -0.0142 & -0.0959 & -0.0597 & 0.02533 \\
\hline EU - HET2 & -0.0985 & -0.0174 & 0.2806 & 0.74539 & -0.084 & 0.04327 & 0.1072 & -0.0687 \\
\hline EU - HET3 & -0.0919 & 0.00248 & 0.19163 & 0.80737 & 0.13788 & -0.1169 & 0.105 & 0.02473 \\
\hline CENT1 & 0.08379 & 0.72604 & -0.0598 & 0.07556 & -0.0604 & 0.08798 & -0.0043 & 0.01968 \\
\hline CENT2 & 0.10136 & 0.81645 & 0.07335 & -0.1632 & 0.11311 & 0.04727 & -0.0521 & -0.0291 \\
\hline CENT3 & 0.12444 & 0.76261 & 0.03305 & -0.0207 & 0.17172 & -0.0152 & 0.05086 & 0.11728 \\
\hline CENT4 & 0.35688 & 0.64531 & 0.08193 & 0.01921 & -0.1432 & 0.24908 & -0.0642 & 0.12866 \\
\hline CENT5 & 0.24741 & 0.68632 & -0.141 & 0.02679 & -0.0731 & 0.06858 & 0.0396 & 0.01857 \\
\hline INFO-INT1 & 0.01622 & 0.04204 & -0.053 & 0.10962 & 0.08768 & -0.0128 & 0.79647 & -0.1231 \\
\hline INFO-INT2 & -0.0116 & -0.079 & -0.0346 & 0.01308 & 0.04736 & -0.0788 & 0.75536 & -0.0411 \\
\hline INFO-INT3 & -0.1816 & 0.00372 & -0.0466 & -0.0032 & -0.0589 & -0.2262 & 0.68807 & 0.08904 \\
\hline TMS1 & 0.59926 & 0.25178 & 0.00766 & -0.2149 & -0.2121 & 0.10857 & 0.23474 & 0.1768 \\
\hline TMS2 & 0.73937 & 0.09519 & 0.1149 & -0.026 & -0.0292 & 0.0388 & 0.02935 & 0.20598 \\
\hline TMS4 & 0.79726 & 0.21869 & -0.0237 & -0.1639 & 0.11041 & -0.1404 & -0.185 & 0.1406 \\
\hline TMS5 & 0.84394 & 0.08008 & -0.028 & 0.09883 & 0.02997 & 0.0703 & -0.0861 & 0.00597 \\
\hline TMS 6 & 0.80253 & 0.21271 & -0.1273 & -0.0244 & 0.07135 & -0.1137 & -0.0798 & -0.0335 \\
\hline PRES1 & 0.04697 & 0.06662 & 0.11788 & 0.07587 & 0.20116 & 0.0314 & 0.02343 & 0.79662 \\
\hline PRES2 & 0.18432 & 0.04609 & -0.0084 & 0.03956 & 0.08464 & -0.0116 & -0.0424 & 0.72004 \\
\hline PRES3 & 0.08742 & 0.04644 & -0.0782 & -0.1156 & 0.0966 & -0.0424 & -0.0555 & 0.77991 \\
\hline COMPA 1 & 0.02985 & -0.0567 & 0.028 & 0.16233 & 0.79859 & 0.08242 & -0.0132 & 0.09766 \\
\hline COMPA2 & -0.0226 & 0.04455 & 0.06932 & -0.0112 & 0.85696 & 0.06761 & 0.04054 & 0.16064 \\
\hline COMPA 3 & 0.03457 & 0.08355 & 0.05941 & -0.1155 & 0.77625 & 0.09908 & 0.04496 & 0.14853 \\
\hline FORM1 & -0.0051 & 0.02559 & -0.178 & -0.1476 & 0.16338 & 0.73066 & -0.1603 & 0.00824 \\
\hline FORM2 & -0.0208 & 0.16665 & -0.0639 & -0.1864 & 0.13928 & 0.56442 & -0.042 & -0.0351 \\
\hline FORM3 & -0.0082 & 0.02185 & 0.00065 & 0.17042 & 0.15172 & 0.84859 & -0.0338 & -0.0104 \\
\hline FORM4 & -0.0061 & 0.14612 & 0.09595 & -0.1555 & -0.1277 & 0.6620 & -0.0675 & -0.0014 \\
\hline
\end{tabular}

\begin{tabular}{|c|c|c|c|c|c|c|c|c|}
\hline Eigenvalue & 4.922 & 3.617 & 2.738 & 2.409 & 2.273 & 1.528 & 1.367 & 1.342 \\
\hline \multicolumn{9}{|l|}{ Variance } \\
\hline Explained (\%) & 10.115 & 9.547 & 8.373 & 7.440 & $7 \cdot 396$ & 7.113 & 6.516 & 3.701 \\
\hline \multicolumn{9}{|l|}{ Cumulative } \\
\hline Variance (\%) & 10.115 & 19.662 & 28.034 & 35.475 & 42.871 & 49.983 & 56.499 & 62.835 \\
\hline
\end{tabular}


8 Grice \& Harris (1998) argue that the psychometric properties of standardized scores are preferred relative to regression estimates of factor scores.
The appropriateness of factor analysis was tested using the Bartlett test of sphericity and the Kaiser-Meyer-Olkin test. The Bartless test of sphericity was significant $(p=0.00)$, whereas the Kaiser-Meyer-Olkin test was above the threshold value of 0.50 (0.65I). These results both suggest that factor analysis is appropriate given the data.

Finally, the reliability of the measures was assessed by using Cronbach alpha coefficients. Table 2.5 presents the Cronbach alpha coefficients for the research variables. Nunnally (I978) suggests that a value of at least 0.70 indicates adequate reliability. With the exception of perceived relative advantage, all the variables meet this threshold. The lower score on perceived relative advantage is not bothersome, given the discussion about potential multidimensionality of this construct earlier.

\section{Table 2.5 CRONBACH ALPHA COEFFICIENTS}

Variable

Cronbach alpha

$\begin{array}{lc}\text { Environmental uncertainty - dynamism (6) } & 0.7547 \\ \text { Environmental uncertainty - heterogeneity (3) } & 0.7822 \\ \text { External pressure (3) } & 0.7045 \\ \text { Centralization (5) } & 0.8230 \\ \text { Formalization (4) } & 0.7153 \\ \text { Information intensity (3) } & 0.7381 \\ \text { Top management support (5) } & 0.8326 \\ \text { Relative advantage (9) } & 0.6861 \\ \text { Compatibility (3) } & 0.7906\end{array}$

The results in this section provide sufficient confidence to consider the employed items valid measures of the constructs. In computing all constructs with multiple items, I use unit-weighted average standardized scores $^{8}$.

\subsection{Results}

2.4.1 Descriptive statistics independent variables On average, respondents have been working in their current function for 5 years and for their organization for II. 3 years. The average age is 43 years. The vast majority of respondents stated that their main area of expertise was IT (68.5\%). The other respondents had a background in either logistics, accounting/finance or marketing/sales. The experience of the respondents suggests that they will be knowledgeable enough to answer the questions about the external and internal environment of the organization. All 
respondents verified that they had been working as the project manager for the SAP implementation within their organization.

Table 2.6 shows an overview of the respondents by industry classification, with the largest number of adopters in manufacturing, wholesale/retail and business services.

\section{Table 2.6 NUMBER OF ERP ADOPTIONS BY INDUSTRIAL CLASSIFICATION}

Industry

Number of ERP adopters
9 This is the average adoption level for model I, as reported upon in section 2.4.3. The descriptive statistics for the other models discussed in section 2.4 .3 exhibit slightly higher adoption levels and standard deviations. The descriptives are however very similar.

$\begin{array}{lr}\text { Chemicals } & 11 \\ \text { Other manufacturing } & 32 \\ \text { Construction } & 3 \\ \text { Wholesale } & 24 \\ \text { Retail } & 3 \\ \text { Transportation } & 3 \\ \text { Financial/ Insurance } & 2 \\ \text { Real estate } & 3 \\ \text { Business Services } & 34 \\ \text { Government } & 5 \\ \text { Education } & 5 \\ \text { Healthcare } & 3\end{array}$

Descriptive statistics for the independent variables are given in table 2.7.

Table 2.7 DESCRIPTIVE STATISTICS INDEPENDENT VARIABLES

\begin{tabular}{lccccr} 
Variable & Mean & Std.Dev. & Min. & Max. & Median \\
\hline $\begin{array}{l}\text { Environmental uncertainty } \\
\text { > dynamism }\end{array}$ & & & & & \\
$\begin{array}{l}\text { Environmental uncertainty } \\
\text { > heterogeneity }\end{array}$ & 0.00 & 0.67 & -1.47 & 2.24 & -0.01 \\
External pressure & 0.00 & 0.84 & -1.61 & 1.77 & 0.08 \\
Centralization & 0.00 & 0.79 & -1.79 & 1.40 & 0.15 \\
Formalization & 0.00 & 0.77 & -2.29 & 1.14 & 0.18 \\
Information intensity & 0.00 & 0.74 & -1.62 & 1,86 & -0.00 \\
Relative advantage & 0.00 & 0.81 & -3.29 & 1.49 & -0.10 \\
Compatibility & 0.00 & 0.55 & -1.62 & 1.37 & -0.04 \\
Complexity & 0.00 & 0.85 & -2.16 & 1.59 & 0.11 \\
& 0.00 & 1.00 & -2.25 & 1.38 & 0.47
\end{tabular}

2.4.2 Descriptive statistics dependent variable Descriptive statistics for the usage of the SAP modules is given in table 2.8 . 
Table 2.8 Descriptive statistics SAP usage Per module (IN \%) (see appendix в for an overview of the SAP modules)

\begin{tabular}{|c|c|c|c|c|c|c|c|c|c|c|c|c|c|}
\hline Status & $\mathrm{FI}$ & $\mathrm{CO}$ & TR & IM & PS & BW & HR & PM & $\mathrm{QM}$ & PP & MM & SD & EC \\
\hline Not in use & 4.6 & 6.4 & 90.8 & 60.6 & 60.6 & 88.1 & 62.4 & 64.2 & 84.4 & 62.4 & 14.7 & 22.0 & 90.8 \\
\hline In use & 95.4 & 93.6 & 9.2 & 39.4 & 39.4 & 11.9 & 37.6 & 35.8 & 15.6 & 37.6 & 85.3 & 78.0 & 9.2 \\
\hline \multicolumn{14}{|c|}{ Length of usage: } \\
\hline$<3 \mathrm{yr}$. & 25.7 & 24.8 & 3.7 & 16.5 & 18.3 & 8.3 & 20.2 & 16.5 & 6.4 & 10.1 & 22.0 & 21.1 & 0.9 \\
\hline$>3 \mathrm{yr}$. & 69.7 & 68.8 & 5.5 & 22.9 & 21.1 & 3.7 & 17.4 & 19.3 & 9.2 & 27.5 & 63.3 & 56.9 & 8.3 \\
\hline
\end{tabular}

The average adoption level is 0.620 (standard deviation 0.185; min: 0.20, max: I.००, mean: 0.64$)^{9}$.

Descriptive data of the usage of the SAP modules clearly indicate that the financial modules (F I , CO) are an essential ingredient of almost any SAP implementation. In fact, the accounting module is often seen as the 'backbone' of the ER P system; it's hard to think of organizational transactions that will ultimately not have some kind of impact on the accounting module. Only the material management ( $\mathrm{M}$ ) and the sales and distribution (SD) modules show similar adoption rates. Several modules show adoption rates in the range of $35-40 \%$. These modules are the asset/ investment management module (I M), project systems module (PS), the human resource management module ( $\mathrm{HR}$ ), the plant maintenance module ( $\mathrm{PM}$ ) and the production planning module (P P). The relatively low adoption rate of the $\mathrm{H}$ m module is striking, given that the functionality offered in this module (e.g. payroll administration, time management and personnel development) is relevant across all industries (similar to the accounting suite, which shows much higher adoption rates). The other modules are only used by small numbers of SAP adopters. The low adoption rates of the treasury (TR) and the enterprise controlling (EC) modules can be attributed to the fact that the use of these modules is limited to certain industries and/or very large firms.

As explained before, the dependent variable (adoption level) was measured as a ratio, with the number of modules in use as the numerator, and the number of relevant modules as the denominator. As an alternative specification of the model, the number of modules was used as the dependent variable, simultaneously controlling for the number of relevant modules as an independent variable. Results for these two specifications of the model were similar, in terms of which hypotheses should be accepted and rejected. 
Controlling for the number of relevant modules does introduce one significant problem. Several organizations reported the use of modules that were not considered to be relevant to their industry by the interviewed ERP-consultants. After further inspection, the source of these conflicting results was found in the industry classification of organizations. This was done on basis of organizations' industry classification code in REACH, a database with financial information for all Dutch organizations. This industry classification code only captures the main activity of organizations. The use of modules that were not deemed relevant by the consultants, could be attributed to secondary business activities of the organization in other industries. This problem was solved by adjusting the number of relevant modules (the denominator in the adoption level ratio) to reflect important secondary activities. In addition, all organizations were screened for important secondary activities and, if necessary, the denominator of the adoption level ratio was adjusted.

The survey also gathered data on the implementation date of the SAP package (in general) and the implementation date of the specific modules. Although not all respondents indicated the implementation date per module, certain implementation patterns can easily be observed. A typical sAP implementation starts with back office functionality (the financial suite) and is followed by front office functionality (the logistics suite) one, two or three years later (with some ERP implementations taking even more than five years).

2.4.3 Multivariate analysis Ordinary least squares regression analysis ${ }^{\text {IO }}$ was used to test the hypotheses associating the independent variables (external, internal and innovation characteristics with the adoption level of ERP software. To assess the robustness of the results, several different models were analyzed. In this section I report the results of the key models and discuss the statistical results of the performed analyses. The broader implications of these results are discussed in the final section of this chapter.

The Pearson correlation matrix was examined for the existence of multicollinearity problems. Correlations are reported in table 2.9. Although there are several significant correlations, the magnitude of the correlation coefficients does not suggest any serious multicollinearity problems. As an additional test for multicollinearity problems, variance inflation factors are examined. None of these vi F-scores indicate multicollinearity concerns, given that the vif values are all in the range of
10 Given that the adoption level is a limited dependent variable (the range is restricted to values from o to 1), there are some potential hazards to treating it as a continuous variable. However, given that the adoption level variable is normally distributed, and the number of corner observations is small, a special econometric model is deemed unnecessary. See Wooldridge (2000) for a discussion of limited dependent variable models. 
Table 2.9 CONSTRUCT CORRELATION MATRIX

\begin{tabular}{|c|c|c|c|c|c|c|c|c|c|c|c|c|}
\hline & $\begin{array}{c}1 \\
\text { Env. dyn. }\end{array}$ & ${ }^{2}$ Env. het. & $\begin{array}{l}3 \\
\text { Ext. pres. }\end{array}$ & $\begin{array}{l}4 \\
\text { Cent. }\end{array}$ & $\begin{array}{l}5 \\
\text { Form. }\end{array}$ & $\begin{array}{l}6 \\
\text { Info.int. }\end{array}$ & $\begin{array}{l}7 \\
\text { Rel. adv. }\end{array}$ & $\begin{array}{l}8 \\
\text { Comp. }\end{array}$ & $\begin{array}{l}9 \\
\text { Compl. }\end{array}$ & $\begin{array}{l}10 \\
\text { Elapsed } \\
\text { time }\end{array}$ & $\mid \begin{array}{l}11 \\
\text { Top manag. } \\
\text { supp. }\end{array}$ & $\begin{array}{l}12 \\
\text { Firm size }\end{array}$ \\
\hline 1 & 1.000 & & & & & & & & & & & \\
\hline 2 & $0.414^{\star *}$ & 1.000 & & & & & & & & & & \\
\hline 3 & 0.064 & -0.021 & 1.000 & & & & & & & & & \\
\hline 4 & -0.058 & -0.076 & 0.156 & 1.000 & & & & & & & & \\
\hline 5 & -0.079 & -0.172 & 0.004 & $0.219^{*}$ & 1.000 & & & & & & & \\
\hline 6 & -0.104 & 0.163 & 0.075 & -0.050 & $-0.199^{*}$ & 1.000 & & & & & & \\
\hline 7 & 0.042 & 0.003 & 0.166 & $0.233^{*}$ & 0.140 & 0.087 & 1.000 & & & & & \\
\hline 8 & 0.072 & 0.039 & $0.294^{\star *}$ & 0.054 & 0.182 & -0.008 & $0.260^{* *}$ & 1.000 & & & & \\
\hline 9 & -0.016 & -0.047 & $0.367^{\star *}$ & 0.128 & 0.083 & 0.078 & $0.221^{*}$ & 0.380 ** & 1.000 & & & \\
\hline 10 & 0.097 & 0.031 & $0.328^{\star *}$ & 0.021 & 0.070 & 0.044 & 0.123 & 0.100 & 0.077 & 1.000 & & \\
\hline 11 & -0.069 & -0.151 & $0.239^{*}$ & $0.444^{* *}$ & 0.007 & -0.016 & $0.233^{*}$ & 0.049 & $0.234^{*}$ & 0.024 & 1.000 & \\
\hline 12 & -0.016 & 0.121 & -0.041 & $-0.345^{* *}$ & |-0.007 & $0.205^{*}$ & -0.078 & -0.042 & -0.146 & 0.121 & $-0.258^{* *}$ & 1.000 \\
\hline
\end{tabular}

I.202-I.626, all below the common cutoff threshold of Io (Hair et al., 1998).

Model I: all SAP modules As an initial analysis, I start with an analysis of all ERP modules (see Appendix в). The regression analysis results are given in table 2.IO.

In addition, I performed assumption tests with regard to (a) independence of the errors, (b) homoscedasticity of the errors (versus the predictions) and (c) the normality of the error distribution. No violations of these assumptions were detected. To alleviate concerns about the relatively low number of observations (given the high number of independent variables), I performed several separate regressions with sets of seven independent variables each. These analyses show similar results as the analyses reported later in this chapter. 
11 For directional predictions, one-tailed tests are used. Otherwise, twotailed tests are employed. 12 For directional predictions, one-tailed tests are used. Otherwise, twotailed tests are employed.

\begin{tabular}{|c|c|c|c|}
\hline Constant & & & .627 \\
\hline \multicolumn{4}{|l|}{ External environment: } \\
\hline Environmental dynamism & + & -0.164 & $-1.624^{\star}$ \\
\hline Environmental heterogeneity & + & 0.036 & 0.334 \\
\hline External pressure & + & 0.228 & $2.117^{\star \star}$ \\
\hline \multicolumn{4}{|l|}{ Internal environment: } \\
\hline Centralization $^{a}$ & $?$ & -0.178 & -1.650 \\
\hline Formalization & + & 0.008 & 0.084 \\
\hline Information Intensity & + & 0.168 & $1.718^{* *}$ \\
\hline \multicolumn{4}{|l|}{ Innovation characteristics: } \\
\hline Relative advantage & + & 0.389 & $3.857^{\star * *}$ \\
\hline Compatibility & + & 0.056 & 0.560 \\
\hline Complexity & - & -0.146 & $-1.418^{*}$ \\
\hline \multicolumn{4}{|l|}{ Control Variables: } \\
\hline Elapsed time & + & 0.103 & 1.070 \\
\hline Top management support & + & 0.062 & 0.572 \\
\hline Industry dummy (manufacturing) & & -0.387 & $-3.454^{\star \star \star}$ \\
\hline Industry dummy (wholesale/retail) & & -0.080 & -0.717 \\
\hline Firm size & + & 0.038 & 0.369 \\
\hline
\end{tabular}

F: 2.978; Significance of F: 0.001; R-square: $32.1 \%$, Adjusted R-square: $21.4 \%$; $n=108$.

$\mathrm{a}=$ two-tailed test.

${ }^{* * *}=$ significant at the $p<0.01$ level; ${ }^{* *}=$ significant at the $p<0.05$ level; ${ }^{*}=$ significant at the $p<0.10$ level

The adjusted $\mathrm{R}$-square of the model is $2 \mathrm{I} .4 \%$, which suggests that variation in the independent variables does explain a reasonable part of the variation in the adoption levels of E R P software.

The results for the impact of external environmental characteristics on ER P adoption levels are ambiguous. One component of environmental uncertainty, dynamism, is significantly negatively related to E RP adoption levels. This direction is opposite to the hypothesized effect and would thus lead to the rejection of hypothesis 1 . The empirical results regarding the impact of external pressure are in conformity with hypothesis 2. External pressure is positively associated with ER P adoption levels. The regression results provide mixed evidence with regard to the impact of characteristics in the internal environment on ERP adoption levels. A two-tailed test for centralization shows no association between centralization and the adoption level. Yet, the coefficient is at the verge of significance. Therefore, a conclusion with regard to hypothesis 3 (null form) is 
postponed till the analyses of the alternative models. Hypothesis 4 , which states a positive impact of formalization on ERP adoption levels, is rejected. Hypothesis 5, which states a positive impact of information intensity on ERP adoption levels, is accepted. For the cluster of innovation characteristics the results are again mixed. There is strong support for the positive impact of perceived relative advantages on ERP adoption levels. Hypothesis 6 is accepted. There is no evidence to support a positive relation between compatibility and ERP adoption levels; therefore hypothesis 7 is rejected. Finally, there is weak support for the negative impact of complexity on the adoption level. Given that the result is only significant at the $\mathrm{p}<0$. Io level, hypothesis 8 is rejected.

For the control variables, only the industry dummy for manufacturing was found to be statistically significant.

As a robustness test, I ran a second specification of the model. Instead of using the entire relative advantage construct, I also perform an analysis in which the relative advantage measure was replaced by the three components from the principal component analysis (see section 2.3.5). The results are given in table 2.II.

Table 2.11 REGRESSION ANALYSIS RESULTS ${ }^{12}$

\begin{tabular}{|c|c|c|c|}
\hline & Predicted Sign & Standardized Beta & $\mathrm{t}$ \\
\hline Constant & & & 8.296 \\
\hline \multicolumn{4}{|l|}{ External environment: } \\
\hline Environmental dynamism & + & -0.183 & $-1.790^{\star *}$ \\
\hline Environmental heterogeneity & + & 0.040 & 0.375 \\
\hline External pressure & + & 0.231 & $2.141^{\star \star}$ \\
\hline \multicolumn{4}{|l|}{ Internal environment: } \\
\hline Centralization $^{a}$ & $?$ & -0.202 & $-1.842^{\star}$ \\
\hline Formalization & + & 0.018 & 0.180 \\
\hline Information intensity & + & 0.140 & $1.390^{*}$ \\
\hline \multicolumn{4}{|l|}{ Innovation characteristics: } \\
\hline Perceived cost advantage & + & 0.188 & $1.846^{\star \star}$ \\
\hline Perceived process advantage & + & 0.313 & $2.969^{\star \star *}$ \\
\hline Perceived information advantage & + & 0.016 & 0.150 \\
\hline Compatibility & + & 0.062 & 0.618 \\
\hline Complexity & - & -0.131 & -1.258 \\
\hline \multicolumn{4}{|l|}{ Control Variables: } \\
\hline Elapsed time & + & 0.091 & 0.931 \\
\hline Top management support & + & 0.067 & 0.606 \\
\hline Industry dummy (manufacturing) & & -0.379 & $-3.345^{\star * *}$ \\
\hline Industry dummy (wholesale/retail) & & -0.076 & -0.681 \\
\hline Firm size & + & 0.032 & 0.307 \\
\hline
\end{tabular}

F: 2.709; Significance of F: 0.002; R-square: 33.5\%, Adjusted R-square: $21.1 \%$; $n=108$.

$\mathrm{a}=$ two-tailed test.

${ }^{* * *}=$ significant at the $p<0.01$ level; ** $=$ significant at the $p<0.05$ level; * $=$ significant at the $p<0.10$ level 
The results corroborate the results obtained in the basic model, with a couple of small differences. In this model, I don't find a significant negative relation between complexity and the adoption level. There was weak support for the role of this variable in the initial analysis. I do find a significant negative relation between centralization and the E R P adoption level. On basis of this result, hypothesis 3 (null form) should be rejected. The decomposition of the perceived relative advantage construct shows that especially perceived relative advantages in the area of cost benefits and process benefits promote higher E RP adoption levels.

Model II: exclusion of the TR, EC and BW modules The interviews with the SAP-consultants led to the identification of two modules whose use was limited to either large banks and insurance films (the treasury (TR) module), or to very large organizations (the enterprise controlling (EC) module). Given that the inclusion of these modules does have an impact on the dependent variable (ratio of used modules over relevant modules), it was deemed necessary to do a robustness test without these two modules. In addition, O'Leary (2000) mentions that the business workflow (вw) module is a so-called cross-application module, which can be used throughout the $\mathrm{R} / 3$ system. This implies that the $\mathrm{Bw}$ Module is solely useful in combination with other modules. Because of the special nature of these three modules, I run a regression where these modules are left out of the calculation of the dependent variable ${ }^{\mathrm{I} 3}$. The regression analysis results are given in table $2 . \mathrm{I} 2$. The results are in conformity with the earlier models, with a couple of important differences. First of all, the results in this model are overall stronger. Removing the three idiosyncratic SAP modules probably results in a purer measure of the ER P adoption level. In this model, the hypothesized negative relation between complexity and the ERP adoption level is established. Again, a negative relation between centralization and the ERP adoption level is found. In addition, the control variables elapsed time and the industry dummy for wholesale/retail are significant in this model.

As a final sensitivity analysis, I again replace the relative advantage measure with the three components from the principal component analysis. The results are in line with those reported in table 2.12. With regard to the three relative advantage components, again only the relative advantages in the area of cost benefits and process benefits are significantly associated with higher E R P adoption levels.
13 I also ran a specification of the model in which only the treasury (TR) and enterprise controlling (EC) module were left out. The results are in conformity with the results presented here.

14 For directional predictions, one-tailed tests are used. Otherwise, twotailed tests are employed. 


\begin{tabular}{|c|c|c|c|}
\hline & Predicted sign & Standardized Beta & $\mathrm{t}$ \\
\hline Constant & & & 9.054 \\
\hline \multicolumn{4}{|l|}{ External environment: } \\
\hline Environmental dynamism & + & -0.198 & $-2.070^{\star \star}$ \\
\hline Environmental heterogeneity & + & 0.069 & 0.673 \\
\hline External pressure & + & 0.174 & $1.702^{\star *}$ \\
\hline \multicolumn{4}{|l|}{ Internal environment: } \\
\hline Centralization & $?$ & -0.223 & $-2.170^{\star \star}$ \\
\hline Formalization & + & 0.017 & 0.181 \\
\hline Information intensity & + & 0.222 & $2.392^{* * *}$ \\
\hline \multicolumn{4}{|l|}{ Innovation characteristics: } \\
\hline Relative advantage & + & 0.349 & $3.644^{\star * *}$ \\
\hline Compatibility & + & 0.108 & 1.134 \\
\hline Complexity & - & -0.162 & $-1.661^{\star \star}$ \\
\hline \multicolumn{4}{|l|}{ Control Variables: } \\
\hline Elapsed time & + & 0.133 & $1.453^{*}$ \\
\hline Top management support & + & 0.124 & 1.203 \\
\hline Industry dummy (manufacturing) & + & -0.508 & $-4.776^{\star \star *}$ \\
\hline Industry dummy (wholesale/retail) & + & -0.164 & $-1.54^{*}$ \\
\hline Firm size & + & 0.050 & 0.514 \\
\hline
\end{tabular}

F: 3.979; Significance of F: 0.000; R-square: 38.8\%, Adjusted R-square: 29.0\%; $n=108$. ${ }^{* * *}=$ significant at the $p<0.01$ level; ** $=$ significant at the $p<0.05$ level; * $=$ significant at the $p<0.10$ level

Further robustness checks Additional models that were analyzed, but are not reported here include: (I) a model where the financial accounting (FI) and the controlling (Co) module were left out of the model. This was motivated by the fact that almost all respondents used these models, (2) a set of models in which all the individual modules were removed on a one-by-one basis. This was motivated by concerns that the results may be driven by one particular module. Finally, (3) I tested several models in which the dependent variable was adjusted to incorporate the use of ERP modules from other ERP packages (respondents could indicate that they used an ERP module from a vendor other than SAP; this was however quite rare). The results of all these models were in line with the results reported in this section. Therefore I conclude that the results obtained in the analyses in this section can not be explained by one individual module. 


\subsection{Discussion, limitations and suggestions for further research}

2.5.1 Discussion This chapter provides insight in the (determinants of) the adoption level of E R P software. Although several descriptive studies have studied differences in adoption rates of ERP software across countries and industries, few studies have focused on the adoption levels of E R P software in a systemic way. In this study, I have developed a metric that allows the comparison of adoption levels across firms. This metric builds on the modular structure of ERP systems and measures the adoption level of ERP in terms of the proportion of relevant ER P-modules that is being employed. On a descriptive note, the chapter illustrates that firms vary widely in terms of the adoption level of the ER P software. In this study I have analyzed how several contextual and technological factors influence the adoption level of E R P systems.

The results show that internal organizational characteristics play an important role in determining the adoption level of E R P software. Information intensity is positively associated with the adoption level of ERP software. Centralization is negatively associated with the adoption level of ERP software.

The positive association of information intensity with ERP adoption levels is in conformity with the hypothesis. Higher information intensity suggests a higher dependency on information in order to be able to produce goods or deliver services. The information intensity construct captures this in terms of the dependency on the currency, timeliness and reliability of information. Given that ERP adds to the information processing capabilities of the firm, firms with higher levels of information intensity will choose higher E RP adoption levels.

Centralization was negatively associated with ERP adoption levels. Centralization is typically thought of as a facilitating condition for adoption of innovations (because of the presence of a dominant political coalition that has the power to decide upon the acquisition of an organization-wide system). In this study, centralization has a negative impact on E R P adoption levels. It may very well be the case that centralization is important in taking the first hurdle of assuring top management approval and funding for the ERP implementation, but it is of no or lesser relevance when it comes to the subsequent diffusion of ERP software. Although highly speculative, this may also be the reason why top management support (one of the control variables) was unrelated to ERP adoption levels. A plausible explanation for the fact that higher E RP adoption levels are observed in decentralized settings is that the monitoring capabilities 
Of ERP are used to improve incentives. This makes it feasible to give lower-level managers more responsibilities (Hubbard, 2000).

I do not find a relation between formalization and ERP adoption levels. It has been said that by adopting an ERP package, firms do not adopt software but implement a 'way of doing business'. During the configuration process of the ERP packages, a plethora of choices have to be made regarding the way in which particular business functions are executed. This process typically leads to the standardization of business processes. In fact, many multinational organizations use ERP implementations as a vehicle to 'roll-out' very formalized and standardized ways of doing business across their locations. Because of the interdependencies that are introduced by adopting a set of ERP modules, it is very hard to change the configuration of the package afterwards, because changes made in a specific part of the organization may have an impact on several other business processes further down the chain of activities. There is however no difference in E R P usage between more and less formalized business settings. One explanation for this finding may be that high levels of formalization also bring along a high possibility of discrepancies between the rules and procedures as being employed before the ERP introduction and the standardized procedures as embedded in the ER P system. Thus, implementing ERP systems in an already highly formalized organization may be more difficult than implementing ERP systems in a setting with low formalization, because current rules and procedures do not pose any serious restrictions in the latter setting.

For environmental uncertainty, the results are somewhat mixed. Due to problems with the construct validity, I had to use two components of environmental uncertainty instead of the entire construct. A separate analysis of the effect of heterogeneity and dynamism showed that dynamism was negatively related to ER P adoption levels. This result contradicts hypothesis 1 . Firms that face higher environmental uncertainty are theoretically expected to implement new information technologies in order to cope with this uncertainty. One explanation for the fact that dynamism has a negative impact on the adoption level of ERP, may be the inflexibility that is introduced by high adoption levels of ERP. If an organization has adopted an ERP system across a large share of its business functions, it will be very hard to make changes in the ERP system, because a change in one functional area will automatically introduce change in other areas. Firms that are faced with high dynamism have to change their products, services, marketing practices or production technologies quite often. These changes may be hindered by a full-fledged E R P 
system. Therefore, firms that face high dynamism will seek lower adoption levels, in order to regain some flexibility in their IT infrastructure.

External pressure was shown to have a positive impact on ERP adoption levels. A similar phenomenon has consistently been found in the context of EDI technology. Although the impact of external pressure is much more direct in the context of interorganizational systems (because a dominant party in the supply chain can coerce its suppliers or customers to implement EDI technology), a similar phenomenon seems to be occurring in the context of ERP systems. In many industries, E RP soon became an industry standard. Many firms are currently ‘tying' their E R P systems together. The impact of external pressure on E RP adoption levels may very well stem from this type of development.

The results for the impact of traditional innovation characteristics (complexity, compatibility, perceived relative advantage) are again mixed. A general explanation for limited evidence in this area may be that Do I theory applies less well in explaining the diffusion of complex technologies (Fichman, 2000). Newell et al. (2000) argue that classic Do I theory would predict a slow diffusion of business process reengineering, whereas rapid diffusion is observed in practice. A similar observation can be made with regard to ERP technology. Whereas the sheer complexity of these systems would predict slow diffusion rates, firms have embraced this technology rapidly.

No evidence was found to support the hypothesis that compatibility has a positive effect on E RP adoption levels. An explanation may be that if organizations perceive E R P as being incompatible with the firm's practices, they simply do not take the initial hurdle of ERP adoption. Once this additional hurdle has been taken, innovation characteristics are of diminishing importance and no longer drive the decision to adopt additional modules. If this is the case, compatibility would still be relevant in explaining why some organizations do and others do not adopt ERP software.

With regard to complexity, there is weak evidence to support the hypothesis that complexity leads to lower E RP adoption levels. This may be a matter of the use of a single-item measurement instrument in this area. An alternative explanation would be that if an organization perceives E R P to be too complex (for instance because the IT department is lacking necessary ERP skills), firms simply never adopt the ERP package. This would be in line with the explanation given above for compatibility.

There is however one classic Do I variable for which I do find very 
15 Confining the analysis to adopters results in a potential for sample selection bias. This is discussed in more detail in the limitations section of this chapter. strong evidence. The results indicate that perceived relative advantage leads to higher ERP adoption levels. Perceived advantages provide the economic and political legitimacy for the investment in E R P. Given that ERP benefits will start to accrue once the technology has been adopted in multiple areas, organizations that perceive higher advantages will also seek higher adoption levels.

Finally, the impact of several control variables was studied. Elapsed time since the initial introduction of ERP did not have a significant impact on the ERP adoption level in one model, and a weak positive impact in the second model. This result can be explained by the presence of several 'big bang' implementations in the dataset. While most organizations choose to implement E RP on a module-by-module basis, there are some organizations that opt for an implementation strategy in which an entire ERP suite is implemented simultaneously. This confounds the results on this particular variable, and may very well explain why there was only weak support for the role of the elapsed time variable.

The dummy variable that was used for manufacturing organizations was significant. The negative sign of the coefficient can be explained by the way the dependent variable was constructed. The adoption level was measured as the ratio of modules in use over the relevant modules. Interviews with consultants showed that firms in manufacturing can potentially use all sAP modules. This increases the denominator and therefore has an effect on the adoption level. The same result was not obtained for the dummy that captured wholesale and retail organizations.

Finally, firm size did not have an impact on ERP adoption levels. This result may be surprising at first. However, by restricting the sample to SAP users only, the sample is already biased towards large firms ${ }^{15}$, because the SAP package is typically used by large firms. It may very well be that beyond a particular threshold, firm size no longer has an impact on ERP adoption levels.

Overall, the results provide empirical support for the role of the three clusters (external environmental, internal environmental and technological characteristics) in determining the E RP adoption level in organizations. Evidence was found to suggest a negative impact of environmental dynamism and centralization on ERP adoption levels, and a positive impact of information intensity. The study finds only limited evidence with regard to the classic Do I variables that have often been observed to promote the adoption of (technological) innovations. Only for relative advantage I find unequivocal results.

In this study, my goal was to gain an understanding of the role of 
several contextual factors in explaining the adoption level of ER P systems. Scholars in innovation research have argued (e.g. Fichman, 2000) that the quest for a single theory of innovation has been unsuccessful. A main insight from this literature is that the particular characteristics of the technology, and the type of benefits that result from the technology, should drive the identification of factors that may promote or inhibit the adoption and diffusion of the technology. Critical benefits of ERP are the integration of data across multiple business functions, the created opportunities for business process reengineering and the enhancement of information processing capabilities. In this study I have identified several environmental, organizational and technological characteristics that may play a role in explaining the employment of ERP systems in organizations. These contextual factors represent conditions under which the benefits of these integrated systems are higher or lower. The results of the study indicate that high ER P adoption levels are especially observed in decentralized, information-intensive firms. ERP systems can play a pivotal role in providing the information that is necessary to run these businesses. Information-intensive organizations are critically dependent on the quality of the information that they are using. The production of their products/services is accompanied by vast streams of information that are necessary to successfully deliver the product/service. In decentralized organizations, the monitoring capabilities of ERP can be used to improve incentives and thereby increase the returns to delegation.

Another important insight from this study concerns the role of environmental dynamism. Firms that are faced with high environmental dynamism (e.g. frequent changes in competitor practices, consumer tastes and/or product/service technology) choose lower ERP adoption levels. These organizations need to maintain flexibility in their Iт infrastructure to be able to cope with this dynamism. The finding that environmental dynamism negatively impacts ER P adoption levels, seems to suggest that ERP systems do not provide this flexibility.

The model presented in this study is not fully explanatory for ERP systems or any other similar technology, but this study has established how E R P adoption levels differ between organizational contexts.

2.5.2 Limitations This chapter should be read with the following limitations in mind.

A first limitation concerns the study of the adoption level as the dependent variable. The focus on the adoption level implies that the 
analysis is confined to those organizations that were innovative enough to already adopt ERP. This implies that there is a potential for sample selection bias (Heckman, I979) and range restriction on study variables (Hoffman, I995). Given the high adoption rates of ERP (Mabert et al., 2000; van Everdingen et al., 2000) and the reported range on the study variables, these issues are unlikely to cause serious problems in this study. Nevertheless, they should be seen as a limitation of this study.

A second limitation concerns the fact that only SAP adopters are studied. Although there are no reasons to assume that the findings would have been different when other E R P vendors would have been included, this possibility can not be completely ruled out.

A third limitation is the use of a single informant in the surveyed firms. Although the project manager of the E RP implementation will be the most knowledgeable respondent in terms of ERP-related matters, this is not necessarily the case for several of the other variables that are measured in this study.

A fourth limitation concerns the use of a single-item measure for complexity. This study found only weak evidence to support a negative relation between complexity and the ERP adoption level. The failure to produce a result in this area may have been due to a poor measurement of this particular variable.

2.5.3 Suggestions for further research There are several opportunities for further research. I will mention four areas for future research that are of particular importance. This study has developed a metric for the adoption level of ERP software as the ratio of modules in use over the number of relevant ERP modules. Although this is already a contribution to the literature, future research can develop other measures for the degreeof-ERP implementation, in order to corroborate the results from this study. Variation in adoption levels of ER P systems will not only manifest itself in differences in the usage of particular modules, but also in differences in terms of the intensity of the usage of these modules. Organizations with the same adoption level (as measured in this study) do not necessarily employ the same functionality, or might differ in terms of the relative proportion of employees that are using the ERP software. Future research could try to address this by developing and employing alternative measures for the adoption level of E RP software.

A second area of further research would be to study the impact of other environmental, organizational and innovation characteristics on ERP usage. This study found only very limited evidence on the role of 
innovation characteristics in promoting higher E R P adoption levels. This may be a deficiency of diffusion-of-innovations theory in explaining the adoption levels of ERP software, but it may also very well be that other innovation characteristics are more important in explaining variations in ERP adoption levels. Future research in this area is therefore warranted.

A third possibility for further research would be to study the role of external pressure in more detail. Proponents of rational-efficiency theories would argue that nonadopters learn of the benefits of ERP technology over time and adopt this technology as soon as the benefits outweigh the costs. But it is also possible that $\mathrm{E}$ RP adoption can be explained by institutional (threat of lost legitimacy) or competitive (threat of lost competitive advantage) bandwagon pressures (see Abrahamson \& Rosenkopf (I993) for a discussion of these phenomena). Future research could assess the relative magnitude of these various types of external pressure in more detail. In addition, it would be interesting to study whether the outcomes of ERP projects differ between organizations that were pressured to adopt (e.g. because the parent company decides to roll out the same ERP package across different locations) and organizations that 'voluntarily' decided to use ERP software.

A final interesting area of future research would be to study the adoption patterns of organizations in more detail. Although not explicitly a goal of this study, I do observe some 'typical' patterns in the adoption of ERP software. Organizations often start with the accounting modules (often regarded as the backbone of ERP systems) and subsequently add modules in primary business functions. But there are also organizations that employ a 'big bang' implementation approach and implement an entire suite of SAP modules in one implementation project. Future research could try to go further in identifying these implementation patterns and, more importantly, their consequences. 



$$
52
$$




\section{THE FINANCIAL IMPACT OF ERP SYSTEMS}




\subsection{Introduction}

This chapter empirically examines the financial performance impact of Enterprise Resource Planning (ERP) systems. Although consultancy reports often claim that ERP adoption is motivated by expectations regarding cost reduction, improved customer satisfaction/service, efficiency improvements through the use of best business practices and reductions in product cycle times, we actually know relatively little about the success of these systems.

This study aims to provide empirical evidence on the actual success of ERP systems. There are several reasons why studying the financial impact of ERP systems is an appropriate research question. First, ERP systems require large investments in software, possibly hardware and especially additional organizational change efforts. Given the often intangible nature of the benefits from IT investments, it's difficult for individual organizations to pinpoint the performance impact of ERP technology in advance. In addition, it's also difficult to determine the exact implementation cost of ERP systems, although there are some consultancy-based publications that give a reasonable assessment. O'Leary (2000) cites a study of the META group, that mentions an average cost of ownership of \$I5 million, and a cost of \$53,320 per user. Cooke \& Peterson (I998) mention an average implementation cost of \$20 million. There are several reasons why cost estimates vary so widely. First of all, there are differences in the cost items that are included (e.g. software, hardware, consultancy services, internal staff cost). More importantly, ERP implementations vary widely in scope. The cost associated with a full implementation (all modules) is obviously quite different from an implementation in one isolated area of the organization (e.g. an implementation of the human resource management module). Thus, the implementation costs are dependent upon the chosen adoption level (e.g. the proportionate share of the relevant modules being used). Despite the variance in ERP implementation cost estimates, it's safe to say that ERP investments are substantial. Given the speed with which the ERP phenomenon has spread across the marketplace, it's likely that ERP implementations have supplanted other capital investments over the last decade.

A second justification for the research question is that the benefits of ERP implementation do not seem to be self-evident; the value of an ERP system is not derived from the system itself but merely from the way the system is used (Kremers \& Van Dissel, 2000). Some companies have been able to generate large gains from their ERP systems 
(Bingi et al., I999; Palaniswamy \& Frank, 2000; Ragowsky \& Somers, 2002), whereas others were forced to scale back their projects and/or even abandon their E R P implementation (Davenport, I998, Olson, 2004, Ragowsky \& Somers, 2002). These mixed results suggest the need for additional research to tease out factors that contribute to improved financial performance from ER P systems.

This chapter addresses the benefits of E R P systems by assessing the effect of E R P investment on firm profitability. In addition, I consider the role of the adoption level and over- and underinvestment in E RP as potential determinants of the performance impact of ERP. In summary, this study addresses the following questions:

What is the effect of ERP investment on firm performance?

What factors are associated with stronger positive relationships between ERP adoption and firm performance?

By studying the performance effects of ERP systems, this chapter intends to contribute to our understanding of the impact of ERP implementations. In addition, this study identifies several factors that may influence the relationship between ERP adoption and firm performance. Specifically, this study is the first to use a detailed adoption level metric in analyzing the adoption level effects of ERP systems. In addition, this study is the first to consider the potential role of over- or underinvestment in E RP systems.

The next section provides a literature review and the hypotheses. This section discusses empirical studies that have investigated the performance effects of using ER P systems. Section 3.3 gives details on the research methodology that was used in this study. In section 3.4, the results of the study are given. In this section, I will first replicate several analyses performed in prior studies in this area. Subsequently, I add several new analyses to this literature. Section 3.5 provides the conclusion, limitations of the study and suggestions for future research.

\subsection{Literature review and hypothesis development}

In this section I review prior literature on the performance effects of ERP systems. After some introductory remarks about the information systems success literature in general (section 3.2.I), I discuss the literature that has investigated ERP performance effects in more detail (section 3.2.2). Finally, I discuss the role of the E R P adoption level and over- and 
underinvestment in ERP as factors that may influence the relation between ERP and firm performance. (section 3.2.3).

3.2.1 Pitfalls in information systems success studies Many studies in the information systems' (Is) area have tried to study the impact of Iт investments on corporate performance (see Dedrick et al. (2003) for a recent overview of this literature). Since firms started to invest heavily in IT, there has been considerable debate in the is literature on the performance effects of IT investments. For many years, researchers have been trying to solve the 'productivity paradox'; the phenomenon that IT spending and productivity/profitability measures do not show a positive association. By now, many plausible explanations for the productivity paradox have surfaced in the literature (Brynjolfsson, I993; Brynjolfsson \& Hitt, I996, I998; Hitt \& Brynjolfsson, I996), but the question about measuring IT returns is still one of the most prevailing questions in the IT research literature.

Researchers in this area face the problem of identifying the unique effect of IT on organizational performance, knowing that a large variety of other factors impact organizational performance. Academic scholars have not been able to find a conclusive, positive relationship between IT investment and performance. This might however be due to the following reasons:

(a) Many researchers have ignored the fact that there is a time lag between Iт investment and performance (Weill \& Olson, I989; Mukhopadhyay et al., I995). As a result, some studies have failed to show IT performance impacts simply because they ignored this time lag between the iт implementation and the time at which the benefits start to accumulate.

(b) No distinction is made between different types of IT investments. One of the few studies that does distinguish between different types of IT investments is the study by Weill (I992). Weill shows that the use of transactional information systems (of which ERP systems would be a good example) is significantly and consistently associated with strong firm performance over multiple years. Dos Santos et al. (I99I) illustrate that financial markets do reward the announcement of investments in innovative IT-applications, but that the announcement of investments in non-innovative IT-applications does not affect the market value of the firm.

(c) Many studies have focused on firm-or industry-specific Iт investments and suffer as a result from low external validity. 
(d) IT is often treated as a single factor; when aggregating over all systems, the effects of successful and unsuccessful technologies may cancel each other out (Mukhopadhyay et al., I995).

(e) IT success has been assessed in many different ways. The subtitle of the literature review by Delone \& McLean (I992), 'the quest for the dependent variable', says a lot in that respect.

(f) Although firms may on average be in equilibrium, there will be organizations that have not reached their optimal IT (ERP) investment level yet, which creates the possibility that over-or underinvestment in IT (ERP) confounds the analysis of IT performance effects.

This study will try to overcome these problems by focusing on the financial performance effects of a single technology, ERP systems, across several industries and incorporating a potential time lag by analyzing the impact of E RP systems in the first three years after implementation. In addition, I will consider the possibility of over-or underinvestment in Iт. The next section will review studies that have empirically assessed the success of ER P systems using financial performance data.

3.2.2 ERP Success Although there is a massive number of research studies on the success of information systems, empirical research into the success of E R P systems is relatively scarce. In this section I summarize and comment upon the findings of the research studies that have been undertaken so far. This discussion will be structured by means of a framework taken from Dehning \& Richardson's (2002) literature review of returns on investments in IT studies. This framework is presented in figure 3.I. I will use this framework to structure the discussion of empirical studies that have assessed E R P systems success. Results of process measure studies are discussed in 3.2.2.I, event/market studies in 3.2.2.2 and finally results of financial statement studies in 3.2.2.3.

Figure 3.1 FRAMEWORK FOR EVALUATING RESEARCH ON THE BENEFITS OF IT INVESTMENTS (Dehning \& Richardson, 2002 [adapted])

2

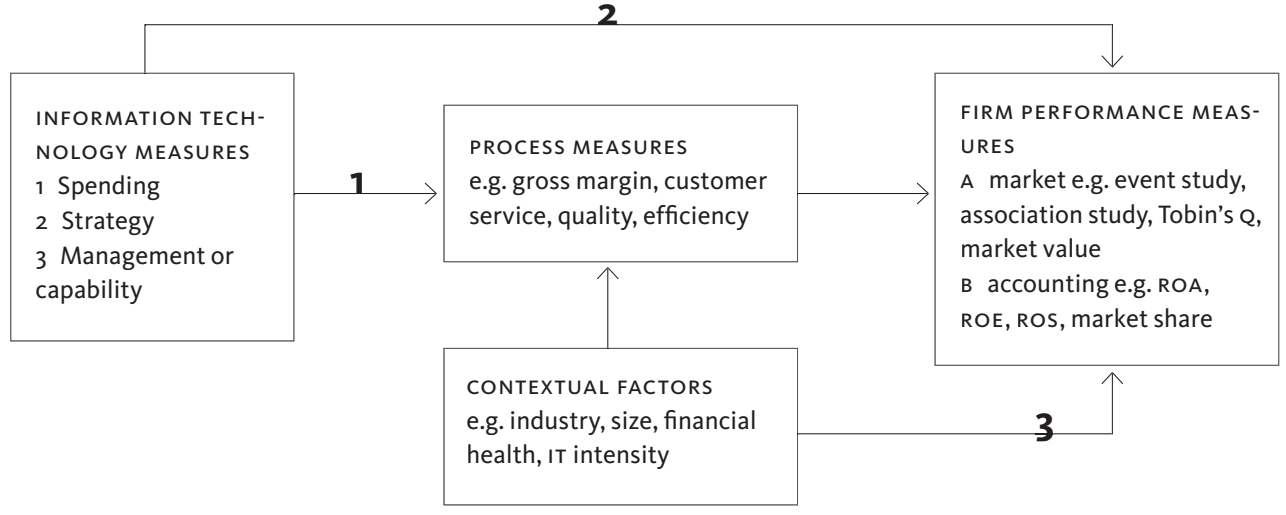


3.2.2.1 Process measures Studies (arrow 1) Process measures studies investigate the impact of IT investments on process measures of performance (e.g. lead times, quality improvements in products, reductions in inventory levels, delivery times). These are metrics that would typically be affected by operational information systems such as ERP systems. McAfee (2002) conducted a natural experiment at a U.s. manufacturer of high-end computer equipment. The study compares the performance of corporate groups that were charged with customer order fulfilment. McAfee isolates the impact of ERP adoption on operational performance metrics such as the proportion of orders that were shipped late and production lead time. The results show that operational performance decreases immediately after the implementation of the ERP system. Subsequently, both lead times and on-time delivery percentages start to improve along a learning curve. After several months, the operational performance exceeds the pre-ER P performance.

Palaniswamy \& Frank (2000) provide five case studies in manufacturing organizations. They document among others the following advantages of ERP systems: reduced inventory levels, increased efficiency in lot sizes, better coordination among facilities and less paperwork.

Given the small number of process measure studies that have been performed so far, it's hard to arrive at general conclusions. For researchers it's difficult to get access to the sort of data that are necessary to perform this type of study. In addition, these studies typically employ case study methodology and hence suffer from external validity concerns.

3.2.2.2 MARKET AND EVENT StUdies (ARrow 2A) Several studies have used event study methodology to study the effect of ERP investments. Event studies focus on the reaction of investors to public announcements by organizations. The rationale behind this type of analysis is that a firm's market value reflects the present value of expected future cash flows, as they are perceived by investors. By disclosing its decision to implement an ERP system, a firm provides the financial market with information. Event studies track how financial markets respond to such information.

The study by Ranganathan \& Samarah (200I) shows positive and significant excess returns pertaining to ERP related announcements (both adoption and completion). The study also documents an industry effect; manufacturing firms accrue more positive excess returns than service firms. Hayes et al. (200I) also show positive market reactions to initial ERP announcements, with the most positive reactions for small and healthy firms. The study also documents that there is a difference 
16 Strictly speaking, the Hunton et al. (2002) study is not an event study because it does not capture the actual reaction of the financial markets to ERP implementation announcements. The study does however capture the reaction of financial analysts to ERP implementation plans, but on basis of an experimental study. Given that the conceptual idea behind this is the same as for event studies, the study has been included in this part of the literature review. in market reaction with respect to the ERP vendor chosen; the market responds better to the adoption of large packages from sAP and Peoplesoft.

Two studies have used alternative methods to assess the impact of ERP implementations on the market value of organizations. Hunton et al. (2002) investigate the reactions of financial analysts to ER P implementation plans in an experimental setting ${ }^{16}$. The study documents significantly larger post-announcement earnings forecasts than preannouncement forecasts. This demonstrates that financial analysts respond favourably to the announcement of E RP implementation plans. Similar to the Hayes et al. (200I) study, this study also documents interaction effects with firm size and health.

Hitt et al. (2002) assess the impact of E RP on the market valuation of organization by using the Tobin's Q measure. They document a change in Tobin's Q from pre- to post-implementation. Although the effect is quite weak, this does suggest that financial markets recognize the value of ERP adoption and completion.

Overall, the results in this domain have been remarkably congruent and point in the direction of positive effects of ERP on market valuation.

3.2.2.3 FinAnCial Statement studies (ARrow 2B) Several studies have used financial statement data to assess the success of ERP systems. A distinction can be made between studies that have investigated absolute performance improvements, and studies that have employed matched pair designs to assess the relative performance improvements induced by E R P implementations. In this section, the studies by Poston \& Grabski (200I), Hitt et al. (2002), Hunton et al. (2003) and Nicolaou (2004) are reviewed.

Absolute performance improvements Poston \& Grabski (200I) is the first study to employ financial statement data in studying the performance effects of ERP systems. Given that this particular study has motivated several other studies in this area, I will discuss it in more detail than the other studies.

Poston \& Grabski (200I) start from a distinction between internal coordination and external (or market) transaction costs (Gurbaxani \& Whang, I99I). These are the cost categories that can theoretically be affected by the implementation of information systems. Unfortunately, these cost categories can not be readily found in the financial statements 
of an organization. Therefore, Poston \& Grabski (200I) match these cost categories to the appropriate financial statement categories. This matching procedure is depicted in Appendix c. For this study, the impact of ERP adoption on decision information costs is particularly important. Decision information costs arise because information is communicated between organizational levels. These costs consist of information-processing costs, communication costs, documentation costs and opportunity costs due to poor information. ER P systems provide firms with a means to decrease these decision information costs. Information processing costs are reduced through the use of a single, integrated database. In a situation with legacy systems, information first needs to be aggregated across applications. In an E R P environment this is no longer necessary. The use of a single, integrated database also lowers communication and documentation costs. The increased accuracy and timeliness of the information will translate into lower opportunity costs due to poor information.

Poston \& Grabski (200I) use a set of ERP adopters and compare their performance prior to the ERP implementation with their performance in the first, second and third year after the implementation. The implementation of ERP systems is not associated with improvements in the ratio of sales, general and administrative expenses divided by revenues. Similarly, no impact on residual income is found. The study does find evidence of a decrease in the ratio of cost of goods sold divided by revenues in the third year after the implementation. Finally, the study does show that ERP implementations are associated with more efficient use of the labour force; the number of employees needed to support a given level of revenue is significantly lower throughout the entire three year period after implementation. Overall, the results show very little impact of ERP implementations.

Hitt et al. (2002) improve upon the design of the Poston \& Grabski (200I) study by using a matched-pair design. However, they also perform part of their analyses for adopters only. The results indicate that SAP adopters improve their financial performance metrics during the implementation period. Hitt et al. explain this rather counterintuitive result by arguing that many ERP components are already completed and operational by the time that the firm publicly declares the project to be complete. Given the fact that many firms implement ERP on a module-by-module basis (most often resulting in an implementation time span of multiple years), this seems to be a plausible explanation. An alternative explanation provided by Hitt et al. is that many organizational 
changes that are brought along by the ERP system begin to generate gains very quickly. This may be a questionable assertion, given that the evidence in process measure studies points in the direction of initial performance drops, followed by gradual performance improvements. In a different area, Granlund \& Malmi (2002) and Scapens \& Jazayeri (2003) study the impact of ERP systems on management accounting and control systems. The studies indicate that after ERP implementation, ERP-facilitated changes in reporting practices are postponed to a later stage because organizations first struggle with operational ERP problems. Only after these problems have been resolved, organizations can start to think about real performance improvements in the area of reporting. Therefore, the more plausible reason for the findings in Hitt et al. is that firms postpone announcements about ERP completion until a suite of ERP modules has been implemented.

Hunton et al. (2003) show a similar analysis as Poston \& Grabski, but with other performance metrics. Results indicate no improvements in return on assets (ROA), return on sales (ROS), assets turnover (ATO) and return on investment (ROI) for ERP-adopters. Overall, there seems to be a decreasing trend in these performance indicators in the first two years after implementation, but these decreases are not significant.

Overall, there is little evidence to suggest absolute performance improvements after ERP adoption. This may be interpreted as a signal that E RP investments are not paying off, but there is also an alternative explanation. Hitt \& Brynjolfsson (I996) suggest that firms do translate IT investments into productivity improvements, but that these productivity gains are transferred to consumers through price decreases. Therefore, these productivity gains are not translated into absolute performance improvements in terms of typical financial accounting measures of performance. If this explanation holds, firms that underinvest in information technology are expected to show a declining performance. To assess the validity of this argument in an ERP context, several scholars have started to assess the relative performance effects of E RP systems. These studies are discussed in the next section.

Relative performance improvements Studies that have followed upon the Poston \& Grabski (200I) study have all employed matched pair design in analyzing the performance impact of E RP systems. In a matched pair study, each ERP adopter is matched with another organization, comparable in terms of firm size and industry. This matched firm should be a nonadopter. Instead of testing absolute performance improvements, 
matched pair studies focus on the relative performance impact of ERP.

Hitt et al. (2002) compare the performance of SAP adopters with nonadopters ${ }^{17}$ on three sets of performance metrics (productivity, financial performance and stock market valuation). The results of the study indicate that SAP adopters outperform nonadopters on productivity and financial performance metrics.

The study by Hunton et al. (2003) builds on the Poston \& Grabski (200I) study and tries to explain why this study found relatively little effects of ERP adoption within a group of ERP-adopters only. Using a matched pair design, Hunton et al. compare the financial performance of a set of ERP adopters with a set of similar firms that have not adopted an ERP system. The study improves upon the design of the Hitt et al. (2002) study by verifying that the nonadopters are actually nonadopters. Hunton et al. (2003) document how the performance of E R P adopters remains more or less constant, whereas the performance of matched nonadopters starts to decline. It takes time before these differences between adopters and nonadopters start to emerge. This neatly fits with the notion of ERP systems as a competitive necessity; firms face a competitive disadvantage when they do not adopt these systems. Abrahamson \& Rosenkopf (I993) discuss the notion of competitive bandwagon pressures. If an innovation is rapidly diffused across an industry (as is the case with ERP systems), and the innovation becomes a success, nonadopters will not be able to reap the success from the technology, and their performance will fall below the industry average.

A final contribution to this stream of literature is the study by Nicolaou (2004). He examines the longitudinal impact of ERP systems implementation. Like Hunton et al. (2003), this study employs a matched pair design and compares the performance of ERP adopters with a matched set of nonadopters. The results regarding the performance benefits of E R P are mixed. Overall, the results indicate that the differential performance of ERP-adopters first starts to decline (in the year of completion and the first year after completion). Because of the disruptive nature of ERP implementations, adopters are first faced with a deterioration of their performance versus nonadopters. But this trend reverses and towards the end of the time window (three and four years after the ERP implementation), the ERP adopters actually outperform the nonadopters.

Overall, the results from relative performance measure studies are somewhat mixed. Although there seems to be general consensus that in the long run E R P adopters will outperform the nonadopters, differences
17 Curiously, Hitt et al. (2002) classify all non SAPusers as non ERP adopters. 
have been observed in the timing of this effect. Nicolaou (2004) documents an initial drop in the differential performance of the ERP adopters, but this trend is reversed later. This same pattern is not observed in other studies in this area, although it is consistent with results from process measure studies (section 3.2.2.I) that indicate that the performance of ERP adopters initially drops, but starts to improve along a learning curve later on.

Contextual factors (arrow 3) Hunton et al. (2002) also incorporate an interaction effect of firm size and firm health. Results indicate that large/unhealthy adopters have more to gain from an E RP implementation than large/healthy adopters. The underlying idea is that large/unhealthy adopters can employ the E R P implementation as a means to 'level the playing field'. The interaction effect works in the opposite direction for small/unhealthy organizations. They will not be able to bear a disruptive and risky E RP implementation, whereas small/healthy adopters can use the ER P system to even improve their financial health further. A similar size/health interaction was also observed in Hayes et al. (200I) and Hunton et al. (2002).

Nicolaou (2004) further contributes to the literature by incorporating various implementation characteristics (vendor choice, implementation goal, modules implemented and implementation time period). Regarding vendor choice, the results indicate that the differential performance effect of ERP adoption is highest for those that adopt SAP or Oracle. This result is consistent with the findings of the Hayes et al. (200I) event study, which shows that financial markets react more strongly to implementations of ER P packages from the largest vendors.

Limitations of prior research Prior research in this domain suffers from several limitations. I will discuss three limitations: (a) the timing of the ERP investment event, (b) the measurement of the ERP adoption level and (c) the ignored potential for over-or underinvestment in ERP. The first two limitations are concerned with measurement issues. This study offers empirical refinements in these areas. The third limitations concerns a theoretical issue that has been ignored in prior studies.

First of all, prior studies have relied on publicly announced implementation/completion dates as the basis for assessing the year of ERP implementation (Poston \& Grabski, 200I, Hunton et al., 2003 and Nicolaou, 2004). This potentially influences the analysis because E RP implementations often span multiple years. If firms wait with announcing 
the ERP implementation until completion, there is the problem that prior performance in earlier studies measures the financial performance during the implementation period, or already includes the financial performance effects of the first modules that were implemented. In this study I rely on information from the ERP project managers for assessing the year of implementation. Consistent with the definition of this variable in chapter 2 , this study defines the year of adoption $(t=0)$ as the first year in which two or more interfaced sAP modules were being employed. The advantage of this approach is that the measurement of prior performance in this study does not pick up early ERP performance effects or implementation effects ${ }^{\mathrm{I} 8}$. This is an important empirical refinement of the timing of the ERP event.

A second important limitation of prior research concerns the adoption level of ERP. This potentially important variable is ignored in the Poston \& Grabski (200I) and Hunton et al. (2003) studies. If an organization only uses a limited part of the functionality of the package (e.g. only back-office functions like accounting and payroll) the integration benefits are bound to be limited as well. It's only if an organization employs a significant part of the E RP-functionality that true integration benefits can start to be realized.

Hitt et al. (2002) is the first study that tries to capture economies of scope and scale in ERP adoption. SAP users are labelled as level o, I, 2a, $2 \mathrm{~b}$ and 3 users on the basis of the modules they employ. A firm that has implemented a single module or an unusual combination of two modules is classified as a level o user. Level I users have implemented the core manufacturing, finance and is modules. Firms that also employ the project management module are classified as level za users, if the human resource management module is used, firms are classified under level $2 \mathrm{~b}$. Firms that employ modules in all areas are described as level 3 users. Although this is clearly an improvement on earlier studies, the theoretical notion behind the identified adoption levels is unclear and seems to be driven by particularities observed in the combinations of modules in the Hitt et al. dataset.

Their results indicate that greater use of ERP (a higher adoption level in their taxonomy) is associated with higher performance. Remarkable is the finding that especially the use of the human resource management module is accompanied by a boost in performance. Hitt et al. attribute this to increased investments in modern human resource practices. Full implementation (level 3) shows a slight performance decrease as compared to adoption level $2 \mathrm{~b}$. This would suggest diseconomies of
18 Although this definition of the year of implementation is arguably better that the measure employed in earlier studies, it does introduce some problems of its own. The postimplementation effects do not immediately capture the effect of the entire ERP project, because the implementation of some modules will occur in $t+1$ or even further down the time window. 
scale in ERP implementation. Hitt et al. refer to the risks of minor user errors that have profound enterprise-wide effects in a full-fledged system. In a legacy systems environment, errors have a much more isolated effect.

Nicolaou (2004) uses a taxonomy in which organizations are classified in three categories: (I) use of primary modules only (modules that support supply chain activities), (2) use of secondary modules only (support modules, e.g. financials and human resources) and (3) use of both primary and secondary modules. The underlying notion behind this taxonomy is clearer than the Hitt et al. (2002) metric, but this taxonomy suffers from two limitations. First, the use of primary modules only is quite uncommon. Most manufacturing organizations adopt the financial modules (the 'backbone' of the ERP system) first and add primary modules later, as was discussed in chapter 2 . The relatively low number of observations (I4 out of $\mathrm{I}_{3} 8$ ) in this category also suggests that this category is quite uncommon. Secondly, this taxonomy does not capture any variance within each of the categories. As a result, an organization that solely employs the production planning (Р P) module would be put in the same category as an organization that has interfaced this module with the quality management $(\mathrm{QM})$ and materials management (м м) module.

Nicolaou's (2004) results regarding the impact of the modules implemented are mixed. For some performance metrics, firms that only implement support modules (back-office functionality) actually perform better than firms that adopt primary modules as well. However, the opposite is true for other performance metrics. The results regarding the impact of implementation scope are therefore inconclusive.

To overcome the deficiencies associated with the adoption level metrics employed in earlier studies, I propose the use of the adoption level metric that was used in chapter 2 of this dissertation. This measure can be seen as an empirical refinement of adoption level metrics that were used in the studies discussed before. The theoretical expectation with regard to the performance impact of the adoption level is developed in the next section.

A final limitation of prior research in this literature concerns the potential for over-or underinvestment in ERP. Prior research does not recognize this possibility. Chapter 2 of this dissertation provides a benchmark model of E R P investment that can be used to identify firms that have over- or underinvested in ERP. This argument will be further elaborated upon in the next section. 
3.2.3 Hypotheses development To overcome the problems associated with the adoption level metrics used earlier, the adoption level metric that was developed in chapter 2 of this dissertation can be used. All of the ERP benefits that were discussed in chapter I (integration of business processes, more comprehensive information processing and reporting capabilities, adoption of 'best business practices') increase with the adoption level. This effect is most pronounced for the benefits that stem from the integration of business processes. With two interfaced modules, one 'line of communication' can be facilitated (between module A and в). With three interfaced modules, three 'lines of communication' can be facilitated (A-B, A-C and B-C). In other words, the benefits that stem from ERP are network benefits. These network benefits increase with every node (module) that is added to the network. In addition, with each additional module a costly stand-alone system is replaced.

Although the effect may be less pronounced, other types of ERP benefits also increase with the adoption level. With each module added, the organization invests in its information processing and reporting capabilities. Especially the consolidation of business information from multiple sources becomes much easier when the ERP adoption level increases. Finally, with each module added, the organization creates new opportunities for business process re-engineering. By adopting the reference models that are embedded in E R P systems, organizations can learn from the best practices of other organizations in their field. Although in the short run, the cost level associated with a higher adoption level is also higher, this effect will be offset by larger network benefits in the long run. Therefore, I hypothesize:

HYPOTHESIS 1 The greater the ERP adoption level, the greater the longitudinal impact on a firm's financial performance.

Previous studies have been inconclusive with regard to the impact of the E R P adoption level on firm performance. An alternative explanation for differences in ERP performance impact across organizations is the potential for a mismatch between the ERP adoption level and several contingent variables (the firm's organizational environment). Preceding studies have assumed that ERP is equally applicable in all firms, hence there would be similar performance effects across organizations. Yet, there are studies that suggest that there may be 'misfits' between industry- and company-specific business practices and the reference models that are incorporated in E RP systems (Soh et al., 2002). In chapter 2 of 
this dissertation, a model was developed that explains the ERP adoption level as a function of environmental (internal and external) and technological contingencies. The underlying notion of this chapter was that these contingent factors may impact the net benefits from ERP. The overall evidence in this chapter pointed in the direction that the ERP adoption level is influenced by contingencies such as environmental uncertainty (to be more specific, environmental dynamism), external pressure, centralization, information intensity and the perceived relative advantage of ERP technology. Although ultimately all firms are expected to move to their optimal ERP adoption level, at any point in time some firms will be off equilibrium (see Ittner et al. (2002) for a discussion of this phenomenon in the context of activity-based costing adoption by manufacturing plants). In the context of ERP, there are several reasons why firms may be temporarily off equilibrium. First, some heavily publicized failures of ERP technology (e.g. Davenport, I998; Olson, 2004; Ragowsky \& Somers, 2002) may have created uncertainties about the value of ERP technology. These uncertainties may prevent the timely adoption of ERP technology. Second, it is possible that firms may first experiment with ERP in isolated areas before moving to a higher adoption level or deciding to abandon the technology altogether. Davenport (1998) gives several examples of firms that did start with an ERP implementation, but that eventually abandoned it. Third, towards the end of the I990's, many firms decided to replace their legacy systems with E R P technology. These decisions may however have been driven by Y $2 \mathrm{~K}$ concerns and the introduction of the European currency, instead of a systemic evaluation of ERP benefits. As a consequence, firms may have chosen an inappropriate E RP adoption level. These factors all suggest a high likelihood that at any point in time, some organizations have been off equilibrium.

Taking this argument one step further, I suggest that firms that adopt ERP software and do not realize a positive performance impact may have failed to match their organizational characteristics to the adoption level of the ER P software. In contrast, firms that adopt E RP software and achieve higher performance are believed to have realized the proper fit between the adoption level of ERP and their organizational characteristics.

If the model in chapter 2 captures the appropriate adoption level for firms, then any residual deviation from this model should adversely impact firm performance. This may be a matter of either over- or underinvestment compared to the benchmark model. 
Therefore, I examine the performance differences associated with the degree of mismatch between the ERP adoption levels and the contextual factors that reflect the environmental and technological characteristics (as measured in chapter 2). This leads to hypothesis 2 :

HYPOTHESIS 2 A firm's financial performance is decreasing with the degree of over-and underinvestment in ERP software.

\subsection{Research methodology}

My primary data source stems from the survey that is described in chapter 2 . The study reported in chapter 2 studies the determinants of ERP adoption levels among Dutch users of the software package SAP R/3. For this study, I had access to a database with member data of the 'Vereniging van Nederlandse sAP Gebruikers' (vNSG): the Dutch user organization of SAP. The 300 organizations in this database were contacted by e-mail ${ }^{19}$. For the study reported in chapter 2, I08 usable responses were obtained. In this chapter I combine adoption level data from this survey with financial data that were taken from REACH, a database with corporate information and financial data of all Dutch firms. Unfortunately, for a large percentage of the Io8 respondents of the initial survey, no or limited financial data are available. The main reasons why financial information was lacking was that several organizations were not required to publish detailed financial information given their size. In addition, some organizations from the survey are part of a larger group of companies, and financial statements are only available at the consolidated level. The possibility to study the financial impact of ERP implementations on the basis of this dataset was further reduced by the problem that some of the firms in this dataset implemented ERP very recently, and therefore no financial data for the years after implementation were available. Ultimately, for 50 (out of 108 ) firms, financial data were available, although often certain financial performance metrics were missing (e.g. inventory turnover is not relevant in many industries).

Because of the low number of observations, I decided to contact all the firms from the list of SAP users (chapter 2) once more, with the exclusion of firms that had already participated in the earlier survey. These firms were contacted by e-mail with the simple request to indicate in which year the first modules of their E R P system 'went live' (consistent with the timing of the ERP event for the surveyed organizations).

In total this led to the addition of another 42 firms to the dataset for
19 This list was complemented with additional user data from (a) announcements of SAP implementations in a Dutch professional magazine in the logistics area: (b) public announcement of customer data by SAP Netherlands itself and (c) public announcement of customer data by SAPconsultants in the Netherlands.

20 The number of respondents to this question about the implementation date of the SAP package was significantly higher, but again for several firms no (or very limited) financial data were available. 21 ROA = Income before extraordinary items / average assets in Hunton et al. (2003) 
this study, leading to a total of 92 (sometimes incomplete) firm observations ${ }^{2 \circ}$. Ultimately, four observations were removed because of events (e.g. mergers, acquisitions) within the time window that might confound the results, leading to a total of 88 ERP adopters for which the performance effects could be analyzed.

Due to limited data availability, several performance metrics from prior studies could not be employed (e.g. analyses on basis of sales, general and administrative expenses). The financial performance metrics used in this study were chosen on basis of data availability and a fair representation of both profitability and activity measures of performance in the analysis. Given that there may be different payoffs from IT investments, it is important to use a range of performance metrics. First, E R P may result in lower cost to produce goods or deliver services. This would be reflected in a profitability measure such as the profit margin. Increased efficiency in business operations is supposedly reflected in activity measures of performance, such as inventory turnover or accounts receivable turnover. Finally, I employ several metrics that capture overall financial performance (ROA, ROE). An overview of the performance metrics employed in this study is given in table 3.I.

Table 3.1 FINANCIAL PERFORMANCE MEASURES

\begin{tabular}{|c|c|c|}
\hline Ratio & Measurement & also used in: \\
\hline \multicolumn{3}{|l|}{ Profitability Measures } \\
\hline \multirow[t]{3}{*}{ Labour productivity } & Sales / No. of Employees & Hitt et al. (2002); \\
\hline & & Nicolaou (2004); \\
\hline & & Poston \& Grabski (2001 \\
\hline \multirow[t]{3}{*}{ Return on assets (ROA) ${ }^{21}$} & Pretax income / Assets & Hitt et al. (2002); \\
\hline & & Hunton et al. (2003); \\
\hline & & Nicolaou (2004) \\
\hline Return on equity (ROE) & Pretax income / Equity & Hitt et al. (2002) \\
\hline Profit margin & Pretax income / Sales & Hitt et al. (2002) \\
\hline \multicolumn{3}{|l|}{ Activity Measures } \\
\hline \multirow[t]{2}{*}{ Inventory turnover } & cogs / Inventory & Hitt et al. (2002) \\
\hline & (taken from REACH database) & \\
\hline \multirow[t]{2}{*}{ Asset turnover (ATO) } & Sales / Assets & Hitt et al. (2002); \\
\hline & & Hunton et al. (2003) \\
\hline Accounts receivable turnover & Sales / Accounts receivable & Hitt et al. (2002) \\
\hline
\end{tabular}


3.3.1 Matching Procedure Each ER P-adopting company was matched with a control group company on both industry and size at the year preceding the ERP adoption year (time $t$-I). The purpose of a matched pair design is to remove the confounding effects of extraneous variables and market forces that could influence firm performance (Bharadwaj, 2000). The underlying assumption is that financial and operating performance vary by industry and firm size. By choosing a suitable industry benchmark, some of the variation in performance can be controlled for. Bharadwaj (2000) also points at accounting literature that has acknowledged that firm size and industry type are strong predictors of the chosen accounting methods.

Matching was done using the four digits в I $^{22}$ code. Companies were also matched on size, using a $20 \%$ range on total assets. Matches were selected by choosing a firm with the closest size match. If a match could not be found on the four-digit level, a three-digit or ultimately two-digit match was used. If a match could not be obtained on the basis of this procedure, the sales revenue was used as an alternative firm size measure and the above procedure was repeated. To validate the matching procedure, two activities were performed. First, firms that were listed as SAP users by either SAP or the Dutch user organization of SAP were removed from the list with potential matches. A second activity was to e-mail or phone the selected matched firms to confirm that they did not adopt an ERP system during the sample period. The following questions were asked: 'Has your organization implemented an E R P system? If so, which one, and in which year was the system implemented?' Matched firms that indicated that they were using an ERP package were removed and a new match was searched for.

I was unable to find matches for ig firms. Thus, for $69^{23}$ out of 88 SAP-adopters, a match was obtained. For some of the large Dutch organizations that employ SAP, there is simply no other firm of comparable size in the same industry. In addition, in some industries (e.g. chemicals, oil and gas exploration, utilities) ER P was immediately embraced by all large organizations in this industry. As a result, it is impossible to find a large nonadopter in these industries.

Table 3.2 presents tests on mean differences in terms of size (total assets) and return on assets (ROA) for the sample and matched firms in time period $t$-I and also for the average over the three years preceding ER P system adoption. As shown in the table, the mean differences are not significant, lending further support to the validity of the employed matching procedure.
22 BIK is a Dutch industrial classification code, comparable to the U.s. SIC code.

23 The 69 SAP-adopters for which a match was found, consist of 39 firms from the survey and 30 additional firms. 
Table 3.2 MATCHING COMPARISON BETWEEN ADOPTING AND CONTROL GROUP OF FIRMS

\begin{tabular}{|c|c|c|c|c|c|c|}
\hline \multirow[b]{2}{*}{ Matched Variable } & \multicolumn{2}{|c|}{ ADOPTERS } & \multicolumn{2}{|c|}{ MATCHED NONADOPTERS } & \multirow[b]{2}{*}{ Mean difference } & \multirow[b]{2}{*}{$\begin{array}{l}t \text {-value for mean } \\
\text { difference ( } p \text {-value) }\end{array}$} \\
\hline & Mean & St.dev. & Mean & St.dev. & & \\
\hline Total assets & & & & & & \\
\hline$(t-1$, in euro's) & $393,287.40$ & $967,413.05$ & $376,197.60$ & $1,069,467.84$ & $12,710.14$ & $-0.285(0.776)$ \\
\hline \multicolumn{7}{|l|}{ ROA } \\
\hline$(t-1)$ & 0.0966 & 0.11794 & 0.0790 & 0.11982 & 0.0150 & $0.729(0.469)$ \\
\hline Total assets & & & & & & \\
\hline $\begin{array}{l}\text { (3-year average, } \\
\text { in euro's) }\end{array}$ & $322,485.40$ & $735,741.95$ & $320,595.90$ & $816,937 \cdot 35$ & $-2,234.90$ & $-0.285(0.776)$ \\
\hline ROA & & & & & & \\
\hline (3-year average) & 0.0964 & 0.08304 & 0.0978 & 0.13062 & -0.0021 & $-0.112(0.911)$ \\
\hline
\end{tabular}

3.3.2 Analyses At first, this study will replicate the analyses of the financial performance studies that were discussed in section 3.2.2. To do so, this chapter analyzes the impact of ERP systems implementation on a set of profitability and activity (process) measures. This question will be addressed from multiple angles. Given the inconsistencies in the results from prior studies in this field, I will start my analysis with a replication of the analyses performed in the Poston \& Grabski (200I), Hunton et al. (2003) and Nicolaou (2004) studies.

Four types of analysis are performed. The first two analyses are replications of analyses from prior work in this area.

I Performance effects of ERP adoption for the ERP adopters only (section 3.4.I). In this part of the chapter I study the performance impact of ERP for a group of SAP-adopters. This test allows me to assess whether there are absolute performance improvements as a result of ERP adoption.

I I Matched-pair analysis (section 3.4.2). In this part of the study, the performance of sAP-adopters is compared with a matched firm in the same industry and of the same firm size. This analysis is aimed at identifying relative performance improvements. It is possible that ERP adopters realize a stable performance, whereas nonadopters are faced with a declining performance. This would not be picked up in analysis I. Therefore I add this second analysis which compares the performance of a group of ERP adopters with a group of matched nonadopters. At 
first, I employ the analysis that is also employed in Hunton et al. (2003). This analysis regresses post adoption performance on E RP adopters versus nonadopters, controlling for prior performance. I complement this analysis with a more refined analysis that is also employed in Nicolaou (2004). On basis of an interrupted time series model, I assess the impact of ERP in the three post-adoption years separately.

Subsequently, I add two analyses as contributions to this literature (section 3.4.3):

I I I Impact of adoption level. In section 3.2.2.3 I have argued for a more refined measure to capture the E RP adoption level. I will replicate the matched pair analysis approach as used in Hunton et al. (2003) and test whether inclusion of the ERP adoption level (measured for each year separately) increases the explanatory model of the model.

IV Impact of over- and underspending. Using the residuals from the regression analysis in chapter 2 , I can identify firms that have overspent and underspent on ERP technology. This analysis allows me to test hypothesis 2 . This analysis is necessarily restricted to the surveyed organizations for which financial performance data is available. Again, I employ the approach used in Hunton et al. (2003) as the basis for this analysis, and extend this analysis by including the potential over- or underinvestment in ER P.

For all the analyses that follow, I reduce the influence of extreme performance measure observations by winsorizing the data at the 5 th and $95^{\text {th }}$ percentiles.

\subsection{Results}

In this section, I give an overview of the results from the analyses mentioned before. I start with the replication of results from prior studies (section 3.4.I and 3.4.2) and subsequently add two new analyses (section $3 \cdot 4 \cdot 3)$.

3.4.1 Analysis I: performance effects of ERP adoption (adopters only) The industry profile of the responding firms in table 3.3 shows that they span a wide range of industries, although the majority of firms is active in manufacturing or wholesale and retail. Roughly $50 \%$ of the E RP implementations were undertaken in I998 and I999, when many firms were tackling $\mathrm{Y} 2 \mathrm{~K}$ and European currency introduction issues.

Table 3.4 presents descriptive statistics for the performance measures used in this study, for both adopters and the matched nonadopters. 
Table 3.3 NUMBER OF ERP SYSTEMS ADOPTIONS BY YEAR AND INDUSTRY

Panel A: ERP Adoption by calendar year

\begin{tabular}{lccc}
\hline Year & Number of adopters & Percentage of respondents & Cumulative percentage of respondents \\
1994 & 4 & 4.55 & 4.55 \\
1995 & 4 & 4.55 & 9.09 \\
1996 & 8 & 9.09 & 18.18 \\
1997 & 4 & 4.55 & 22.73 \\
1998 & 19 & 21.59 & 44.32 \\
1999 & 24 & 27.27 & 71.59 \\
2000 & 9 & 10.23 & 81.82 \\
2001 & 11 & 12.50 & 94.32 \\
2002 & 5 & 5.68 & 100
\end{tabular}

Panel B: Number of ERP Adopters by Industrial Classification

\section{Industry}

Oil and gas exploration

Food manufacturing

Paper and allied products manufacturing

Chemicals

Basic metals manufacturing

Fabricated metal products

Manufacturing of machines and devices

Medical and optical goods manufacturing

Other manufacturing

Utilities

Construction

Wholesale, retail

Transportation

Banking and insurance

Consultancy

Leisure

Table 3.4 DESCRIPTIVE STATISTICS

\begin{tabular}{|c|c|c|c|c|}
\hline & $\begin{array}{l}\text { ERP Adopters } \\
\text { Mean [median] } \\
\text { 3-year average } \\
\text { before adoption }\end{array}$ & $\begin{array}{l}\text { Matched Nonadopters } \\
\text { Mean [median] } \\
\text { 3-year average } \\
\text { before adoption }\end{array}$ & $\begin{array}{l}\text { ERP Adopters } \\
\text { Mean [median] } \\
\text { 3-year average } \\
\text { after adoption }\end{array}$ & $\begin{array}{l}\text { Matched Nonadopters } \\
\text { Mean [median] } \\
\text { 3-year average } \\
\text { after ERP event }\end{array}$ \\
\hline Labour productivity & $\begin{array}{c}317.30[211.98] \\
\quad(n=69)\end{array}$ & $\begin{array}{c}487.73[292.83] \\
\quad(n=67)\end{array}$ & $\begin{array}{c}437.33[246.81] \\
\quad(n=69)\end{array}$ & $\begin{array}{c}495.45[322.91] \\
(n=67)\end{array}$ \\
\hline ROA & $\begin{array}{c}0.09[0.08] \\
(n=69)\end{array}$ & $\begin{array}{c}0.08[0.06] \\
(n=68)\end{array}$ & $\begin{array}{c}0.06[0.06] \\
(n=69)\end{array}$ & $\begin{array}{c}0.03[0.03] \\
(n=68)\end{array}$ \\
\hline ROE & $\begin{array}{c}0.34[0.23] \\
(n=69)\end{array}$ & $\begin{array}{c}0.38[0.23] \\
(n=68)\end{array}$ & $\begin{array}{c}0.17[0.15] \\
(n=69)\end{array}$ & $\begin{array}{c}0.09[0.09] \\
(n=68)\end{array}$ \\
\hline Margin & $\begin{array}{c}0.06[0.05] \\
(n=66)\end{array}$ & $\begin{array}{c}0.06[0.04] \\
(n=67)\end{array}$ & $\begin{array}{c}0.04[0.03] \\
(n=69)\end{array}$ & $\begin{array}{c}0.03[0.01] \\
(n=67)\end{array}$ \\
\hline Assets turnover & $\begin{array}{c}1.76[1.62] \\
(n=66)\end{array}$ & $\begin{array}{c}1.95[1.82] \\
(n=68)\end{array}$ & $\begin{array}{c}1.88[1.65] \\
(n=69)\end{array}$ & $\begin{array}{c}1.75[1.59] \\
(n=68)\end{array}$ \\
\hline Accounts receivable turnover & $\begin{array}{c}6.78[5.20] \\
\quad(n=64)\end{array}$ & $\begin{array}{c}6.54[5.84] \\
\quad(n=67)\end{array}$ & $\begin{array}{c}6.53[5.38] \\
(n=68)\end{array}$ & $\begin{array}{c}6.69[5.96] \\
\quad(n=67)\end{array}$ \\
\hline Inventory turnover & $\begin{array}{c}9.67[7.35] \\
(n=48)\end{array}$ & $\begin{array}{c}11.19[8.71] \\
(n=57)\end{array}$ & $\begin{array}{c}13.14[8.19] \\
\quad(n=51)\end{array}$ & $\begin{array}{c}11.28[8.51] \\
\quad(n=57)\end{array}$ \\
\hline
\end{tabular}

\section{Number of ERP adopters}

$\begin{array}{rr}11 & 2 \\ 15 & 5 \\ 21 & 2 \\ 24 & 7 \\ 27 & 2 \\ 29 & 2 \\ 33 & 7 \\ 17,22,25,26,30,31,34,36 & 2 \\ 40,41 & 8 \\ 45 & 4 \\ 50,51,52 & 3 \\ 60,63 & 30 \\ 65,66 & 2 \\ 72,74 & 3 \\ 92 & 8\end{array}$


To test for significant changes in the performance ratios, paired sample t-tests ${ }^{24}$ were performed. This test compares the performance ratios after vs. before the ERP implementation. Performance was divided into two periods: pre-adoption and post-adoption. The year of the ER P implementation is year $t=0$. Both the pre-adoption and post-adoption period span three years. Some firms implemented an ERP system in 200I or 2002. For these firms financial performance information for the years $t+2$ and/or $t+3$ was lacking.

Pre-adoption performance was measured using an average of the financial ratios in the periods $t-3$ to $t$-I. If financial information for $t-3$ was lacking, the average of $t-2$ and $t$-I was used. If information for $t-3$ and $t$-2 was lacking, the financial performance of $t$-I was used as the benchmark. The results for the tests are given in table 3.5 .

Table 3.5 PAIRWISE SAMPLE t-TEST RESULTS FOR DIFFERENCES IN RATIO, AFTER VS. 3-YEAR AVERAGE PRIOR TO ADOPTION (T STATISTIC)

COMPARISON OF RATIO AFTER VS. BEFORE (3 YEAR AVERAGE) ERP ADOPTION

\begin{tabular}{|c|c|c|c|c|c|c|c|}
\hline & \multicolumn{4}{|c|}{ Profitability measures } & \multicolumn{3}{|c|}{ Activity measures } \\
\hline & $\begin{array}{l}\text { Revenues/ } \\
\text { Employees }\end{array}$ & $\begin{array}{l}\text { Pretax income/ } \\
\text { Assets }\end{array}$ & $\begin{array}{l}\text { Pretax income/ } \\
\text { Equity }\end{array}$ & $\begin{array}{l}\text { Pretax income/ } \\
\text { Sales }\end{array}$ & Sales/Assets & $\begin{array}{l}\text { Sales/Acc. } \\
\text { Receivable }\end{array}$ & $\begin{array}{l}\text { Inventory } \\
\text { turnover }\end{array}$ \\
\hline year of impl. & 1.617 & $-1.894^{\star}$ & $-3.633^{\star \star \star}$ & -1.129 & 1.573 & $-1.685^{\star}$ & $2.425^{\star \star}$ \\
\hline vs. prior average & $N=82$ & $N=86$ & $N=85$ & $N=82$ & $N=83$ & $N=80$ & $N=56$ \\
\hline 1 year after & $2.510^{\star *}$ & $-2.760 * \star \star$ & $-2.968 * \star \star$ & -1.537 & 0.767 & $-2.001^{\star *}$ & $2.501^{\star \star}$ \\
\hline vs. prior average & $N=82$ & $N=86$ & $N=85$ & $\mathrm{~N}=82$ & $N=83$ & $N=80$ & $N=56$ \\
\hline 2 years after & $2.261^{* *}$ & $-3.167^{\star \star \star}$ & $-3.489^{\star \star \star}$ & 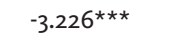 & $2.477^{\star \star}$ & 0.382 & $2.521^{\star *}$ \\
\hline vs. prior average & $N=79$ & $N=83$ & $N=83$ & $N=79$ & $N=80$ & $N=77$ & $N=54$ \\
\hline 3 years after & $2.281^{\star \star}$ & $-3.931^{\star \star \star}$ & $-4.806^{\star * \star}$ & $-4.007^{\star \star *}$ & 1.100 & $2.210^{\star \star}$ & $2.286^{\star \star}$ \\
\hline vs. prior average & $N=71$ & $N=77$ & $N=77$ & $N=73$ & $N=73$ & $N=71$ & $N=51$ \\
\hline
\end{tabular}

* = significant at 0.10 level, two-tailed; ${ }^{* *}=$ significant at 0.05 level, two-tailed; ${ }^{* \star}=$ significant at 0.01 level, two-tailed.

The results indicate negative performance effects of ERP systems on profitability measures. This is shown by negative impacts on return on assets and return on equity in all the years after the implementation. The profit margin decreases in the second and third year after implementation. These negative performance effects can probably be attributed to the disruptiveness of the ERP implementation. These implementations are notoriously difficult and are more often than not accompanied by large budget and time overruns. The continuance of this effect through- 
24 Kolmogorov-Smirnov tests indicate violations from the normality assumption for some of the employed performance metrics. To analyze the impact of nonnormal distributions of performance metrics, I also analyze the ERP performance impact using a nonparametric Wilcoxon test. The effect of using a nonparametric test in this case is that all the results are a bit more pronounced. Overall, the results are qualitatively similar to the results shown in table 3.5, with some small exceptions. Labour productivity significantly improves in $t=0$ already, the margin significantly decreases in year $t+1$ already. out the entire time window can probably be attributed to the fact that many organizations adopt ERP on a module-by-module basis, over a time period of multiple years. Data gathered in the survey for chapter 2 show that organizations that do not employ a big-bang implementation (all implementations at once), on average take about 2.5 years to complete their ERP implementation. The typical adoption pattern is one in which secondary modules are implemented first and primary modules later. This implies that the most disruptive implementations (the primary 'core' modules) occur towards the end of the time window in this study. This may explain the continuance of the negative performance effects over the three years. As a sensitivity analysis I perform the same matched pair analysis once more, but restricted to those organizations that (a) provided information on the implementation date of individual modules in the survey and (b) completed their entire ERP implementation in $t+\mathrm{I}$ ultimately. This does restrict the analysis to the small number of 28 organizations. An analysis of the profitability impact of ERP in $t+3$ for these organizations does still show negative ERP impacts, but these effects are insignificant. Although these results should be interpreted with great caution given the small number of observations, this analysis does give further credence to the explanation for the continued negative profitability impact that I provide here.

Remarkably, the decrease in profitability is not found with regard to labour productivity. To the contrary, positive performance effects are found throughout the entire post-adoption period. Note that the same result was also obtained in the Poston \& Grabski (200I) study. Initially, one may be inclined to think that this increase in labour productivity can be attributed to the large-scale dismissals of redundant employees, that often accompany ERP implementations. Especially in administrative functions, redundancies are likely because data no longer need to be entered at multiple locations once the ER P system is installed. However, a more detailed analysis of this result shows that the increase in labour productivity is caused by an increase in revenues. Paired-sample $\mathrm{t}$-tests indicate significant increases in the revenue level, and insignificant changes in the employment level. This would suggest that an ERP system can boost the capacity of organizations to generate sales revenues. An alternative explanation is that the ERP system is used to accommodate the growth of the organization.

The findings with regard to the activity measures of performance are somewhat mixed. Throughout the entire time window, there are positive performance effects on inventory turnover. For assets turnover, 
a positive effect is observed in year $t+2$. Finally, accounts receivable turnover significantly decreases at first, but recovers towards the end of the time window. In the third year after adoption, there is a significant improvement over the prior average.

I test for the difference in pre-and post-adoption financial performance using the individual year observations. As an alternative, I use the approach that is also applied in Hunton et al. (2003). In this procedure, the post-adoption performance for $t+2$ reflects the average performance for $t+\mathrm{I}$ and $t+2$, and the performance in $t+3$ reflects the average performance for years $t+\mathrm{I}$ to $t+3$. The results corroborate the results presented here ${ }^{25}$.

On a post hoc basis, I separately analyze the ERP performance impact in manufacturing $(n=39)$ and wholesale/retail $(n=26)$ organizations. For manufacturing organizations, the overall results are quite similar to the results obtained earlier, although there are some small differences. In comparison with other companies, the labour productivity gains are less pronounced (but still present) in manufacturing organizations, profitability decreases (as indicated by ROA, ROE and the margin) are only incurred in years $t+2$ and $t+3$, whereas assets turnover already starts to improve at an earlier stage. The negative impact on accounts receivable turnover is only observed in $t=0$, in the post-adoption years this metric neither improves nor deteriorates.

The findings for wholesale/retail organizations also correspond with the earlier findings, but again there are some small differences. The positive impacts on inventory turnover and labour productivity, and the negative impacts on ROA, ROE and the margin are less pronounced, whereas the positive impact on assets turnover is much more pronounced.

Finally, I also perform the same analysis with only those observations for which data for the entire time window is present. The results are again similar to the results presented in table $3 \cdot 4^{26}$.

Overall the results are inconclusive; certain profitability measures (ROA, ROE, profit margin) indicate a drop in performance, probably because of the disrupting nature of ERP implementations, which tend to be lengthy and expensive. At the same time, labour productivity significantly increases after the ERP implementation. With regard to the activity measures, there is a clear improvement in inventory turnover after ERP adoption. Accounts receivable turnover initially deteriorates but recovers and even improves in the third year after implementation. Given that organizations typically start with the implementation of the
25 There are three minor differences. In the alternative analysis, the assets turnover effect is observed for both $t+2$ and $t+3$. The accounts receivable increase towards the end of the time window is no longer observed, because the negative performance impact in $t+1$ cancels out positive effects in subsequent years.

26 There are some minor differences in comparison with the results presented in table 3.5. The positive impact on inventory turnover in the year of adoption and assets turnover in year $t+2$ are no longer observed, although the latter is approaching significance. The negative impact on the margin is now already observed in year $t+1$. 
financial modules, it is possible that the initial decrease in performance is associated with start up problems with the accounting modules. The improvement of accounts receivable turnover towards the end of the time period suggests that firms quickly recover from these problems and eventually even enhance their performance.

3.4.2 Analysis II: matched pair analysis As explained earlier, I employ a matched pair design with the ERP adopters being matched on industry and firm size. This facilitates a test for differences between pre- and post-adoption for E RP firms and matched non-ERP firms.

The regression model employed is the following:

Performance Measure $=\aleph_{0}+\aleph_{I}$ Prior Performance $+\beta_{2} *$ ERP Adoption $+e$

This models employs the same post-adoption performance measures that were used in prior analyses. This dummy is 1 in case of adoption and $\mathrm{o}$ in case of nonadoption. Only complete matches are used. This implies that SAP-adopters for which no match could be obtained are dropped from the analysis, restricting the analyses to a maximum of 69 organizations. The regression controls for prior performance. The regression results for the various performance measures are shown in table 3.6.

To a certain extent, the results from the prior analysis and this analysis are similar. The results again demonstrate the ERP effects in the area of labour productivity and inventory turnover. Adopters improve their performance on these performance metrics both in absolute and in relative terms. The results with regard to accounts receivable turnover are also in line with the results from the prior analysis. Accounts receivable turnover deteriorates in the short run but recovers later.

There are also certain areas where the results are quite distinct from the prior analysis. Although in absolute terms there was limited evidence for a positive performance impact on assets turnover, the matched pair analyses show a positive impact of ERP over the entire time window. Finally, the profitability decreases that were documented in absolute terms, do not seem to play a role in relative terms. To the contrary, the analysis seems to suggest that in the third year after ERP adoption, the adopters actually start to outperform the nonadopters. A differential performance analysis can shed further light on this issue. This analysis is reported later in this section. 
Table 3.6 REGRESSION RESULTS FOR PERFORMANCE VARIABLES (THIRD, SECOND AND FIRST YEAR AFTER ADOPTION), CONTROLLING FOR PRIOR PERFORMANCE (3 YEAR PRE-ADOPTION AVERAGE) (t STATISTIC)

FINANCIAL PERFORMANCE IN POST-ADOPTION PERIOD = INTERCEPT + PRIOR PERFORMANCE + ERP ADOPTION

\begin{tabular}{|c|c|c|c|c|}
\hline & Intercept & Prior Performance & ERP-adoption & Adjusted R.sq. \\
\hline Revenues/Employees $t+3$ & $-189.616(-2.544)$ & $0.780(12.758) * \star \star$ & $0.174(2.837) * * *$ & .577 \\
\hline Revenues/Employees t+2 & $-220.041(-2.678)$ & $1.457(12.591) * * *$ & $0.161(2.653) * \star *$ & .550 \\
\hline Revenues/Employees $t+1$ & $-115.482(-3.269)$ & $0.938(26.664) * * *$ & $0.086(2.432) * *$ & .848 \\
\hline Pretax income / Assets $t+3$ & $-0.039(-2.955)$ & $0.514(6.773) * \star *$ & $0.184(2.419) * *$ & .303 \\
\hline Pretax income / Assets $t+2$ & $-0.001(-0.060)$ & $0.383(4.769) * * *$ & $0.101(1.255)$ & .150 \\
\hline Pretax income / Assets $t+1$ & $0.002(0.149)$ & $0.452(5.918) * * *$ & $0.100(1.311)$ & .210 \\
\hline Pretax income / Equity $t+3$ & $-0.134(-1.469)$ & $0.215(2.466) * *$ & $0.220(2.516)[0.013]^{\star *}$ & .077 \\
\hline Pretax income / Equity $t+2$ & $0.007(0.201)$ & $0.486(6.367) * \star *$ & $0.094(1.236)$ & .232 \\
\hline Pretax income / Equity t+1 & $0.069(1.441)$ & $0.284(3.426) * * *$ & $0.012(0.142)$ & .067 \\
\hline Pretax income / Sales $\mathrm{t}+3$ & $-0.027(-2.687)$ & $0.706(10.713) * * \star$ & $-0.014(-0.213)$ & .489 \\
\hline Pretax income / Sales t+2 & $-0.003(-0.399)$ & $0.548(7.408) * * *$ & $0.048(0.653)$ & .293 \\
\hline Pretax income / Sales $t+1$ & $-0.018(-2.292)$ & $0.716(11.794) * * *$ & $0.102(1.679)$ * & .517 \\
\hline Sales / Assets $t+3$ & $0.173(1.103)$ & $0.758(12.157) * \star \star$ & $0.143(2.299) * *$ & .551 \\
\hline Sales / Assets $t+2$ & $-0.109(-0.832)$ & $0.833(16.973) * * *$ & $0.177(3.606) * * *$ & .690 \\
\hline Sales / Assets $t+1$ & $0.023(0.217)$ & $0.876(20.142) * * *$ & $0.112(2.565) * *$ & .754 \\
\hline Sales / Acc. Receivable $t+3$ & $-1.523(-2.536)$ & $0.866(17.760) * * \star$ & $0.076(1.559)$ & .734 \\
\hline Sales / Acc. Receivable t+2 & $3.716(6.066)$ & $0.582(8.015) * * *$ & $0.028(0.389)$ & .330 \\
\hline Sales / Acc. Receivable t+1 & $2.866(8.220)$ & $0.847(18.192) * * *$ & $-0.101(-2.163) * *$ & .721 \\
\hline Inventory turnover $\mathrm{t}+3$ & $-9.559(-4.139)$ & $0.823(13.555) * * *$ & $0.157(2.585) * *$ & .662 \\
\hline Inventory turnover $\mathrm{t}+2$ & $-7.732(-4.491)$ & $0.168(15.077)^{* * *}$ & $0.168(3.042) * \star \star$ & .691 \\
\hline Inventory turnover t+1 & $-4.135(-3.268)$ & $0.842(15.679) * * *$ & $0.157(2.919) * * *$ & .700 \\
\hline
\end{tabular}

Cumulative performance effects An analysis that is ignored in prior studies, is to assess the performance impact of ERP on a cumulative basis. The underlying notion is that if an ERP system consistently leads to a small positive differential performance (the ERP adopter consistently outperforms the nonadopter, but the difference is relatively small), the effect will ultimately be larger. To assess this possibility, I employ the same regression model as specified in table 3.6, but replace the individual year observations by a cumulative performance measure for the three post-adoption years. The results indicate significant performance improvements for ERP adopters (two-tailed tests) with regard to labour 
productivity $(p<0.0 \mathrm{I})$, return on assets $(p<0 . \mathrm{IO})$, assets turnover $(p<0.0 \mathrm{I})$, return on equity $(p<0 . \mathrm{IO})$ and inventory turnover $(p<0.0 \mathrm{I})$, but no effects on the gross margin and accounts receivable turnover. These effects are in line with the results presented in table 3.6. Although speculative, the results seem to indicate early improvements on activity measures that lead to overall profitability increases in later time periods.

Differential performance An alternative way to address the matched pair analysis is by focusing on differential performance. This analysis has the additional advantage that it explicitly controls for differences in the prior performance of ERP adopters and the matched control firms. This is done by employing a statistical model that is also used in Nicolaou (2004) and Banker et al. (2002). In this model, the ERP implementation shifts a firm's performance along a time-series in the years following the system implementation. Because the possibility exists that the ERP impact decays or builds over time, I employ a functional form in which the effects for the adoption and the three post-adoption years are analyzed separately. This is achieved by incorporating separate dummy variables for the year of implementation and the three post-adoption years. The coefficient of the dummy should capture the magnitude of the ERP impact. To assess the incremental improvement of the E R P adopter in relation to a matched nonadopter, I employ the following statistical model:

\section{$\Delta$ Financial Performance $_{\text {itpost }}=\mathrm{f}\left(\Delta\right.$ Financial Performance $\left._{\text {itPRE }}, \mathrm{I}_{\mathrm{it}}\right)+\mathrm{e}$ where:}

$\Delta$ Financial Performance ${ }_{\text {itpost }}$

the difference in performance for the ith pair between the ERP implementing company and the matched control company in time period $t$. This analysis is performed for all the performance ratios employed earlier.

$\Delta$ Financial Performance $_{\text {itPRE }}$ the difference in the average performance for the $i$ th pair of the ERP-adopter and the matched control firm for the three years preceding the adoption.

$\mathrm{I}_{\text {it }}$ an intervention function, in which I equals 1 when the intervention (e.g. ERP implementation) occurs, and o otherwise. 
The results are reported in table 3.7. Overall, the results from this analysis corroborate the results from the analysis reported in table 3.6. With regard to the profitability measures, labour productivity again starts to improve relative to the nonadopters towards the end of the time window. The same holds for return on assets and return on equity. The same short-run positive impact on the profit margin is also observed here. With regard to the activity measures, there is again evidence to suggest an increase in assets turnover. Finally, there is no evidence of a positive impact on accounts receivable or inventory turnover in this analysis, although the trend with regard to inventory turnover is moving in a positive direction.

Table 3.7 INTERRUPTED TIME SERIES REGRESSION MODEL OF POST-ADOPTION DIFFERENTIAL PERFORMANCE ON PRE-ADOPTION DIFFERENTIAL PERFORMANCE AND PERIOD OF ERP SYSTEM USE DUMMIES (t-STATISTIC)

\begin{tabular}{|c|c|c|c|c|c|c|c|}
\hline & $\begin{array}{l}\text { Revenues/ } \\
\text { Employees }\end{array}$ & $\begin{array}{l}\text { Pretax income/ } \\
\text { Assets }\end{array}$ & $\begin{array}{l}\text { Pretax income/ } \\
\text { Equity }\end{array}$ & $\begin{array}{l}\text { Pretax income/ } \\
\text { Sales }\end{array}$ & Sales/Assets & $\begin{array}{l}\text { Sales/Acc. } \\
\text { Receivable }\end{array}$ & $\begin{array}{l}\text { Inventory } \\
\text { turnover }\end{array}$ \\
\hline Intercept & $\begin{array}{c}16.848 \\
(0.408)\end{array}$ & $\begin{array}{c}0.005 \\
(0.729)\end{array}$ & $\begin{array}{c}-0.003 \\
(-0.059)\end{array}$ & $\begin{array}{c}0.002 \\
(0.256)\end{array}$ & $\begin{array}{l}0.001 \\
(0.019)\end{array}$ & $\begin{array}{c}0.312 \\
(0.479)\end{array}$ & $\begin{array}{c}-0.109 \\
(-0.063)\end{array}$ \\
\hline $\begin{array}{l}\Delta \text { Prior Perf. } \\
\text { (three year } \\
\text { prior average) }\end{array}$ & $\begin{array}{l}0.780^{\star * \star} \\
(24.498)\end{array}$ & $\begin{array}{l}0.732^{\star * *} \\
(17.172)\end{array}$ & $\begin{array}{l}0.547^{\star \star \star} \\
(13.389)\end{array}$ & $\begin{array}{l}0.644^{\star \star \star} \\
(16.708)\end{array}$ & $\begin{array}{c}0.875^{\star * *} \\
(36.562)\end{array}$ & $\begin{array}{l}0.691^{\star \star \star} \\
(18.921)\end{array}$ & $\begin{array}{c}0.747^{\star \star} \\
(19.250)\end{array}$ \\
\hline ERP $t+3$ & $\begin{array}{l}0.093^{\star * *} \\
(2.695)\end{array}$ & $\begin{array}{l}0.074^{*} \\
(1.857)\end{array}$ & $\begin{array}{c}0.073^{\star} \\
(1.673)\end{array}$ & $\begin{array}{c}0.011 \\
(0.277)\end{array}$ & $\begin{array}{l}0.078^{* * *} \\
(3.036)\end{array}$ & $\begin{array}{c}-0.019 \\
(-0.488)\end{array}$ & $\begin{array}{l}0.066 \\
(1.586)\end{array}$ \\
\hline ERP $t+2$ & $\begin{array}{l}0.076^{\star *} \\
(2.186)\end{array}$ & $\begin{array}{c}0.035 \\
(0.866)\end{array}$ & $\begin{array}{c}0.028 \\
(0.638)\end{array}$ & $\begin{array}{c}0.018 \\
(0.441)\end{array}$ & $\begin{array}{l}0.110^{\star * \star} \\
(4.240)\end{array}$ & $\begin{array}{c}0.000 \\
(-0.009)\end{array}$ & $\begin{array}{r}0.037 \\
(0.892)\end{array}$ \\
\hline ERP $t+1$ & $\begin{array}{l}0.022 \\
(0.649)\end{array}$ & $\begin{array}{c}0.040 \\
(0.996)\end{array}$ & $\begin{array}{c}0.014 \\
(0.307)\end{array}$ & $\begin{array}{l}0.096^{* *} \\
(2.286)\end{array}$ & $\begin{array}{l}0.040 \\
(1.556)\end{array}$ & $\begin{array}{c}-0.040 \\
(-1.007)\end{array}$ & $\begin{array}{r}0.017 \\
(0.411)\end{array}$ \\
\hline ERP to & $\begin{array}{c}0.005 \\
(0.144)\end{array}$ & $\begin{array}{l}-0.009 \\
(-0.217)\end{array}$ & $\begin{array}{c}0.066 \\
(1.489)\end{array}$ & $\begin{array}{l}0.026 \\
(0.633)\end{array}$ & $\begin{array}{r}0.039 \\
(1.510)\end{array}$ & $\begin{array}{c}0.035 \\
(0.874)\end{array}$ & $\begin{array}{r}0.023 \\
(0.547)\end{array}$ \\
\hline $\begin{array}{l}\text { Model F } \\
\text { (Adj.R-sq.) }\end{array}$ & $\begin{array}{c}122.165 \\
(0.000) \\
61.4 \%\end{array}$ & $\begin{array}{c}60.139 \\
(0.000) \\
41.0 \%\end{array}$ & $\begin{array}{c}36.778 \\
(0.000) \\
29.8 \%\end{array}$ & $\begin{array}{c}56.712 \\
(0.000) \\
41.3 \%\end{array}$ & $\begin{array}{c}270.589 \\
(0.000) \\
77.0 \%\end{array}$ & $\begin{array}{c}72.334 \\
(0.000) \\
47.6 \%\end{array}$ & $\begin{array}{c}74.517 \\
(0.000) \\
55.4 \%\end{array}$ \\
\hline
\end{tabular}

* = significant at 0.10 level, two-tailed; ** =significant at 0.05 level, two-tailed;

$* \star \star=$ significant at 0.01 level, two-tailed.

For each independent variable, the standardized coefficient is presented for average differential performance in the three years prior to adoption and for the four ERP time-period dummies. 
27 The adoption level metric is based on model II in chapter 2. This metric captures the proportionate share of the relevant ERP modules being used. It is therefore different from 'adoption', because adoption simply assesses whether a given organization has adopted a particular innovation or not. 28 Note that the main effect of the ERP adoption level is equal to the interaction term in this regression. It is therefore not possible to include both the main and the interaction effect.
In the previous sections, I have replicated the analyses from prior studies in this field. Although the results from prior research in this area are somewhat mixed, most studies point in the direction that ultimately ERP adopters will outperform nonadopters. This study refines the measurement of the ERP adoption event by using survey information from the ERP implementation project manager, instead of relying on public announcements of ERP implementations/completions. The results indicate the same finding that was also obtained in earlier studies: ERP adopters generally outperform nonadopters. It typically takes two to three years before the ERP adopters start to outperform the nonadopters, which is consistent with the notion of ERP implementations that are disruptive at first, but start to generate learning effects later. In comparison with prior research, this study shows more pronounced absolute performance effects. Where prior studies typically showed no or only a small impact of ERP adoption, this study documents strong absolute performance improvements with regard to labour productivity and inventory turnover and weak performance improvements on activity measures such as assets turnover, accounts receivable turnover. At the same time, I find strong negative impacts on overall profitability indicators.

3.4.3 Additional analyses In this section of the chapter, I will add two variables to these analyses that may shed further light on the financial performance impact of ERP systems. As explained in section 3.2.3, I want to test for the impact of (a) the ERP adoption level and (b) the impact of over-and underspending on the financial performance effects of ERP. I include separate variables for over-and underspending to account for the possibility that there may be different effects from overand underspending.

3.4.3.1 ANALYSIS III: ADOPTION LEVEL EFFECTS This analysis is performed for the ERP adopters for which (a) survey data were obtained and (b) financial performance data were available. This limits the analysis to 39 ERP adopters (+39 matched nonadopters). The ERP adoption level is the adoption level from the previous chapter ${ }^{27}$. Using the detailed survey information on the timing of the implementation of these modules, this adoption level was calculated for $t+\mathrm{I}, t+2$ and $t+3$ separately. To test the effect of the ERP adoption level, I add an interaction term to the regression analysis performed earlier. This results in the following model:

Performance Measure $=\beta_{O}+\beta_{I} *$ Prior Performance $+\beta_{2} *$ ERP Adoption $+\beta_{3} *$ ERP Adoption * ERP Adoption Level ${ }^{28}$ 
If the adoption level adds explanatory power to the model reported earlier, this would provide evidence that the financial performance impact of ERP increases with the adoption level, as stated in hypothesis 1. I restrict the analysis to the profitability and activity measures that could be impacted by the entire suite of ERP modules. Therefore I do not report results for accounts receivable turnover ${ }^{29}$. Results from the analysis are reported in table 3.8 .

Table 3.8 REGRESSION RESULTS FOR THE IMPACT OF THE ADOPTION LEVEL (THIRD, SECOND AND FIRST YEAR AFTER ADOPTION), CONTROLLING FOR PRIOR PERFORMANCE (3 YEAR PRE-ADOPTION AVERAGE) AND ERP ADOPTION

FINANCIAL PERFORMANCE IN POST-ADOPTION PERIOD = INTERCEPT + PRIOR PERFORMANCE + ERP ADOPTION + ERP ADOPTION * ERP ADOPTION LEVEL

\begin{tabular}{|c|c|c|c|c|c|}
\hline & Intercept & Prior Performance & ERP-adoption (1/o) & ERP adoption * & Adjusted \\
\hline & & & & ERP adoption level & R.sq. \\
\hline Revenues/Employees $t+3$ & $-160.350(-1.512)$ & $0.686(7.380) * * *$ & 0.149 (0.715) & $0.036(0.173)$ & .437 \\
\hline Revenues/Employees $t+2$ & $-188.625(-1.755)$ & $0.709(8.193) * * \star$ & $0.080(0.424)$ & $0.077(0.411)$ & .469 \\
\hline Revenues/Employees t+1 & $-74.737(-1.711)$ & $0.900(16.662) * * *$ & $0.155(1.376)$ & $-0.081(-0.720)$ & .786 \\
\hline Pretax income / Assets $t+3$ & $-0.038(-2.304)$ & $0.560(5.802) * \star *$ & $0.353(1.619)$ & $-0.135(-0.622)$ & .380 \\
\hline Pretax income / Assets $t+2$ & $-0.004(-0.317)$ & $0.493(4.896) * * \star$ & $0.264(1.191)$ & $-0.120(-0.545)$ & .264 \\
\hline Pretax income / Assets $t+1$ & $-0.004(-0.279)$ & $0.510(5.319) * \star \star$ & $0.447(2.201)$ & $-0.334(-1.653) \star(a)$ & .304 \\
\hline Pretax income / Equity $t+3$ & $-0.103(-1.449)$ & $0.399(3.549) * \star \star$ & $0.313(1.224)$ & $-0.096(0.375)$ & .163 \\
\hline Pretax income / Equity $t+2$ & $0.035(-0.757)$ & $0.510(4.970) * \star \star$ & $0.067(0.293)$ & $0.015(0.068)$ & .234 \\
\hline Pretax income / Equity $t+1$ & $0.039(-0.712)$ & $0.443(4.238) * * *$ & $0.374(1.682)$ & $-0.343(-1.542) \star(a)$ & .174 \\
\hline Pretax income / Sales $t+3$ & $-0.025(-1.876)$ & $0.713(8.204) * \star \star$ & $0.162(0.822)$ & $-0.141(-0.723)$ & .508 \\
\hline Pretax income / Sales $t+2$ & $-0.002(-0.137)$ & $0.492(4.824) * \star *$ & $0.325(1.447)$ & $-0.220(-0.986)$ & .262 \\
\hline Pretax income / Sales $t+1$ & $-0.017(-1.726)$ & $0.713(9.349) * * *$ & $0.387(2.399)$ & $-0.279(-1.734) * \star$ & .566 \\
\hline Sales / Assets $t+3$ & $-0.027(-0.163)$ & $0.850(12.498) * \star \star$ & $0.004(0.029)$ & $0.144(0.952)$ & .703 \\
\hline Sales / Assets t+2 & $-0.204(-1.388)$ & $0.887(15.956) * \star *$ & $0.072(0.591)$ & $0.075(0.614)$ & .781 \\
\hline Sales / Assets t+1 & $-0.045(-0.466)$ & $0.938(22.046) * * *$ & $0.068(0.757)$ & $0.000(0.003)$ & .866 \\
\hline Inventory turnover $t+3$ & $-0.387(-0.207)$ & $0.827(9.557) * * *$ & $0.032(0.155)$ & $0.051(0.249)$ & .629 \\
\hline Inventory turnover $t+2$ & $0.304(0.202)$ & 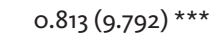 & $0.119(0.623)$ & $-0.042(-0.217)$ & .615 \\
\hline Inventory turnover t+1 & $2.249(3.115)$ & $0.895(14.382) * \star \star$ & $0.190(1.391)$ & $-3.024(-1.172)$ & .780 \\
\hline \multicolumn{6}{|c|}{ (a) = These findings are significant using a one-tailed test, but the signs are not in the hypothesized direction. } \\
\hline \multicolumn{6}{|c|}{ With a two-tailed test, these coefficients are no longer significant. } \\
\hline \multicolumn{6}{|c|}{${ }^{*}=$ significant at 0.10 level, one-tailed; ${ }^{* \star}=$ significant at 0.05 level, one-tailed; ${ }^{* \star *}=$ significant at 0.01 level, one-tailed. } \\
\hline \multicolumn{6}{|c|}{ For each independent variable, the coefficient value and ( $\mathrm{t}$ statistic) are provided. } \\
\hline
\end{tabular}

Results do not indicate any impact of the adoption level on the performance indicators, with the exception of weak negative short-term impacts 
29 Improvements in accounts receivable turnover can only be related to the adoption of the financial ERP suite. Given that there is almost no variance in the adoption of these modules (practically all firms have the financials/ controlling module), I do not report the results for accounts receivable turnover.

30 The residuals are based on model II in chapter 2. on return on assets, return on equity and the profit margin in year $t+\mathrm{I}$. This leads to the rejection of hypothesis 1.

3.4.3.2 ANALYSIS IV: OVER-OR UNDERINVESTMENT The analysis of the impact of over- and underinvestment is performed for the ERP adopters for which (a) survey data were obtained and (b) financial performance data were available. This limits the analysis to $50 \mathrm{E}$ R P adopters. I assume that the residuals from the benchmark model ${ }^{\circ}$ in chapter 2 represent the extent to which an organization has over-invested or under-invested in ERP. To allow for potential differences in the effects of over- and underinvestment, I employ separate variables for positive and negative variables. A potential problem with this analysis is that the residual from chapter 2 represents over-or underinvestment at the completion date, because the adoption level was calculated on basis of all implemented modules, irrespective of the implementation year. Yet, the base year in the financial performance effects analysis in this chapter is the first year in which at least two ERP modules were being employed. Given that ERP implementations may take more than one year to finish, the residuals do not necessarily capture over-or underinvestment in period $t+\mathrm{I}$ or $t+2$. Therefore, I restrict the analysis to time period $t+3$.

The regression model employed is the following:

Performance Measure $t+3=\beta_{0}+\beta_{1}$ Prior Performance $+\beta_{2} *$ Pos.Res. $+\beta_{3} *$ Neg. Res.

The results from this analysis are presented in table 3.9. The coefficient sign for negative residuals has been reversed. By doing so, the expected coefficient sign for both over- and underspending is negative.

Table 3.9 REGRESSION RESULTS FOR THE IMPACT OF ERP OVER-AND UNDERSPENDING ON PERFORMANCE (THIRD YEAR AFTER ADOPTION), CONTROLLING FOR PRIOR PERFORMANCE

FINANCIAL PERFORMANCE IN POST-ADOPTION PERIOD = INTERCEPT + PRIOR PERFORMANCE + ERP OVERSPENDING + ERP UNDERSPENDING

\begin{tabular}{|c|c|c|c|c|c|}
\hline & Intercept & Prior Performance & Overspending & Underspending & Adjusted R.sq. \\
\hline Revenues/Employees $\mathrm{t}+3$ & $-188.67(-1.259)$ & $0.916(11.376) * * *$ & $-0.125(-1.360) *$ & $-0.152(-1.543)^{\star}$ & .765 \\
\hline Pretax income/Assets $t+3$ & $0.04(0.245)$ & $0.620(5.225) * * *$ & $0.101(0.702)$ & $0.197(1.365)^{*}$ & .404 \\
\hline Pretax income/Equity $t+3$ & $0.044(0.797)$ & $0.362(2.479) * \star \star$ & $0.188(1.056)$ & $0.349(2.091) * \star$ & .182 \\
\hline Pretax income/Sales $t+3$ & $0.005(0.381)$ & $0.523(4.029) * * *$ & $0.166(1.046)$ & $0.217(1.348)^{\star}$ & .305 \\
\hline Sales/Assets $t+3$ & $0.082(0.379)$ & $0.855(10.220) * * *$ & $-0.025(-0.248)$ & $-0.006(-0.063)$ & .714 \\
\hline Sales/Accounts receivable $t+3$ & $0.132(0.112)$ & $0.751(7.063) * * *$ & $-0.013(-0.097)$ & $-0.111(-0.844)$ & .527 \\
\hline Inventory turnover $t+3$ & $-10.074(-1.830)$ & $0.871(9.647) * \star \star$ & $0.021(0.184)$ & $-0.038(-0.337)$ & .741 \\
\hline
\end{tabular}


With regard to labour productivity, the results are in conformity with hypothesis 2 . Both over- and underspending are associated with decreases in longitudinal performance. Remarkably, the results for the other profitability indicators (return on assets, return on equity and the gross margin) indicate that organizations that underspend on ERP are rewarded with a better performance. This can probably be attributed to the absolute negative performance impact of ERP in this domain, as documented in section 3.4.I. With regard to the activity measures, no association between over- or underspending and financial performance is found.

As an alternative, I compute the financial performance in $t+3$ as the average of the financial performance in $t+\mathrm{I}, t+2$ and $t+3$. The results are similar to those presented in table 3.9, with some minor differences ${ }^{3}$. Finally, I use the absolute value of the residuals to compute a single variable that simply measures the mismatch between organizational characteristics and the chosen ERP adoption level. The results indicate a negative impact of the mismatch on labour productivity, but a positive impact on the other three profitability indicators (ROA, ROE and the profit margin). For the activity measures, there is no impact of the mismatch on performance. Overall, these results lead to the rejection of hypothesis 2.

\subsection{Discussion, limitations and suggestions for further research}

3.5.1 Discussion In this study, I have tested the financial performance effects of ERP adoption. The costs and risk associated with ERP implementations make it important to study the payoff of this technology. Overall, the results from this study indicate that ER P adoption leads to performance improvements.

The value of ERP technology was studied from different angles. I started with an analysis in which the absolute performance impact for a group of ERP adopters was assessed. The results are mixed. There is strong evidence to suggest that E R P implementation leads to higher labour productivity (higher sales revenue levels can be supported with the same employee level) and improvements in activity measures of performance. At the same time, profitability measures of performance deteriorate after ERP adoption. These negative performance effects can probably be attributed to the high cost associated with ERP implementations, in combination with the disruptiveness of this organizational change effort. Another reason why I may have found such strong negative impacts on profitability is the fact that ERP implementations from I998
31 With regard to ROA, the coefficient for the negative residual is now insignificant. For the profit margin, the coefficient for the positive residual is positive, in contradiction to hypothesis 1 . 
and 1999 made up a very significant part of the dataset. These years were the heyday for ERP vendors. Many ERP-implementations in I998 and 1999 were driven by technical, non-business motives such as the Y $2 \mathrm{~K}$ problem and the introduction of the European currency. Implementations that are merely driven by technical, system-related objectives, have a higher probability of failure than implementations that are based on both technical as well as business motives (Nicolaou, 2004).

This analysis was complemented with a matched pair analysis. This makes it possible to compare the performance of the ERP adopter with a similar firm (in terms of firm size) in the same industry. In this way, relative performance improvements can be assessed. Remarkably, the negative impact on profitability indicators is no longer obtained in this matched pair analysis. To the contrary, towards the end of the time window ERP adopters actually start to outperform the nonadopters in this respect. This suggests that, although the profitability of ERP adopters is negatively impacted in the short run by the ERP implementation, the loss of competitiveness for nonadopters is even larger. Overall, the results of the matched pair analysis indicate strong positive performance effects from ER P adoption.

Subsequently, I add two analyses as contributions to this literature. First, I use the adoption level from chapter 2 and address the question whether the positive performance impact of ERP is larger for firms with higher ERP adoption levels. However, the results do not suggest any impact for the adoption level. This contradicts prior studies from Hitt et al. (2003) and Nicolaou (2004) that did find performance effects of E RP scope, although this variable was measured quite differently in these studies. The failure to find an effect of the ERP adoption level may be caused by the typically quite large E RP implementations for the organizations in this chapter. On average, the ER P adopters already employ 5 modules in the first year after adoption, with a relatively small variance. It may be the case that beyond a certain threshold adoption level, additional modules no longer add enough value to contribute to the aggregated performance indicators employed in this study.

In addition to studying the effect of the adoption level, I also add the impact of over- and underspending. Ultimately, firms will be moving towards an optimal ERP adoption level, but the possibility exists that firms are temporarily off equilibrium and have not reached their optimal E R P adoption level yet. In this study I suggest that firms that adopt ERP software and do not realize a positive performance impact may have failed to match their organizational characteristics to the adoption 
level of the ERP software. In contrast, firms that adopt ERP software and achieve higher performance are believed to have realized the proper fit between the adoption level of ERP and their organizational characteristics. The empirical results do not support the role of this mismatch in explaining performance differences between E R P adopters.

An explanation ${ }^{2}$ for these results may be that the model discussed in chapter 2 does not accurately predict the ideal optimal level. Given the large part of the variance in ERP adoption levels that is not explained by the model in chapter 2 , this is a serious concern.

3.5.2 Limitations This study has several limitations. An obvious first limitation is the use of sap-adopters only. Prior event studies show that the financial markets react more favourably to the announcement of an investment in a large, well-known software package such as SAP (Hayes et al., 200I). Generally speaking, this study has shown performance improvements from ERP adoption. There is a concern that these performance improvements are simply sAP effects, and would not be obtained for other ERP vendors that offer software of perhaps lesser quality. There are two reasons why I think this is not a concern for this study. First of all, ER P packages all share the same underlying rationale: integration of business processes through the use of a single, common database. These integration benefits should be similar across vendors. The second reason is related to SAP being the market leader in ERP systems. This creates the possibility that relatively more SAP-implementations (than implementations of other ERP systems) are based on poorly justified investment criteria. The status of SAP is such that many regard it is a safe choice. An implementation team that chooses SAP will not have to justify itself at great lengths for having made this choice.

A second limitation concerns the use of a three-year time window. Given that it may take more than 3 years before E R P benefits start materializing, this time window may be too short. Although the ERP implementation costs can immediately be identified, the ERP benefits are not immediately evident. Given the fact that many organizations spend multiple years on their ERP implementation, it is very well possible that ERP benefits start to emerge more than three years after the implementation. This would call for longer time windows. Unfortunately, with a longer time horizon, there will be serious difficulties in disentangling the E R P benefits from other longitudinal factors affecting firm performance.

A third limitation of the study concerns the sample. The use of publicly available financial performance data, in combination with the choice
32 In this analysis it was not possible to employ a matched pair design. Results from the financial performance analysis indicate that the application of this technique can have a significant impact on the results. It is possible that a matched pair analysis would demonstrate the hypothesized effects of over-and underspending, but on basis of this study this can not be determined. 
for a high-end, complex ER P system, confines the analysis to relatively large organizations. The results may not generalize to smaller firms. This limitation is especially important because ERP vendors are currently targeting smaller firms, the SAP Business One product being a key example of this trend.

A fourth limitation concerns the definition of the year of ERP implementation in this study. In this study, the implementation year is the year in which the first combination of two or more interfaced E R P modules was employed. This leads to the large benefit that the pre-adoption time window is guaranteed to be free from early ERP performance effects, as may have been the case in prior research. It also introduces a problem though. The post-adoption time window can coincide with the implementation period for modules that are added later during the implementation project. Although typical E R P implementations are finished within I-2 years, this may still impact the postadoption performance effects in this study.

A final limitation of the study concerns the small sample size. This problem is particularly acute for the analyses reported towards the end of the chapter.

3.5.3 Suggestions for further research Future research can address the limitations discussed in section 3.5.2 in the following manner. First, future studies could start studying how ERP influences more operations-based measures of financial performance. These operations-based performance measures (e.g. lead times, quality improvements in products, reductions in inventory levels, delivery times, customer retention) will have an effect on more aggregate measures of corporate performance in the long run. By understanding the impact of E R P implementations on operations-based measure of performance, and their relation to aggregate measures of performance, we can add to our understanding of financial performance effects of ERP systems. Future research can also aid to our understanding by decomposing aggregate measures of financial performance into several lower level metrics (e.g. DuPont analysis, see Dehning \& Stratopoulos, 2002).

Second, a lot of work stills needs to be done on identifying factors that mediate the relation between ERP systems (or IT investments in general) and firm performance. It is likely that the impact of ERP on firm performance is mediated by certain managerial choices. The effectiveness with which IT investments are converted to useful output can vary between organizations. Factors that may be studied include, but 
are certainly not limited to the complementary effects of using E RP with other management practices (e.g. Total Quality Management (TQM), Just-In-Time manufacturing (Јгт), the use of nonfinancial performance measures (e.g. Wier et al., 2005)), and the role of strategic alignment (e.g. Tallon et al., 2000).

Third, future research could replicate these analyses in different contexts (e.g. smaller organizations) and across multiple ERP vendors. Especially the question how ERP impacts the performance of smaller organizations deserves more attention, given that many ERP vendors are now targeting this market. 

$\Delta$ 
SUMMARY AND
CONCLUSION 


\subsection{Introduction}

This dissertation brings together two empirical studies on ERP systems. More specifically, the first study focuses on the determinants of the ERP adoption level. The second study deals with the financial performance effects of ER P implementations. This final chapter summarizes the purpose, design and empirical results of the two studies. In addition, the chapter draws attention to the limitations of the two studies. Finally, the chapter discusses directions for further research.

\subsection{The determinants of ERP adoption levels}

In the first empirical study, I investigate the determinants of ERP adoption levels. The benefits of ERP systems stem from the integration of business functions. Key benefits include the integration of business data through the use of a single, central database, the improvement of information processing capabilities and the creation of reengineering opportunities through the use of reference models embedded in the software. Unfortunately, increased integration may also result in increased rigidity of the ERP system. I have argued in this dissertation that firms make this trade-off between ERP network benefits by choosing an appropriate adoption level based on the modular structure of ER P systems. In the first empirical study, I investigate the role of several environmental, organizational and technological characteristics in determining this adoption level.

In chapter 2 of this dissertation I develop a research model that predicts that the ERP adoption level will be dependent upon environmental characteristics (environmental uncertainty, environmental pressure), internal organizational characteristics (centralization, formalization, information intensity) and classical diffusion of innovations (DoI) variables (perceived relative advantage, perceived compatibility and perceived complexity). These contextual factors represent conditions under which the benefits of these integrated systems are higher (lower).

Data for the study are gathered through a survey among Dutch users of the ERP package SAP. Measurement instruments for the mentioned determinants of the ERP adoption level are derived from prior literature, whereas this dissertation develops a metric to capture the adoption level of ERP. This metric takes advantage of the modular structure of ERP to arrive at a measure that captures the proportionate share of the relevant ERP modules being used. By using this metric, I also go beyond the simple, dichotomous measures of adoption that are typically employed in IT adoption studies. The results are summarized in table 4.I. 
Table 4.1 SUMMARY OF RESULTS FOR DETERMINANTS OF

ERP ADOPTION LEVEL STUDY

Variables Hypothesized sign Empirical results

Cluster 1: External Environment

Environmental uncertainty

Positive

Negative (environmental dynamism)

External pressure

Positive

Positive

Cluster 2: Internal Environment

Centralization

? Negative

Formalization

Positive

Not significant

Information intensity

Positive

Positive

Cluster 3: Technology

Relative advantage

Compatibility

Positive

Positive

Complexity

Positive

Negative

Not significant

Negative

The results from the survey indicate that the adoption level of E R P software is driven by external, internal and technological contingencies.

With regard to external environmental factors, the results from the study indicate that pressure from external parties (e.g. competitors, business partners) promotes higher E R P adoption levels. An interesting finding is obtained with regard to environmental dynamism (one of the components of environmental uncertainty). Contrary to my expectation, firms that are faced with high environmental dynamism (e.g. frequent changes in consumer tastes, government legislation, competitor practices) choose lower ER P adoption levels. Arguably, these organizations need to maintain flexibility in their IT infrastructure to be able to cope with this dynamism. ERP systems have often been criticized as being inflexible and rigid. To avoid this rigidity, E R P adopters in dynamic environments deliberately seek lower E R P adoption levels.

The results also suggest that ERP systems play a crucial role in the information supply in organizations. This is indicated by the positive relation between information intensity and E R P adoption levels. In information-intensive organizations, the production of products/services is accompanied by vast streams of information that are necessary to successfully deliver the product/service. ER P systems provide these information processing capabilities. These information processing capabilities may also explain why decentralization was shown to be associated with higher ER P adoption levels. By increasing the monitoring capabilities of organizations, ERP may increase the returns to decentralization. For- 
malization does not have the proposed effect on ERP adoption levels.

Consistent with prior literature on diffusion-of-innovations, the perceived relative advantage of $\mathrm{E}$ R P was shown to have a very strong impact on ERP adoption levels. It is the perceived relative advantage that provides the economic legitimacy to invest in ERP. There is also evidence to suggest a negative relation between perceived complexity and the adoption level, although this evidence is relatively weak. No evidence was found to support the role of perceived compatibility in determining the E RP adoption level.

\subsection{The financial impact of ERP systems}

In the second empirical study in this dissertation, I assess the financial performance impact of ERP implementations. Firms that have to decide on ERP investments will have difficulties in quantifying the effects of E RP in advance, especially given that many IT benefits are intangible in nature. By studying the longitudinal impact of E R P on firm performance, this study has tried to shed some light on the payoffs of ERP investments. This is done by assessing the impact of ERP technology on a range of financial performance metrics. A distinction is made between profitability and activity measures. Profitability indicators capture overall profitability of the organization at a very aggregate level, whereas the activity indicators have a more operational nature.

Initially, I focus my attention on absolute performance improvements for the group of ERP adopters only. The group of ERP adopters was derived from the survey conducted in chapter 2 and complemented with a group of additional SAP adopters that did not participate in the survey study. The results indicate strong negative impacts on profitability indicators (ROA, ROE and profit margin), probably caused by the ERP implementation cost and the disruptiveness of the ER P implementation effort. At the same time, there is strong evidence for improvements in labour productivity and inventory turnover. To the extent that these are lead indicators of performance, one would expect positive profitability effects in later periods.

Subsequently, I use a matched pair analysis to assess the relative performance improvements from ERP adoption. By employing a matched pair analysis, one can rule out the explanation that performance changes are sheerly based on performance trends in the entire line of industry. Matching is done on industry code and asset level in the year prior to adoption. No significant differences in prior performance are found for 
the group of adopters and nonadopters, suggesting a successful matching procedure. The results of the matched pair analysis confirm the positive performance impact of ERP on inventory turnover and labour productivity. In addition, ERP adopters also consistently outperform the nonadopters on assets turnover. Remarkably, the negative impact on profitability indicators is no longer obtained in this matched pair analysis. To the contrary, ER P adopters actually start to outperform the nonadopters towards the end of the three year time window. This would suggest that the negative impact from the disruptive ERP implementation is even offset by the loss of competitiveness for nonadopters. This gives further credibility to the notion of ERP systems as a competitive necessity. The results are summarized in table 4.2.

Table 4.2 SUMMARY OF RESULTS FOR FINANCIAL PERFORMANCE IMPACT OF ERP STUDY

\begin{tabular}{|c|c|c|}
\hline & $\begin{array}{l}\text { Empirical Results Absolute } \\
\text { Performance Effects }\end{array}$ & $\begin{array}{l}\text { Empirical Results } \\
\text { Matched Pair Analysis }\end{array}$ \\
\hline Labour Productivity & Positive & Positive \\
\hline Return On Assets (RoA) & Negative & Positive in last year analysis \\
\hline Return On Equity (ROE) & Negative & Positive in last year analysis \\
\hline Margin & $\begin{array}{l}\text { Negative in the later } \\
\text { years of the analysis }\end{array}$ & Short-run positive effect \\
\hline Assets turnover & Inconclusive & Positive \\
\hline $\begin{array}{l}\text { Accounts receivable } \\
\text { turnover }\end{array}$ & $\begin{array}{l}\text { Initially negative, } \\
\text { positive effect in } \\
\text { last year analysis }\end{array}$ & No effect \\
\hline Inventory Turnover & Positive & Positive \\
\hline
\end{tabular}

In the final part of the second empirical study, I investigate whether the adoption level of ERP increases the magnitude of the financial performance impact. Given that an ERP system typically brings along network benefits, and becomes more valuable when it is employed in more business areas (similar to the way in which telecommunications technologies become more valuable when more people have adopted them), I predict positive performance effects of higher adoption levels. The results from the empirical analysis do not back up this expectation, perhaps because the ERP implementations studied here are typically large implementations (many modules across different functional areas).

In addition, I study the impact of under- and overinvestment in ERP on firm performance effects of ERP adoption. Assuming that the model 
in chapter 2 predicts the optimal ERP adoption level in light of the organizational contingencies, the residuals from the regression analysis in chapter 2 reflect over- and underinvestment in ERP technology. Although on average, firms are expected to have chosen the optimal adoption level, some firms may be temporarily off equilibrium, for instance because they are still experimenting with the technology or are uncertain about its benefits. The empirical results do not support the role of this mismatch in explaining performance differences between ERP adopters.

\subsection{Limitations}

An important limitation of this dissertation is that results are confined to sAP adopters only. This dissertation has consistently attributed the observed empirical results to ERP technology. Although different ERP packages share the same underlying logic, the possibility that the results in this study are to a certain extent unique for SAP, can not be completely ruled out.

The second limitation is related to the first one. The restriction to SAP adopters has an impact on the sample selection. Although SAP has recently introduced a midsize market version of its package, it still is a fairly complex E RP solution, typically adopted by quite large organizations. Therefore, results from this dissertation may not generalize to small firms.

A final limitation concerns the choice of the respondents in the survey study that lies at the heart of this dissertation. Given my interest in explaining the adoption level of ERP software, I decided to contact the project managers that were responsible for the ERP implementation project. Although they are arguably the perfect respondents with regard to the adoption level of the various SAP modules, they are not necessarily the best informed respondents on several independent variables that were employed in this study. To the extent that these project managers (that often have a background in information technology) are more ITminded than business-minded, their assessment of variables such as environmental uncertainty may be less accurate. Although this limitation is especially relevant for the first study, it is also relevant for the second study. The benchmark model from the first study is used to identify firms that have over- or underinvested in ERP in the second study. If project managers are not well-informed about certain organizational contingencies, this may distort the measurement of over- and underspending in the second study. 


\subsection{Directions for further research}

There are several opportunities for further research. In sections 2.5.3 and 3.5.3 I sketch future research possibilities that are directly related to the two studies presented in this dissertation.

First, we know little about ERP implementations in midsize and small organizations. When ERP systems first entered the market, they were characterized as too complex for small organizations. Currently, the large ERP vendors are targeting smaller organizations, because the market for their product among large organizations is saturated. Studying the value proposition of ERP in this market is therefore an important possibility for future research in this area.

Secondly, the impact of ERP systems on the quality of managerial information has remained relatively unexplored. The transaction system of ERP systems contains a large amount of business information, assembled within one central database. By eliminating manual re-entries of business information in standalone systems, ERP systems have the potential to enhance the quality of information. At the same time, mistakes that are made when entering information are bound to have more pronounced effects. Studying the net effects of ERP systems on the quality of managerial information could therefore be an interesting research topic. Related to this is the possibility to study the effects of socalled 'business intelligence' (a new term for a range of decision support technologies) applications. These technologies are used to extract information from the ER P data repository, but we know relatively little about the effects of these technologies (e.g. on decision making quality).

Finally, future research should start to address other outcome effects of ERP systems. One particularly fruitful area would be to study the impact of ERP systems on internal control and management control system design. Davenport (I998) suggests that the introduction of ERP may both give rise to command-and-control organizations in which organizational units' performance is constantly and instantaneously monitored, but would also facilitate very flat organizations in which the use of business information is free to anyone. A similar tension is discussed in Hubbard (2000), in a study about monitoring technologies. Monitoring capabilities can both increase and decrease the returns to decentralization, by solving control and coordination problems. Future research could study how organizations employ ER P technology and the role of E RP in addressing control and coordination concerns. 



\section{List of literature used Appendices Summary in dutch nederlandse samenvatting Curriculum vitae}




\section{List of literature used}

Abrahamson, E. \& Rosenkopf, L. (1993). Institutional and competitive bandwagons: using mathematical modeling as a tool to explore innovation diffusion, Academy of Management Review, 18 (3), 487-517.

Arnold, V., Hunton, J.E. \& Sutton, S.G. (I999). On the death and dying of originality in the workplace: a critical view of enterprise resource planning systems' impact on workers and the work environment, Critical perspectives on accounting symposium, April I999, New York, N Y.

Banker, R.D., Chang, H. \& Kao, Y. (2002). Impact of information technology on public accounting firm productivity, Journal of Information Systems, 16 (2), 209-222.

Baptista, R. (I999). The diffusion of process innovations, International Journal of the Economics of Business, 6 (1), 107-129.

Bendoly, E. (2002). Theory and support for process frameworks of knowledge discovery and data mining from $E R P$ systems, Information Q Management, 40 (7), 639-647.

Bharadwaj, A. (2000). A resource-based perspective on information technology capability and firm performance: An empirical investigation, MIS Quarterly, 24 (1), I69-196.

Bingi, P., Sharma, M.K. \& Godla, J.K. (I999). Critical issues affecting an ERP implementation, Information Systems Management, 16 (3), 7-I4.

Bradford, M. \& Florin, J. (2003). Examining the role of innovation diffusion factors on the implementation success of enterprise resource planning systems, International Journal of Accounting Information Systems, 4 (3), 205-225.

Brynjolfsson, E. (I993). The productivity paradox of information technology: Review and assessment, Communi- cations of the ACM, 36 (12), 67-77.

Brynjolfsson, E., \& Hitt, L.M. (1996). Paradox lost? Firm level evidence on the returns to information systems spending, Management Science, 42 (4), 54I-560.

Brynjolfsson, E., \& Hitt, L.M. (I998). Beyond the productivity paradox, Communications of the ACM, 41 (8), 49-56.

Chau, P.Y.K., \& Tam, K.Y. (2000). Organizational adoption of open systems: A 'technology-push, need-pull' perspective, Information \& Management, 37 (5), 229-239.

Chwelos, P., Benbasat, I. \& Dexter, A.S. (200I). Research report: empirical test of an EDI adoption model, Information Systems Research, 12 (3), 30432I.

Cooke, D.P. \& Peterson, W.J. (1998). SAP implementation: strategies and results, New York, NY: The Conference Board, Inc.

Cooper, R.B., \& Zmud, R.W. (I990). Information technology implementation research: A technological diffusion approach, Management Science, 36 (2), I23-I39.

Damanpour, F. (I99I). Organizational innovations: A meta-analysis of effects of determinants and moderators, Academy of Management Journal, 34 (3), 555-590.

Davenport, T.H. (1998). Putting the enterprise into the enterprise system, Harvard Business Review, 76 (4), I2I-I3I.

Davenport, T.H. (2000). Mission critical, Boston, MA: Harvard Business School Press.

Dedrick, J., Gurbaxani, V., Kraemer, K.L. (2003). Information technology and economic performance: A critical review of the empirical evidence, ACM Computing Surveys, 35 (1), I-28. Dehning, B., \& Richardson (2002). 
Returns on investments in information technology: A research synthesis, Journal of Information Systems, 16 (1), 7-30.

Dehning, B. \& Stratopoulos, T. (2002). DuPont analysis of an IT-enabled competitive advantage, International Journal of Accounting Information Systems, 3 (3), I65-I76.

DeLone, W.H., \& McLean, E.R. (I992). Information systems success: The quest for the dependent variable, Information Systems Research, 3 (1), 60-95.

Dewar, R.D. \& Dutton, J.E. (I986). The adoption of radical and incremental innovations: An empirical analysis, Management Science, 32 (11), I422I433.

Dillman, D.A. (2000). Mail and internet surveys, New York: John Wiley \& Sons, Inc.

Dos Santos, B.L., Peffers, K. \& Mauer, D.C. (I993). The impact of information technology investment announcements on the market value of the firm, Information Systems Research, 4 (1), I-23.

Downs Jr., G.W., \& Mohr, L.B. (I976). Conceptual issues in the study of innovation, Administrative Science Quarterly, 21 (4), 700-7I4.

Ettlie, J.E. \& Bridges, W.P. (I982). Environmental uncertainty and organizational technology policy, IEEE Transactions on Engineering Management 29 (1), 2-Io.

Ettlie, J.E. (I983). Organizational policy and innovation among suppliers to the food processing sector, Academy of Management Journal, 26 (1), 27-44.

Everdingen van, Y., Hillegersberg van, J, \& Waarts, E. (2000). ER P Adoption by European midsize companies, Communications of the ACM, 43 (4), 27-31.

Ewusi-Mensah, K. (I98I). The external organizational environment and its impact on management information systems, Accounting, Organizations and Society, 6 (4), 30 з-3I6.

Fichman, R.G. (2000). The diffusion and assimilation of information technology innovations, in: Zmud, R.W. (ed.), Framing the domains of IT research: Glimpsing the future through the past, Cincinnati, он: Pinnaflex Educational Resources, Inc.

Fichman, R.G. (200I). Aggregation in the measurement of IT-related innovation, MIS Quarterly, 25 (4), 427455 .

Galbraith, J. (I973). Designing complex organizations, Reading: AddisonWesley.

Gattiker, T.F \& Goodhue, D.L. (2004). Understanding the local-level costs and benefits of E RP through organizational information processing theory, Information \& Management, 41 (4), 43I-443.

Gattiker, T.F. \& Goodhue, D.L. (2005). What happens after E RP implementation: Understanding the impact of inter-dependence and differentitation on plant-level outcomes, MIS Quarterly, 29 (3), 559-585.

Gordon, L.A., \& Narayanan, V.K. (I984). Management accounting systems, perceived environmental uncertainty and organization structure: An empirical investigation, Accounting, Organizations and Society, 9 (1), 37-47.

Granlund, M. and Malmi, T. (2002). 'Moderate impact of E RPS on management accounting: a lag or permanent outcome?' Management Accounting Research 13 (3), 299-32I.

Grice, J.W. \& Harris, R.J. (I998). A comparison of regression and loading weights for the computation of factor scores, Multivariate Behavioral Research, 33 (2), 22 I-247.

Grover, V. \& Goslar, M.D. (I993). The initiation, adoption, and implementation of telecommunications technologies in U.s. organizations. Journal of Management Information Systems, 10 (1), I4I-I63. 
Gurbaxani, V. \& Whang, S. (I99I). The impact of information systems on organizations and markets, Communications of the ACM, 34 (1), 59-73.

Hage, J. \& Aiken, M. (1967). Relationship of centralization to other structural properties, Administrative Science Quarterly, 12 (1), 72-92.

Hage, J. \& Aiken, M. (I969). Routine technology, social structure, and organization goals, Administrative Science Quarterly, 14 (3), 366-377.

Hair, J.F. Jr., Anderson, R.E., Tatham, R.L. \& Black, W.C. (I998). Multivariate data analysis, Upper Saddle River, NJ: Prentice-Hall.

Hayes, D.C., Hunton, J.E., \& Reck, J.L. (200I). Market reaction to ERP implementation announcements, Journal of Information Systems, 15 (1), 3-I8.

Heckman, J.J. (I979). Sample selection bias as a specification error, Econometrica, 47 (1), I53-I6I.

Hitt, L. \& Brynjolfsson, E. (I996), Productivity, business profitability, and consumer surplus: Three measures of information technology value, MIS Quarterly, 20 (2), I2I-I42.

Hitt, L.M., Wu, D.J., \& Zhou, X. (2002), Investment in enterprise resource planning: Business impact and productivity measures, Journal of Management Information Systems, 19 (1), $7 \mathrm{I}-98$.

Hoffman, C.C. (I995). Applying range restriction corrections using published norms: Three case studies, Personnel Psychology, 48 (4), 913-923.

Hong, K-K, Kim, Y-G. (2002). The critical success factors for ERP implementation: An organizational fit perspective, Information \& Management, 40 (1), 25-40.

Hubbard, T.N. (2000). The demand for monitoring technologies: The case of trucking, Quarterly Journal of Economics, 115 (2), 533-560.

Hunton, J.E., Lippincott, B., Reck, J.L. (2003). Enterprise resource plan- ning systems: Comparing firm performance of adopters and nonadopters, International Journal of Accounting Information Systems, 4 (3), I64-I84.

Hunton, J.E., McEwen, R.A. \& Wier, B. (2002). The reaction of financial analysts to enterprise resource planning (ERP) implementation plans, Journal of Information Systems, 16 (1), 3I-40.

Iacovou, C.L., Benbasat, I. \& Dexter, A.S. (I995). Electronic data interchange and small organizations: Adoption and impact of technology, MIs Quarterly, 19 (4), 465-485.

Ittner, C.D., Lanen, W.N. \& Larcker, D.F. (2002). The assocation between activity-based costing and manufacturing performance, Journal of Accounting Research, 40 (3), 7II-726.

Kimberly, J.R., \& Evanisko, M.J. (I98I). Organizational innovation: The influence of individual, organizational, and contextual factors on hospital adoption of technological and administrative innovations, Academy of Management Journal, 24 (4), 689-7I3.

Kremers, M., \& Van Dissel, H. (2000). E RP systems migrations, Communications of the ACM, 43 (4), 53-56.

Kwon, T.H., \& Zmud, R.W. (I987). Unifying the fragmented models of information systems implementation; in Boland and Hirschheim (Eds.) Critical issues in information systems research, John Wiley, New York.

Light, B., Holland, C.P. \& Willis, K. (200I). ERP and best of breed: A comparative analysis, Business Process Management Journal, 7 (3), 216-224.

Lozinsky, S. (I998). Enterprise-wide software solutions: Integration strategies and practices, Reading, ma: Addison Wesley.

Lucas, H.C. Jr., Walton, E.J., \& Ginzberg, M.J. (I988). Implementing packaged software, MIS Quarterly, 12 (4), 537-549. 
Mabert, V.A., Soni, A., \& Venkataramanan, M.A. (2000). Enterprise resource planning survey of U.s. manufacturing firms, Production and Inventory Management Journal, 42 (3/4), 52-58.

Markus, M.L., \& Tanis, C. (2000) The enterprise systems experiencefrom adoption to success, in: Zmud, R.W. (ed.), Framing the domains of IT research: Glimpsing the future through the past, Cincinnati, он: Pinnaflex Educational Resources, Inc.

McAfee (2002). The impact of enterprise information technology adoption on operational performance: An empirical investigation, Process and Operations Management, 11 (1), 33-53.

Miller, D. \& Friesen, P.H. (I982). Innovation in conservative and entrepreneurial firms: Two models of strategic momentum, Strategic Management Journal, 3 (I), I-25.

Moch, M.K. \& Morse, E.V. (I977). Size, centralization and organizational adoption of innovations, American Sociologal Review, 42 (5), 716-725.

Moore, G.C., \& Benbasat, I. (I99I). Development of an instrument to measure the perceptions of adopting an information technology innovation, Information Systems Research, 2 (3), I92-222.

Mukhopadhyay, T, Kekre, S., \& Kalathur, S. (I995). Business value of information technology: A study of electronic data interchange, MIS Quarterly, 19 (2), I37-I56.

Newell, S., Swan, J.A. \& Galliers, R.D. (2000). A knowledge-focused perspective on the diffusion and adoption of complex information technologies: The в P R example, Information Systems Journal, 10 (3), 239-259.

Nicolaou, A, I. (2004). Firm performance effects in relation to the implementation and use of enterprise resource planning systems, Journal of Information Systems, 18 (2), 79-IO5.
Nunnally. J. C. (I978). Psychometric theory, New York: McGraw-Hill.

O'Leary, D. (2000). Enterprise resource planning systems: systems, life cycle, electronic commerce, and risk, Cambridge University Press.

Olson, D.L. (2004). Managerial issues of enterprise resource planning, New York, Ny: McGraw-Hill.

Palaniswamy, R. \& Frank, T. (2000). Enhancing manufacturing performance with E R P systems, Information Systems Management, 17 (3), 43-55.

Palaniswamy, R. (2002). An innovation-diffusion view of implementation of enterprise resource planning (ERP) systems and development of a research model, Information \& Management, 40 (2), 87-II4.

Pedhazur, E.J. \& Pedhazur Schmelkin, L.P. (I99I). Measurement, design, and analysis, Hillsdale, New Jersey: Lawrence Erlbaum Associates, Publishers.

Pierce, J.L., \& Delbecq, A.L. (I977). Organization structure, individual attributes and innovation, Academy of Management Review, 2 (1), 27-37.

Porter, M. \& Millar, V.E. (1985). How information gives you competitive advantage, Harvard Business Review, 63 (4), I49-16o.

Poston, R. \& Grabski, S. (200I). Financial impacts of enterprise resource planning implementations, International Journal of Accounting Information Systems, 2 (4), 27I-294.

Premkumar, G., Ramamurthy, K., \& Nilakanta, S. (I994). Implementation of electronic data interchange: An innovation diffusion perspective, Journal of Management Information Systems, 11 (2), I57-I86.

Premkumar, G., \& Ramamurthy, K. (I995). The role of interorganizational and organizational factors on the decision mode for adoption of interorganizational systems, Decision Sciences, 26 (3), 303-336. Premkumar, G., Ramamurthy, K. \& 
Crum, M. (I997). Determinants of EDI adoption in the transportation industry, European Journal of Information Systems, 6 (2), I07-I22.

Premkumar, G. \& Roberts, M. (I999). Adoption of new information technologies in rural small businesses, Omega, 27 (4), 467-484.

Prescott, M.B., \& Conger, S.A. (I995). Information technology innovations: A classification by Iт locus of impact and research approach, Data Base Advances, 26 (2Q广3), 20-4I.

Ragowsky, A. \& Somers, T.M. (2002), Special section: Enterprise resource planning, Journal of Management Information Systems, 19 (1), II-I5.

Rai, A. \& Bajwa, D.S. (I997). An empirical investigation into factors relating to the adoption of executive information systems: An analysis of EIs for collaboration and decision support, Decision Sciences, 28 (4), 939-974.

Ramamurthy, K., Premkumar, G. \& Crum, M.R. (I999). Organizational and interorganizational determinants of E D I diffusion and organizational performance: A causal model, Journal of Organizational Computing and Electronic Commerce, 9 (4), 253-285.

Ranganathan, C. \& Samarah, I. (200I). Enterprise resource planning systems and firm value: An event study analysis, Working paper presented at the 22nd International Conference on Information Systems, New Orleans.

Rogers, E.M. (1983). Diffusion of innovations, New York: Free Press.

Said, A.A., HassabElnaby, H.R. \& Wier, B. (2003). An empirical investigation of the performance consequences of nonfinancial measures, Journal of Management Accounting Research, 15, I93-223.

Scapens, R. W. \& Jazayeri, M. (2003). E R P systems and management accounting change: Opportunities or impacts? A research note, European Accounting Review 12 (1), $20 \mathrm{O}-233$. Schultz, R.L. \& Slevin,, D.P. (eds.).
(I975). Implementing operations research/management science, New York: American Elsevier.

Soh, C., Kien, S.S., Tay-Yap, J. (2000). Cultural fits and misfits: Is E RP a universal solution?, Communications of the ACM, 43 (4), 27-3I.

Swan, J., Newell, S. \& Robertson, M. (I999). The illusion of 'best practice' in information systems for operations management, European Journal of Information Systems, 8 (4), 284-293.

Tallon, P.P., Kraemer, K.L. \& Gurbaxani, V. (2000). Executives' perceptions of the business value of information technology: A processoriented approach, Journal of Management Information Systems, 16 (4), I45-I73.

Thong, J.Y.L. (I999). An integrated model of information systems adoption in small businesses, Journal of Management Information Systems, 15 (4), I87-2I4.

Tornatzky, L.G., \& Klein, K.J. (I982). Innovation characteristics and innovation adoption-implementation: A meta-analysis of findings, IEEE Transactions on Engineering Management, 29 (I), 28-45.

Weill, P. (I992). The relationship between investment in information technology and firm performance: A study of the valve manufacturing sector, Information Systems Research, 3 (4), 307-333.

Weill, P., \& Olson, M.H. (I989). Managing investment in information technology: Mini case examples and implications, MIS Quarterly, 13 (1), 3I7.

Westphal, J.D., Gulati, R., \& Shortell, S.M. (I997). Customization or conformity? An institutional and network perspective on the content and consequences of TQM adoption, Administrative Science Quarterly, 42 (2), 366-394.

Wier, B., Hunton, J. \& HassabElnaby, 
H.R. (2005). Enterprise resource planning \& nonfinancial performance incentives: The joint impact on corporate performance, Working paper presented at the European Conference on Accounting Information Systems in Göteborg.

Wolfe, R.A. (I994). Organizational innovation: Review, critique and suggested research, Journal of
Management Studies, 31 (3), 405-43I Wooldrigde, J.M. (2000). Introductory econometrics: A modern approach, South-Western College Publishing. Zmud, R.W. (I982). Diffusion of modern software practices: Influence of centralization and formalization, Management Science, 28 (12), I42II43I. 


\section{Appendices}

\section{appendix A Measurement instruments}

This appendix presents the measurement instruments employed in this dissertation.

\section{ADOPTION LEVEL}

Indicate the status of the following SAP-modules within your organization. Indicate, if possible, the implementation date per module (month, year).

Module

A Financial accounting (FI)

в Controlling (CO)

C Treasury (TR)

D Asset/Investment

Management (I M)

E Project Systems (PS)

F Business Workflow

G Human Resources (HR)

H Plant Maintenance and

Service Management (Рм)

I Quality Management (QM)

J Production Planning (P P)

к Material Management (м M)

L Sales and Distribution (SD)

M Enterprise Controlling (EC)

\section{Status of use}

Implementation date (month, year)

Scale

$\mathrm{O}=$ This module is not relevant for our organization

I $=$ This module is not in use, but could in principle be put to use in our organization

$2=$ This module will be used eventually, but the implementation has not started

$3=$ We are currently implementing this module

$4=$ This module has been in use for less than 3 years

$5=$ This module has been in use for more than 3 years.

\section{ENVIRONMENTAL UNCERTAINTY}

- How rapid or intense it each of the following in your primary industry?

(1-5; anchors of the extremes given)

(EU-DYNI) Our organization/division rarely changes its marketing practices to keep up with the market and competitors - Our organization/division must change its marketing practices extremely frequently.

(EU-DYN2) The rate at which products/sercies are getting obsolete in the primary industry is very slow - The rate of product/service obsolescence is very high.

(EU-DYN3) Actions of competitors are quite easy to predict in our primary industry Actions of competitors are unpredictable.

(EU-DYN4) Demand and consumer tastes are fairly easy to forecast in our primary industry - Demand and tastes are almost unpredictable.

(EU-DYN5) The production/service technology is not subject to very much change The modes of production/service change often and in a major way.

(EU-DYN6) The environment causes a great deal of threat to the survival of our organization/division - The environment causes very little threat to the survival of our organization/division. 
- Are there great differences among the products/services you offer, with regard to...?

(EU-HETI) Customer buying habits:

about the same for all products - varies a great deal from line to line

(EU-HET2) The nature of the competition:

about the same for all products - varies a great deal from line to line

(EU-HET3) Market dynamism and uncertainty:

about the same for all products - varies a great deal from line to line

- How severe are the following challenges?

(EU-HOSI) Tough price competion:

this is not a substantial threat - this is a very substantial threat

(EU-HOS2) Competition in product quality:

his is not a substantial threat - this is a very substantial threat

(EU-HOS3) Dwindling markets for products:

this is not a substantial threat - this is a very substantial threat

(EU-Hos4) Scarce supply of labour/material:

this is not a substantial threat - this is a very substantial threat

(EU-Hos5) Government interference:

this is not a substantial threat - this is a very substantial threat

\section{EXTERNAL PRESSURE}

(PRESI) There is pressure to use ERP to meet business partners' requirements:

fully disagree - fully agree

(PRES2) There is pressure from our industry to use ERP as an industry standard:

fully disagree - fully agree

(PRES3) There is pressure to use ERP because we would otherwise lose our

competitive edge: fully disagree - fully agree

\section{CENTRALIZATION}

- To what extent is the responsibility to make the following decisions in your company centralized at the top levels of management?

(CENTI) Capital budgeting:

very small extent - very high extent

(CENT2) New product introduction:

very small extent - very high extent

(CENT3) Entry into major new markets:

very small extent - very high extent

(CENT4) Pricing of major product line:

very small extent - very high extent

(CENT5) Hiring and firing of senior staff:

very small extent - very high extent

\section{FORMALIZATION}

(FORMI) Whatever situation arises, we have procedures to follow in dealing with it: fully disagree - fully agree

(FORM 2) When rules and procedures exist here, they are usually in written form: fully disagree - fully agree

(FORM3) The employees here are constantly checked for rule violations:

fully disagree - fully agree

(FORM4) There are strong penalties for violating procedures:

fully disagree - fully agree 


\section{INFORMATION INTENSITY}

- How dependent is your organization on:

(INFO-INTI) The currency of information: very small extent - very high extent

(IN FO-INT2) The reliability of information: very small extent - very high extent

(INFO-INT3) The timeliness of information: very small extent - very high extent

\section{COMPATIBILITY}

(COMPAI) ERP is compatible with existing hardware and software: fully disagree - fully agree

(COMPA2) The existing operating practices are compatible with the changes to be introduced by ERP:

fully disagree - fully agree

(Сом РА3) The existing values/belief systems of the organization are compatible with changes to work procedures to be introduced by ERP:

fully disagree - fully agree

\section{COMPLEXITY}

(COMP) ERP is difficult to comprehend and use in our organization:

fully disagree - fully agree

\section{RELATIVE ADVANTAGE}

ERP will provide the following advantages over a business situation in which ERP is not employed:

(PRAI) Solving problems associated with 'islands of automation'

(non-integrated systems): fully disagree - fully agree

(PRA2) Enforce homogeneous business processes:

fully disagree - fully agree

(PRA3) Improve business processes by means of 'best practices':

fully disagree - fully agree

(PRA4) Increasing the visibility of employees' performance:

fully disagree - fully agree

(PRA5) Reducing IT expenses:

fully disagree - fully agree

(PRA6) Reducing operations costs:

fully disagree - fully agree

(PRA7) Supplying qualitatively adequate information to support managerial decision-making: fully disagree - fully agree

(PRA8) Improving information flows between business functions in order to improve coordination and communication: fully disagree - fully agree

(PRA9) Centralization of administrative activities:

fully disagree - fully agree

\section{TOP MANAGEMENT SUPPORT (CONTROL VARIABLE)}

(TMSI) Executive sponsor(s) personally participates in the ERP implementation on a regular basis: fully disagree - fully agree

(TMS2) Top management's contact with the executive sponsor on E RP-related issues has been frequent: fully disagree - fully agree 
(TMS3) Top management provides sufficient resources for ERP: fully disagree - fully agree

(TMS4) Top management perceives ERP to be important: fully disagree - fully agree

(TMS5) Top management usually provides constructive feedback on the appropriateness of ERP applications: fully disagree - fully agree

(TMS6) ERP is regarded as a high priority by top management:

fully disagree - fully agree 


\section{appendix B Overview SAP modules}

FINANCIAL ACCOUNTING (FI) gathers and stores all financial accounting data. Is considered to be a core element (backbone) of the sAP system. Functionality includes i.a. general ledger accounting, consolidation and accounts receivable/payable. CONTROLLING (Co) the purpose of the controlling module is to coordinate, control and optimize all business processes within an organization. Functionality includes i.a. budgeting activity-based costing and profitability analysis.

TREASURY (TR) is used for corporate finance purposes. The liquidity of the firm can be monitored using this module. Financial risks can be minimized. Functionality includes i.a. cash management, funds management and market risk management. ASSET MANAGEMENT (AM) is used for the acquisition and depreciation of (fixed) assets. Functionality includes i.a. acquisition, capitalisation, depreciation and retirement.

PROJECT SYSTEMS (PS) coordinates and controls large projects (construction, shipbuilding etc.).

BUSINESS WORKFLOW (BW) is used to structure and optimize business processes. Business Workflow is important in business process re-engineering efforts.

Functionality includes i.a. routing of documents.

HUMAN RESOURCES (HR) is used to support the administration of human resources. Functionality includes i.a. payroll administration, time management and personnel development.

PLANT MAINTENANCE AND SERVICE MANAGEMENT (PM) is used to provide detailed information about the maintenance of large installations.

QUALITY MANAGEMENT (QM) includes i.a. quality control for receipt of goods and delivery of goods and supplier evaluation/selection.

PRODUCTION PLANNING (PP) is used to issue production orders and calculate order costs. Functionality includes i.a. capacity planning, production on demand and master production scheduling.

MATERIAL MANAGEMENT (MM) is used for purchasing, material requirements planning, goods receipts and inventory control. Functionality includes i.a. administration of purchase requisitions, purchase orders, вом's and inventory management. SALES AND DISTRIBUTION (SD) supports a large variety of activities in the area of sales, shipping and billing. Functionality includes i.a. customer analysis, creation of quotation, shipping, administration of invoices.

ENTERPRISE CONTROLLING (EC) this module fulfils the need for executive information that aggregates information across several companies within a group. Functionality includes i.a. profit center accounting and business planning. 
appendix c Cost categories in Poston \& Grabski (2001) study

INFORMATION SYSTEM EFFECTS ON ECONOMIC PERFORMANCE OF THE FIRM

Cost categories

E RP effects on firm costs

Related cost category found

(Gurbaxani and Whang, I99I)

in Compustat database

Internal coordination costs

- AGENCY COSTS

Monitoring costs

Decreases administrative monitoring costs;

Decrease in SG\&A

Decreases cost of defects and errors in product

Decrease in Cogs

and information

Bonding costs

Decreases administrative reporting costs

Decrease in SG\&A

Residual loss

No effect

- DECISION INFORMATION COSTS

Information-processing costs

Enhances decision making;

Increasing revenues and/or decreasing costs

Communication

Enhances decision making;

Increasing revenues and/or decreasing costs

Documentation

Enhances decision making;

Increasing revenues and/or decreasing costs

Enhances decision making;

Increasing revenues and/or decreasing costs

Decrease in total costs;

Increase in revenue

Decrease in total costs;

Increase in revenue

Decrease in total costs;

Increase in revenue

Decrease in total costs;

Increase in revenue

Decreases administrative costs

Decreases administrative costs

Decreases inventory costs

Decreases administrative costs

No effect

No effect
Decrease in SG\&A

Decrease in SG\&A

Decrease in CoGs

Decrease in SG\&A

- CONTRACTUAL

Costs of writing contracts

Costs of enforcing contracts 


\section{Summary in dutch nederlandse samenvatting}

In het afgelopen decennium hebben veel organisaties geïnvesteerd in geïntegreerde informatiesystemen, die onder de noemer Enterprise Resource Planning (ERP) op de markt worden gebracht. Deze standaardsoftware ondersteunt niet alleen het hele scala aan bedrijfsprocessen dat zich binnen een organisatie afspeelt, maar combineert dit tevens met een integrale aanpak van de informatisering van de diverse bedrijfsprocessen. Dit proefschrift beschrijft een tweetal empirische studies naar ERP software. De eerste studie onderzoekt de determinanten van de adoptiegraad van deze systemen. De tweede studie gaat na hoe ERP investeringen de financiële prestaties van ondernemingen beïnvloeden.

Om de populariteit van deze systemen te begrijpen, is het van belang om kort in te gaan op de evolutie van het gebruik van informatiesystemen in organisaties in de voorbije vijftig jaar. De eerste toepassingen van informatiesystemen lagen op het terrein van de boekhouding. Nadat er informatiesystemen waren ontwikkeld waarmee de financiële administratie ondersteund kon worden, volgden andere functionele deelgebieden, zoals de salarisadministratie, de verkoopadministratie, de productieplanning et cetera. Voor deze deelgebieden werden aparte informatiesystemen ontwikkeld, met een eigen gebruikersinterface, een eigen menustructuur en eigen data definities. Elk van deze systemen kent dus zijn eigen gegevensverzameling en elk systeem kent vaak een eigen manier waarop de opgeslagen gegevens worden bewaard. Deze aanpak kent significante nadelen waar het gaat om de informatie-uitwisseling tussen informatiesystemen. Het is namelijk vaak niet mogelijk om informatie tussen deze systemen uit te wisselen. Dit fenomeen is in de informatietechnologie (IT) literatuur bekend onder de goed gekozen naam eilandautomatisering. De gevolgen hiervan zijn kostbaar. Eilandautomatisering zorgt voor situaties waarbij gegevens uit het ene systeem bij gebruik in een ander systeem opnieuw ingevoerd moeten worden, hetgeen niet alleen extra kosten met zich meebrengt maar bovendien de kans op fouten vergroot.

ERP systemen bieden een oplossing voor de problemen die met eilandautomatisering gepaard gaan. Deze systemen bieden namelijk niet alleen functionaliteit voor alle generieke bedrijfsprocessen van een onderneming, maar ze zorgen tevens voor een centrale, éénmalige opslag van bedrijfsgegevens. Dit zorgt tevens voor de stroomlijning van informatieprocessen in organisaties. Tot slot creëren ERP systemen ook mogelijkheden voor organisatie om hun bedrijfsprocessen opnieuw in te richten en de effectiviteit en/of efficiëntie van deze processies te verbeteren. Daarvoor kunnen de standaard bedrijfsprocessen die in het ERP systeem ingebed zijn, gebruikt worden. Ofschoon ERP software belangrijke voordelen kent, zijn er ook belangrijke nadelen aan verbonden. Hier zijn twee aspecten van belang. Ten eerste is E RP software standaardsoftware. De applicatie is dus niet op maat gemaakt van de organisatie en het is mogelijk dat de organisatie zich moet aanpassen aan de ERP software. Ten tweede is de potentiële inflexibiliteit van deze systemen van belang. Naarmate hetzelfde ERP pakket in meer functionele deelgebieden van de organisatie wordt ingezet, wordt het systeem mogelijk steeds meer rigide. Bij een toenemende adoptiegraad wordt de constellatie van onderling afhankelijke modules (onderdelen van het ERP pakket met functionaliteit voor een specifiek functioneel gebied) steeds complexer en daardoor moeilijker te veranderen.

In dit proefschrift beargumenteer ik dat ondernemingen een afweging moeten maken tussen de netwerkvoordelen die voortvloeien uit een hoge adoptiegraad van ERP 
software, en de toegenomen rigiditeit van het systeem. Die afweging wordt gemaakt door ervoor te kiezen om ERP in bepaalde functionele gebieden wel in te zetten en op andere gebieden niet. Dat kan door bepaalde modules wel en andere niet te gebruiken.

In hoofdstuk 2 onderzoek ik de determinanten van de adoptiegraad van ERPsystemen. De adoptiegraad is in deze studie geoperationaliseerd als een ratio, waarbij het aantal gebruikte ERP-modules gedeeld wordt door het aantal voor de onderneming relevante ER P-modules. Hoofdstuk 2 geeft een overzicht van empirische literatuur naar determinanten van het gebruik van informatiesystemen in organisaties. Uit die literatuur wordt een lijst gedistilleerd van variabelen die theoretisch van invloed zijn op de adoptiegraad van ERP software. Deze variabelen hebben betrekking op kenmerken van (a) de externe omgeving van de organisatie, (b) interne organisatiekenmerken en (c) gepercipieerde kenmerken van de ERP software. Deze contextuele factoren stellen omstandigheden voor waarin de netto voordelen van geïntegreerde systemen hoger (lager) zijn.

Data voor deze studie werden verzameld met behulp van een internetenquête onder projectmanagers van SAP-implementaties in Nederland. De keuze voor SAP was gebaseerd op de dominantie van deze Duitse softwareleverancier in deze markt, maar vooral ook op het feit dat de keuze voor één leverancier het vergelijken van de adoptiegraden zou vereenvoudigen.

De empirische resultaten van deze studie laten allereerst zien dat ondernemingen die onder hoge externe druk staan om ERP te gebruiken (bijvoorbeeld omdat klanten of leveranciers erop aan dringen, of uit angst om een concurrentieel nadeel op te lopen), een hogere ERP adoptiegraad hebben. Daarnaast kiezen ondernemingen die in een dynamische markt opereren voor een lagere ERP adoptiegraad, waarschijnlijk om flexibiliteit in hun Iт infrastructuur te bewaren, zodat deze aangepast kan worden aan nieuwe omstandigheden. Hoge adoptiegraden worden gevonden in informatieintensieve organisaties. In deze organisaties spelen informatiestromen een belangrijke rol in het produceren van goederen en het leveren van diensten. ERP systemen leveren een bijdrage aan de informatievoorziening in dit type organisatie. Een analyse van het effect van centralisatie op de ERP adoptiegraad laat zien dat gedecentraliseerde ondernemingen hogere adoptiegraden hebben dan gecentraliseerde organisaties. ERP systemen kunnen gebruikt om toezicht te houden op de prestaties van bedrijfsonderdelen. Doordat de informatieasymmetrie tussen de verticale hiërarchische lagen in de organisatie verkleind wordt, nemen de voordelen van decentralisatie toe. Tot slot blijken gepercipieerde ERP voordelen een positief, en de gepercipieerde complexiteit van het ERP systeem een negatief effect op de adoptiegraad te hebben.

In hoofdstuk 3 van dit proefschrift onderzoek ik de prestatie-effecten van ERP systemen. Gegeven de hoge investeringen die met de implementatie van ERP systemen gepaard gaan, en het hoge risico, is het van belang om onderzoek te doen naar het rendement van deze investeringen. Dit wordt gedaan door de longitudinale ontwikkeling van diverse financiële prestatie-indicatoren te volgen in de jaren na ERP implementatie en te vergelijken met de prestaties van de onderneming voor implementatie. Allereerst richt ik de analyse exclusief op E R P-gebruikers. Analyse van de ontwikkeling van de prestatie-indicatoren na ERP implementatie laat zien dat de winstgevendheid van ondernemingen sterk afneemt na ERP implementatie. Tegelijkertijd nemen de arbeidsproductiviteit en de omzetsnelheid van de voorraad toe.

Deze analyse wordt vervolgens aangevuld met een serie van analyses waarbij de prestatie van de ER P-gebruiker wordt vergeleken met de prestatie van een vergelijkbare onderneming (in termen van grootte) uit dezelfde industrie. Deze vergelijkbare onderneming heeft geen ER P-pakket. In globale termen laten deze analyses zien dat de 
gebruikers van ERP-systemen beter presteren dan vergelijkbare ondernemingen die niet in ERP geïnvesteerd hebben. De winstgevendheid van ERP-gebruikers mag op korte termijn dan wel negatief beïnvloed worden, dit weegt niet op tegen het concurrentieel nadeel dat ondernemingen ervaren die geen E R P-pakket implementeren. Tot slot ga ik na of de adoptiegraad en de mogelijke over- of onderinvestering in ERP gevolgen hebben voor de financiële prestaties van ondernemingen, maar de empirische resultaten wijzen hier niet op. De analyses in hoofdstuk 3 suggereren dat ERP-systemen een concurrentiële noodzaak zijn; ofschoon ze niet noodzakelijkerwijs tot absolute prestatieverbeteringen leiden, betalen ondernemingen die niet investeren in een ERP pakket wel uiteindelijk de prijs in de vorm van slechtere financiële prestaties.

Hoofdstuk 4 rondt dit proefschrift af met een samenvatting van de twee studies, een overzicht van de beperkingen van het onderzoek en mogelijkheden voor toekomstig onderzoek op dit terrein. 


\section{Curriculum vitae}

Mark Vluggen was born on March 22, 1973 in Heerlen, the Netherlands. From I991 to I996 he studied Business Administration at the Faculty of Economics and Business Administration at Universiteit Maastricht. Starting in 1996 , he worked as a lecturer and, later, as an assistant professor at the Department of Accounting and Information Management at Universiteit Maastricht. His research interests include information and knowledge management.

Mark Vluggen werd geboren op 22 maart 1973 in Heerlen. Van I99I tot 1996 studeerde hij bedrijfseconomie aan de Faculteit der Economische Wetenschappen en Bedrijfskunde van de Universiteit Maastricht. Vanaf 1996 werkt hij, eerst als toegevoegd docent en later als universitair docent, bij het Departement Accounting and Information Management van de Universiteit Maastricht. Zijn onderzoeksinteressen liggen op het terrein van informatie- en kennismanagement. 
COLOFON

Enterprise Resource Planning systems:

An empirical study of adoption and effects

Ontwerp Janneke Vlaming grafische

vormgeving, Heerlen

Druk Drukkerij Econoom, Beek

IS B N 90902 II 454

(C) M.P.M. Vluggen, Maastricht 2006 